\title{
UNDERCURRENTS OF THE
}

\section{CHANGES TO WORK THAT}

AUTOMATION BRINGS

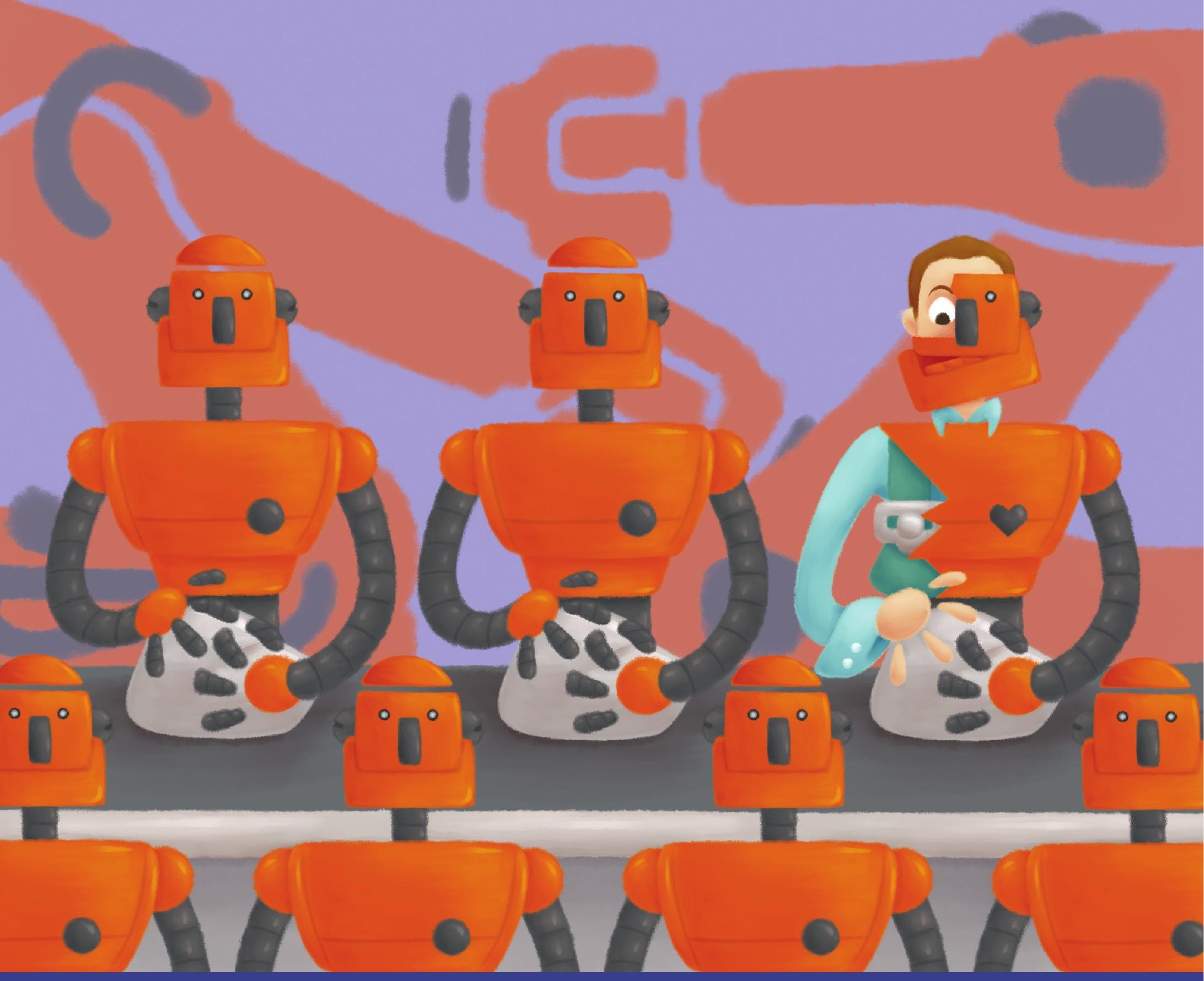

MICHAEL A. KEANE 


\title{
DISSERTATION
}

\author{
to obtain \\ the degree of doctor at the University of Twente, \\ on the authority of the rector magnificus, \\ prof. dr. T. T. M. Palstra, \\ on account of the decision of the graduation committee, \\ to be publicly defended \\ on Wednesday, the $25^{\text {th }}$ of April, 2018 at 16:45 hrs. \\ by

\section{Michael Anthony Keane} \\ born on the $1^{\text {st }}$ of January 1965 \\ in Evergreen Park, Illinois, United States of America
}




\section{Graduation Committee:}

\section{Chairman and Secretary:}

Prof. dr. Th. A. J. Toonen, University of Twente

\section{Supervisors:}

Prof. dr. C. P. M. Wilderom, University of Twente

Prof. dr. T. J. Thatchenkery, George Mason University, USA

\section{Committee Members:}

Prof. dr. J. C. Looise, University of Twente

Prof. dr. H. Schiele, University of Twente

Prof. dr. R. Blomme, Nyenrode University

Prof. dr. J. B. Rijsman, University of Tilburg

\section{Referee:}

Dr. D. Whitney, Corporation for Positive Change, U.S.A. 
This $\mathrm{PhD}$ dissertation has been approved by:

Prof. dr. C. P. M. Wilderom (Supervisor)

Prof. dr. T. J. Thatchenkery (Supervisor)

Cover Design: Megan Anne Keane

Copyright (C) 2018. All rights reserved. No part of this publication may be reproduced or utilized in any form or by any electronic, mechanical or by any means, now know or hereafter invented, including photocopying and recording without otherwise the prior written approval and permission of the author.

ISBN: 978-90-365-4529-7 


\begin{abstract}
Presently there is a gap in the research regarding how the individual building trade union member experiences his or her work with computerized technologies having devalued the required human skills of that work. Computerized and automated technologies have devalued human labor, resulting in workers having different experiences with work. This research relates this devaluing of human labor and the worker having different experiences to the work of a building trades union and how the members of such a union are resistant to or ready for organizational change necessarily required for survival due to the structural model of such a union; the building trades union, in this case the sheet metal workers, has a business model where commoditized labor is their "product."
\end{abstract}

A qualitative method of documentary analysis as well as a quantitative method using an online survey with Likert scale options, including an option to respond individually, was offered to a nationwide selection of members of the sheet metal division of the International Association of Sheet Metal Air Rail and Transportation Workers union.

The quantitative results, obtained using latent class analysis of the survey responses, showed that while there was a sizeable minority of members resistant to change, the majority of rankand-file sheet metal workers were ready to embrace the changes that computerized technology and its subsequent training requirements would have upon their work. The qualitative results show that work has become abstracted, skills have become obsolete or have been deskilled, and skill sets of computerized technology usage are required of the worker. New work in the building trades has workers having to interact with a virtual edifice and, specifically for the sheet metal worker, with virtual ductwork delivery systems, heating, ventilation, and air conditioning (HVAC) equipment and other trade related entities.

Sheet metal workers need to learn to operate different forms of computer interface tools to manipulate these virtual models. Additionally, conversely to other studies where skills devaluation or skills obsolescence has led to declining wages the members of the sheet metal workers' union have actually risen. Finally, with new computerized and automated work for the sheet metal worker there is cause to reimagine and reconsider the collective bargain agreement (CBA), the union contract, as the CBA relates to work from an industrial economy rather than an information economy which this new work is part of. 


\section{Thesis Summary in Dutch}

Er lijkt op dit moment een kloof te bestaan tussen vakbondsleden in de bouw over geautomatiseerde technologieën: ze lijken de vereiste menselijke vakbekwaamheden in het werk te hebben veranderd. Gecomputeriseerde en geautomatiseerde technologieën lijken het vak te hebben aangetast, wat geleid heeft tot uiteenlopende werkervaringen van de leden. Dit onderzoek relateert deze verschillende ervaringen van individuele leden/medewerkers aan het werk van hun vakbond en aan hoe een deel van de vakbondsleden zich verzetten tegen en ander deel zich voorbereid op de (vermoedelijke) veranderingen, dat laatste ook in de richting van veranderingen in de structuur van hun bond. Dit proefschrift analyseert het werk van industriële metaalplaatwerkers. Hun vakbond heeft een bedrijfsmodel met (commoditized oftewel) sterk gestandaardiseerde arbeid als hun "product".

Een kwalitatieve methodiek (i.c. documentanalyse) alsook een kwantitatieve survey methodiek (inclusief een optie om individueel te reageren) werd voorgelegd aan een nationale selectie van leden van een deel van de (Amerikaanse) International Association of Sheet Metal Air Rail and Transportation Workers Union; het betrof hier medewerkers in het metaalplaatwerkindustrie.

De kwantitatieve resultaten, verkregen door gebruik te maken van latent class analysis van de enquêtedata, lieten zien dat hoewel er een aanzienlijke minderheid was van leden tegen de technologische veranderingen, de meerderheid ze accepteerde, alsmede de daar uit voortkomende opleidingseisen die hun dagelijks werk beïnvloeden. De kwalitatieve uitkomsten laten zien dat een deel van het huidige werk overbodig wordt en dat bestaande bekwaamheden onnodig zijn geworden; in plaats daarvan zijn er bekwaamheden in het gebruik van automatisering vereist geworden. Nieuw werk in de bouw verplicht medewerkers om met een virtueel bouwwerk om te kunnen gaan en, specifiek voor een metaalplaatmedewerker, ook met virtuele leidingen, verwarming, ventilatie en air conditioning systemen en daaraan gerelateerde materialen en technieken.

Vakmensen in de metaalplaatindustrie moeten tegenwoordig leren om verschillende geautomatiseerde tools te bedienen die virtuele modellen bewerken. Bovendien, in tegenstelling tot andere studies waaruit blijkt dat bestaande vakbekwaamheden zijn achterhaald, hetgeen meestal leidt tot afnemende lonen, blijkt het ledental van deze Amerikaanse metaalplaatwerkersvakbond gestegen. Ten slotte is er door de komst van gecomputeriseerd en geautomatiseerd werk voor de metaalplaatwerkers reden om de collectieve arbeidsovereenkomsten alsook gerelateerde vakbondsovereenkomsten te herzien, omdat deze zijn gelieerd aan de inhoud van het werk in deze sterk veranderende industrie waar hun banen deel van uitmaken. 


\section{Acknowledgments}

There are so many instances of guidance and support that I have received from Prof. Dr. Celeste P. M. Wilderom that I will fall short in expressing this in a way that accurately reflects what her efforts were. It is undeniable that her efforts of support and guidance are primary reasons that I have completed this journey and I give her my profound thank you for this.

I am also forever indebted to my friend and advisor Prof. Dr. Tojo Thatchenkery. His guidance and support were and are invaluable and I am truly enriched because of his efforts. The support and guidance that he has provided to me is also a primary reason that I have completed this journey. Thank you brother Tojo.

To the members of my graduation committee I say thank you for your time and efforts on my behalf. It is humbling that all of you have sacrificed your time to consider the ideas and passions that animate me.

I must also acknowledge and express my deep gratitude to Prof. Dr. Sheila McNamee and those at the Taos Institute without which my journey could not have begun.

To my brother and sister sheet metal workers I say that you have enriched my life and provided the inspiration for the curiosity which led to this endeavor and I thank you for this.

To the University of Twente I simply say thank you for this opportunity. It may be that I did not deserve this opportunity, but you nonetheless provided one for me and I am indeed grateful.

To my family who through all the highs and lows of this journey as well as the journey called life, you have always been there with loving support and I thank you for this! I especially say thank you to our beautiful daughter Megan for her time and efforts designing the cover of this book.

To my brother and sister ODKM cohort \#2 members and professors at grad. school I cannot thank you enough for the experiences that you gave to me at George Mason University. The conversations that we had were an impetus for me to want to learn more.

Lastly, while I cannot possibly name everyone who has been supportive and an inspiration to me on this journey, I say, nonetheless, that I am forever grateful for your friendship and support. 


\section{Table of Contents}

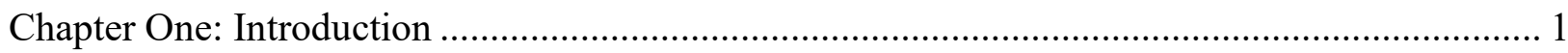

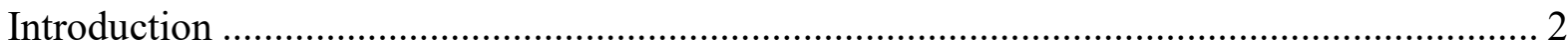

Background of the Problem............................................................................................. 2

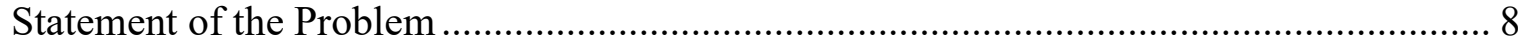

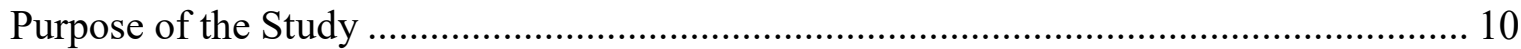

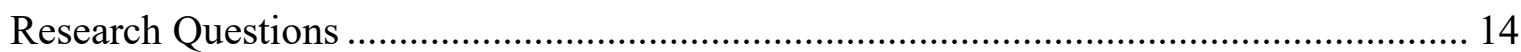

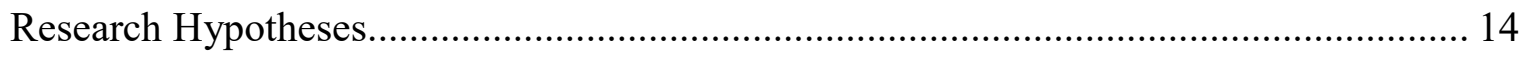

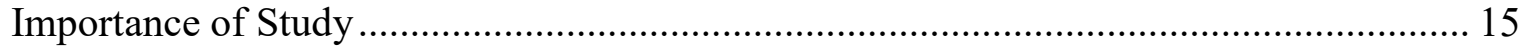

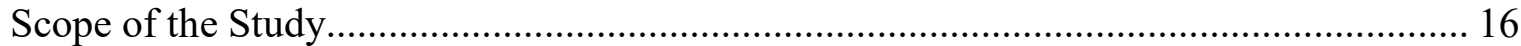

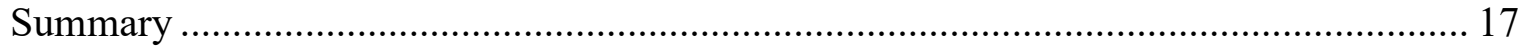

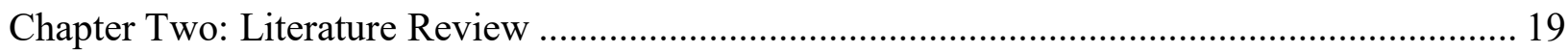

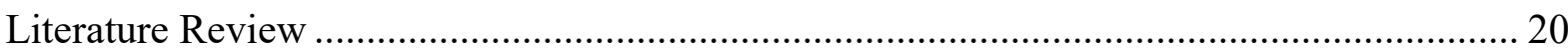

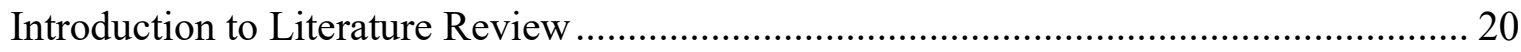

Technology and Skilled Work.................................................................................. 26

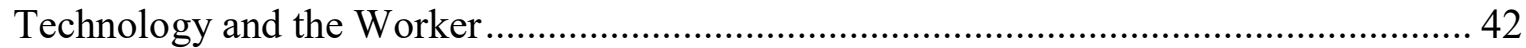

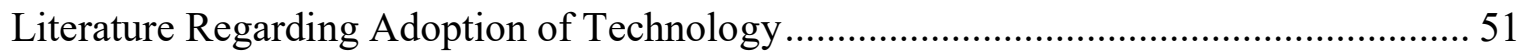

Literature Specifically Related to the Unionized Workforce ............................................... 59

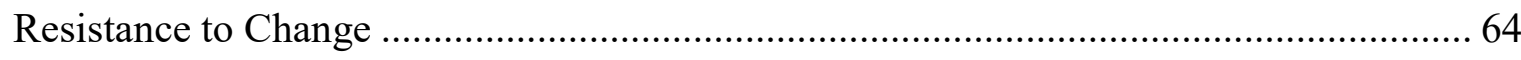

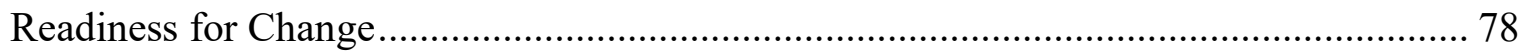

Summary and Conclusion of Literature Review …………………………………....... 84

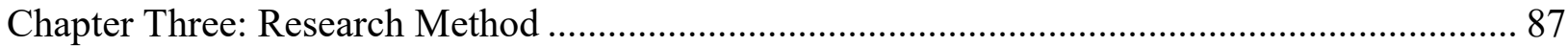

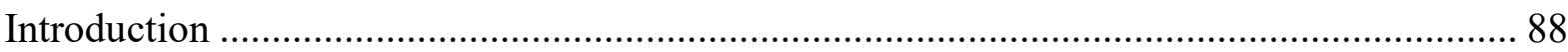

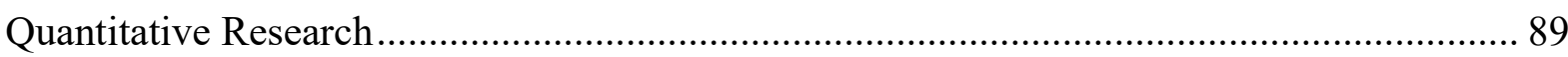

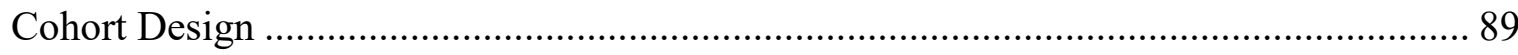

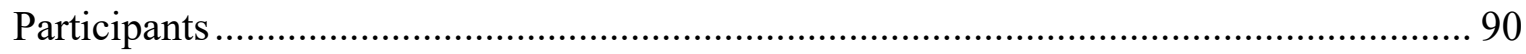

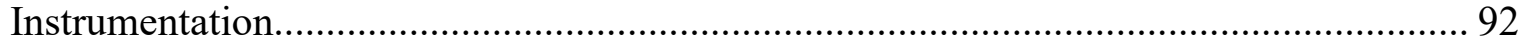

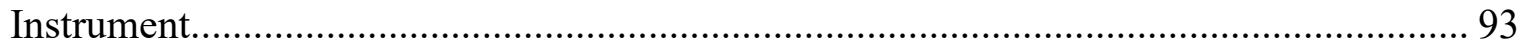

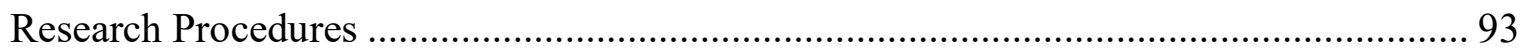

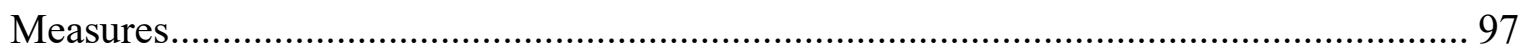

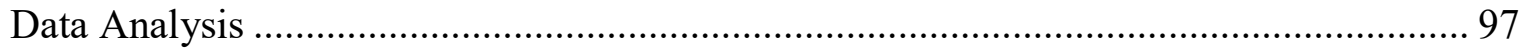




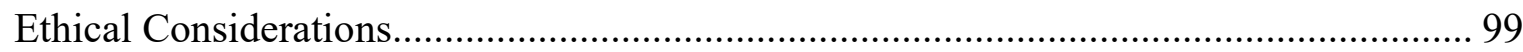

Limitations of the survey part of this research............................................................. 99

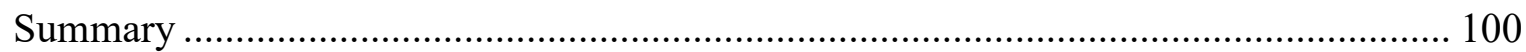

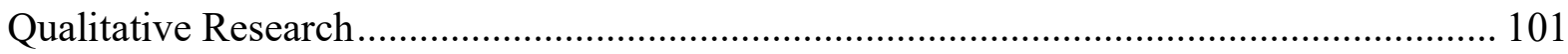

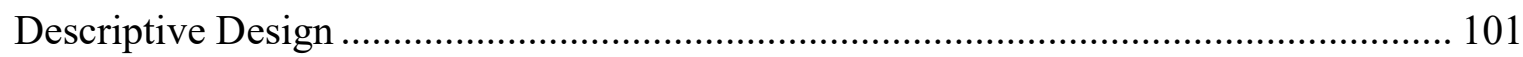

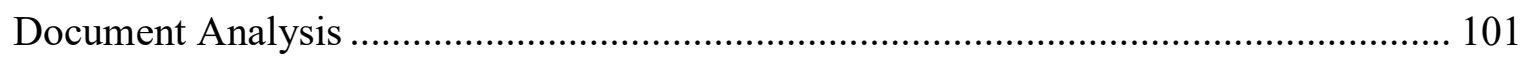

Interpretive Phenomenological Analysis ..................................................................... 102

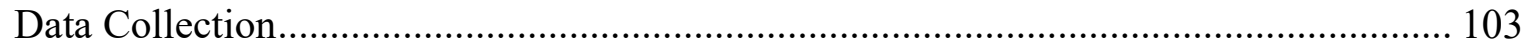

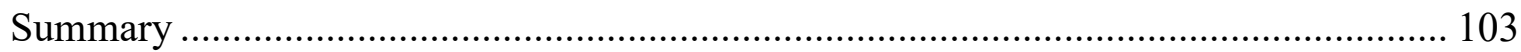

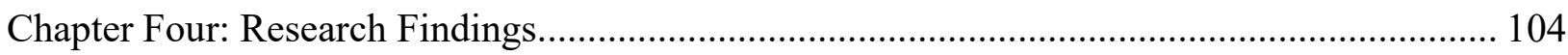

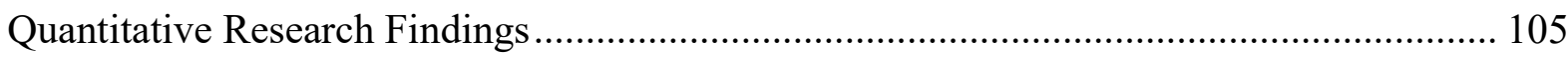

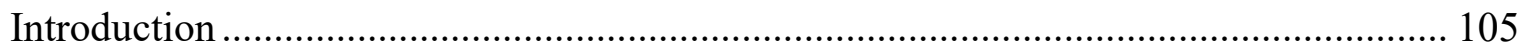

Results of Quantitative Findings ............................................................................. 116

Findings: Latent Class Analysis .............................................................................. 152

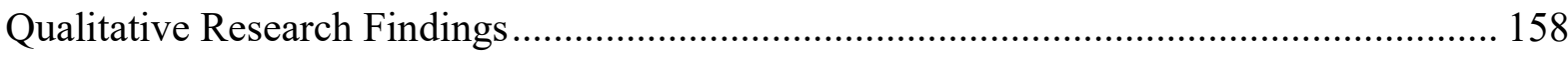

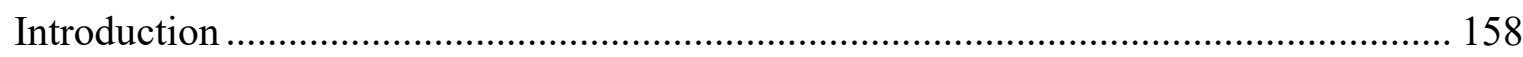

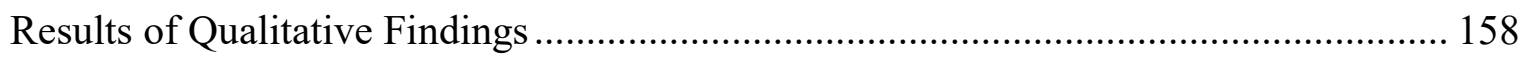

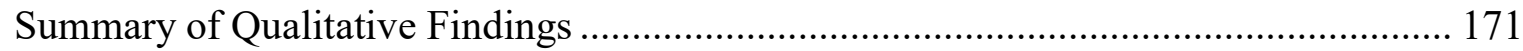

Chapter Five: Conclusions, Discussion, Implications, and Suggestions for Future Research ... 175

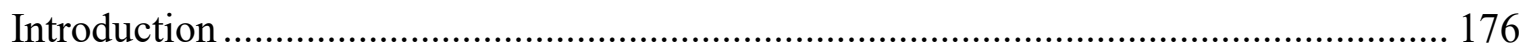

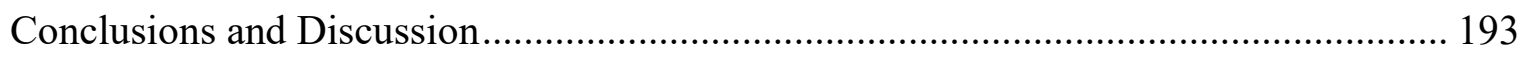

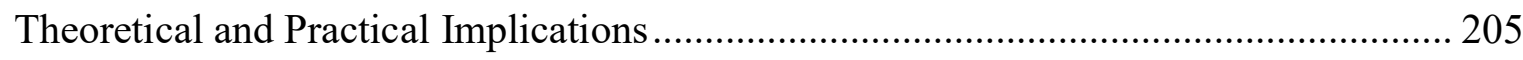

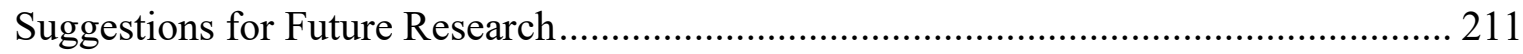

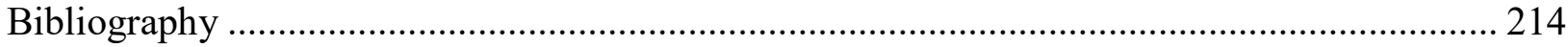

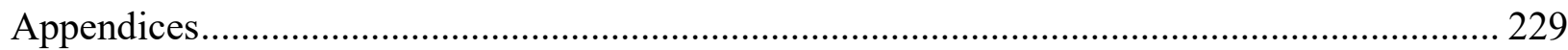

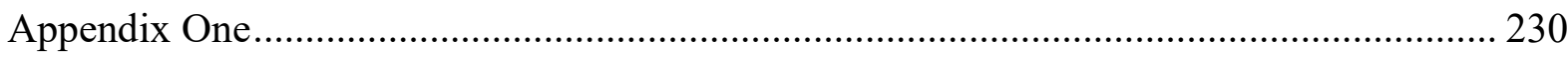

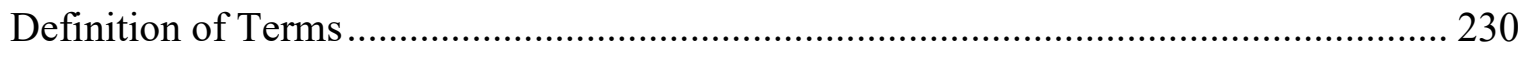

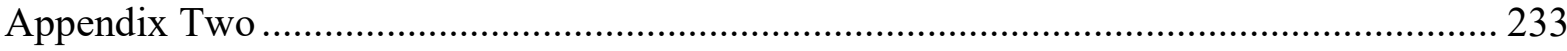

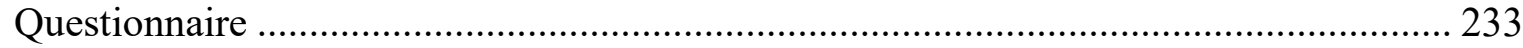

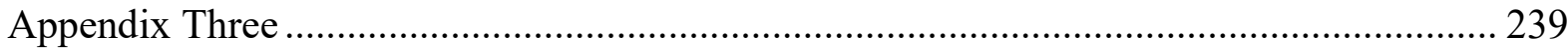

Photos of Sheet Metal Worker and Sheet Metal Work ..................................................... 239 
Chapter One: Introduction 


\section{$\underline{\text { Introduction }}$}

\section{Background of the Problem}

It seems self-evident that technology changes what work means to the individual worker. Yet, a worker may never even consider how his or her experiences with his or her work changes due to such technological changes. The worker may simply experience uneasiness or a feeling of loss due to a sense of no longer being relevant. There are ample examples found in news reports of how technology has altered how work is understood by industries, businesses, and the individual worker. My interest and subsequent inquiry into what automation and technology means to work and the worker's understanding of it began when I sought to learn about the unionized sheet metal workers' resistance to or readiness for change that I was charged with bringing to the union of which I am a proud member. For me, this all started when I had a conversation with two business managers of two different local sheet metal worker unions. The business manager is the leader, the Chief Executive Officer, of his or her respective local union, chartered under the former Sheet Metal Workers' International Association (SMWIA) and now The International Association of Sheet Metal, Air, Rail, and Transportation Workers (SMART). My conversation with these two business managers focused my curiosity on three phenomena. I was curious about the effects of technology on my specific union and its members, on working people in general being concerned about the quantity of work or jobs available, and finally, on the quality of the work available to the individual worker, which is embodied in satisfaction with one's work.

As evidence of these phenomena, one need only look at the jobs-related positions of the current, as of the time of this writing, Democratic and Republican American Presidential nominees; jobs are a primary focus of their respective campaigns. Hillary Clinton, the 
Democratic nominee, states that she wishes to "create incentives for companies to bring back jobs to the U.S..." (Hillary For America, 2016). Implicit to Ms. Clinton's statement is the inference that jobs that were once filled by Americans were lost and she would work to returned these jobs to Americans. Donald Trump, the Republican nominee, states that his plan will, "reclaim millions of American jobs..." (Donald J. Trump for President, Inc., 2016). Here, Mr. Trump implies that the jobs were lost and that he would work to have the jobs returned. He takes the issue a step further by stating that that these jobs were stolen by "sweatshops" and "pollution havens." Regardless of the differences in rhetoric between Ms. Clinton and Mr. Trump, one can easily infer that the pollsters who work for both Ms. Clinton and Mr. Trump respectively have concluded that jobs is a primary issue for the average American voter. While a focus on bringing back jobs to Americans may not be a new political tactic, it has new and more profound meaning due to the automation of work.

Additionally, jobs and the quantity of available jobs are not unique to the people of the United States (U.S.). The very recent, at the time of this writing, results of the "Brexit" referendum, the United Kingdom's (U.K.) referendum vote that resulted in the U.K. leaving the European Union (EU), was in large part due to the perceived threat that globalization poses to jobs available to Britons (Whitely \& Clarke, 2016). Therefore, while the rhetoric is that of politicians pandering to their constituents with the idea of returning something lost to its rightful owner, the anxiety caused by job availability and the changing definitions of what work means to working people is real, especially in "first world" nations. Workers seek security and assurances that they will be gainfully employed during their working years. Yet, at this same time in history, technology's effects on work extends beyond "first world" nations to working people of all nations through deskilling work and resulting in some worker's skills to be outright obsolete. 
Whether job opportunities may appear to be shrinking in the United States, data shows that by many economic measures there is more manufacturing output in the United States at this point in history than at any other point (Ikenson, 2016). Given this fact, the question then arises of what actually is occurring since workers and consequently politicians believe that quality work opportunities are shrinking at the same time that American manufacturing output is increasing. I theorized that there is a false narrative that is accepted due to a paradigmatic understanding of what work is and how the information age has altered that paradigm of work. Those who feel as though “America doesn't manufacture anything anymore" are, to some degree, seeing it simultaneously correctly and incorrectly, which I believe is caused by the historic paradigmatic understanding of work and the new paradigm that the information economy brings to work. For although manufacturing output is actually higher than at any other point in American history and there has been an increase in manufacturing jobs in recent years, the fact is that the number of manufacturing jobs is overall lower relative to manufacturing output (National Association of Manufacturers, 2016). To put it another way, while there is an increase in the number of manufacturing jobs available to Americans, the increase in productivity as a result of automation has resulted in a lower number of jobs available to workers relative to the amount of goods being manufactured.

With these points in mind, I will turn back to my initial inquiry. However, before I detail the highlights of my conversation with the two business managers, it is best to provide context for the conversation. The sheet metal worker trade was, and still is, a skilled trade with a robust concentration of applied mathematics, among many other sciences that are requisite skills, which are used by the rank-and-file sheet metal workers on a daily basis. Historically an apprenticeship within the sheet metal trade had the individual learning applied calculus, "trigonometry, and 
algebra" (U.S. News \& World Report, 2015). Technology has had an impact on everything a sheet metal worker performs as work as well as on how he or she experiences such work; the work that a sheet metal worker once performed that is most relevant to this study centered on the applied calculus portion of a sheet metal worker's learning. It is in this area that the work sheet metal workers once performed has been effected the most.

The largest sector of the sheet metal industry is in air delivery systems, or ductwork. The word ductwork can mean different things to different trades; for the sheet metal worker, its meaning is based around delivering conditioned, either cooled or heated, air to various locations served by an air movement unit, such as furnaces, air-handling units, heat pumps, etc. Since each edifice that requires conditioned air has a unique design, the design of the air delivery system is equally as unique; this is where, historically, the sheet metal worker position of the bench layout person has thrived. It is important to note that the bench layout person was the individual who would learn the applied calculus necessary to create the required delivery system part, which was crafted from raw, flat sheets of metal.

Through the years, the bench layout person has been a highly valuable employee who was sought after by competing mechanical or sheet metal contractors. There were tens of thousands of bench layout person positions throughout the United States and Canada (the claimed jurisdictional area of the SMWIA), but this all changed beginning in the early 1980s. It was at that time that a unionized sheet metal worker, Richard Levine, invented and patented a machine, the plasma table, which began to replace the bench layout person (United States of America Patent No. 4,554,635, 1985). This new technology almost entirely eliminated the bench layout person's work and did so in less than a decade. Without question, the mechanical or sheet 
metal contractor who did not purchase this new technology for his or her sheet metal shop soon found that his or her company had lost its competitive edge.

It was against this backdrop that a then colleague and I brainstormed about where we perceived the trajectory of technology was arcing as it applied to our trade. We concluded that our trade, especially within the shop, as opposed to the field where the physical edifice that is being constructed is being erected, would eventually be fully automated with robotic technologies. My then colleague and I obtained a patent from the United States for a fully automated sheet metal shop (United States of America Patent No. US8285413 B1, 2012). We assigned the patent to the International Training Institute for the Sheet Metal and AirConditioning Industry (ITI), a trust fund of SMART and an organization at which we were both employed at the time.

Our reasoning for assigning the patent to the ITI was that we, as members of SMART, had seen from an organizational perspective the loss of jobs and the resulting loss of membership that was a direct result of Levine's machine. We reasoned that it would be ideal to have our union in control of its own destiny in regards to any job loss that would occur with the advent of a fully automated sheet metal shop. Additionally, we recognized that Levine's machine equally benefited both non-unionized and unionized sheet metal contractors and their non-unionized sheet metal workers and we desired to preclude any non-unionized contractors and workers from benefitting from any robotic technologies. Since Levine's machine had eliminated what was perceived by those within the unionized industry as a competitive advantage, my colleague and I desired that history not repeat itself with robotic technologies.

When I discussed with the two business managers that we had obtained the patent from the United States Patent and Trademark Office and had assigned it to the ITI, their reaction was 
not one that I had hoped for. Both business managers immediately looked down towards the floor; then, after a brief pause, one looked up at me and said, "That's the most progressive thinking that I've ever seen" and the other said, "Oh man." Then the first business manager said to me, "We'll never get reelected promoting that!" The substance of that conversation became the impetus for this inquiry. Change brought about by computerized technology (CT) had already come to the sheet metal industry and the impact of information technology on the trade had not concluded; in fact, more changes were coming to the industry and from what I experienced, at least some of the leadership of the union demonstrated resistant behaviors towards these changes for selfish reasons. I was curious whether the rank-and-file sheet metal workers were as equally resistant to these coming changes or if they foresaw these changes and stood ready to accept them.

I thought about and reflected upon those workers from history who altogether lost their livelihoods due to the advent of a new technology. One example is the typographers who used to create the mechanical typesetting for daily newspapers and other printed materials. Surely, they must have recognized that their livelihoods were in jeopardy with the advent of computerized printing. In fact, "computers transformed the craft entirely..." as the number of members in the International Typographical Union, which dissolved in 1986, "fell from over 106,634 in 1964 to only about 38,000 working members by the mid-1980s" (Arnesen, 2007). In addition to this, there are many historical examples where a workforce in general and the individual worker in particular faced, whether they realized it at the time, uncertain personal economic futures due to technology's impact upon their work. Technology, for better or for worse, has already had a dramatic effect on both the careers offered in the sheet metal industry and the career of individual sheet metal workers. Furthermore, it seems ominously clear that technology's effects 
on what work is, what work means to the worker, and how the worker experiences work are far from over.

As the ITI's Director of Building Information Modeling Technologies, I was assigned to usher in a computerized work curriculum, which naturally meant change to the industry. After years of naively expecting fellow sheet metal workers to see what I saw, I came to understand that my fellow sheet metal workers did not see the profound changes to our work that I felt was occurring as a result of technology; therefore, I wanted to know how the members of SMART saw and felt about the automation of much of their work. Were they resistant to these changes? Were they intimidated by CTs or did they embrace them? Did they foresee that change was inevitable and were ready for these changes? Did they maybe want to lead the change? What role did they want the union's leadership to take? How did they want their union to approach technology? Did they feel that technology would have a negative effect or positive one on their ability to find employment now and in the future? Did they have any sense of doom related to their career as a sheet metal worker? Were they bravely facing the effects that technology has on their work? Or, did they feel that all is lost? In short, are the members of SMART ready for or resistant to the changes presented by $\mathrm{CT}$ ? In an effort to examine whether the rank-and-file workers of SMART were a diverse heterogeneous population and to conceptualize patterns of responses among a sample of these rank-and-file members, I conducted an online survey and applied latent class analysis (LCA) to the response data within this dissertation.

\section{$\underline{\text { Statement of the Problem }}$}

It is a presumption to suggest that the working person likely spends little or no time thinking about paradigms in general and paradigms regarding work specifically. I believe that work for the vast majority is their portion of the transaction with an employer where they receive 
from their employer the completion of the transaction in the form of wages, benefits, and/or other compensation. Little time is spent philosophically pondering what work is and the individual's relationship to it. For many, the relief and excitement of being chosen for that position by an employer can in short time lead to frustration with the work and devolve into the proverbial "you can take this job and shove it" attitude. However, no matter what the attitude may in fact be, a living wage job is a stressor for many and a need for all. There was a time not so long ago when an individual without a high school diploma could find work aplenty within the factories that were abundant within big and small cities alike. For those who lived in small cities or towns, one factory oftentimes supplied the majority of jobs to the townspeople. Those times are gone. For many workers, knowledge of the Rust Belt in the United States and its implicit loss of factory jobs combined with knowledge of sweatshop factories in "developing" nations can lead to feelings of resentment, betrayal, anger, and even xenophobia. However, as was discussed above, by some economic measures, there is more manufacturing output within the United States now than at any other point in its history (Ikenson, 2016). Therefore, while many people feel as though America no longer manufactures anything anymore, the paradigm shift of work, brought on by computer and information technologies, has eliminated many jobs and deskilled many others. For example, building information modeling (BIM) enables a mechanical engineer to create a model that simultaneously performs the work that a sheet metal worker once did as the engineer is creating a design model. Simply put, a design model and a construction model are created simultaneously, thereby eliminating work that a sheet metal worker would have performed and resulting in a decrease in the skills that are required of a sheet metal worker and a decrease in employment opportunities. 
The individual worker finds pride in the work that he or she performs to earn a living. Furthermore, the education system functions to equip and enable the youth of a society to be able to compete for a career in a profession that the individual enjoys working in and it is fashionable to ask a young child, "What do you want to be when you grow up?" For adults, discussing our individual professions is common small talk at any given social function. We all identify with our work, as the work that we do provides a foundational value to who we are as human beings. Yet, however this phenomenon has historically been, computer and information technologies have changed the paradigm of what work is; one consequence of this paradigm shift is found in how computerization, automation, and the abstraction of work as a whole is threatening the value of human labor. There has been little formal inquiry into how the individual worker experiences his or her work with such work having been devalued by computerization. This study investigates how sheet metal workers see themselves and their work under this new paradigm using documentary analysis, a questionnaire, and a small number of interviews.

\section{Purpose of the Study}

As Director of Building Information Modeling Technologies for the ITI, I was charged with creating a program that included building a BIM software tool and a training program, which would enable the members of SMART to perform BIM work. With the ITI being a trust training fund, with an equal number of trustees from both labor and management, I found myself in the midst of a change dynamic within the sheet metal industry that the trustees were ill prepared for. The program that I had created received a tepid welcome from the management side and ambivalence from the union leadership.

From the management side, I often heard that they did not want the union in their office.

They saw the BIM worker as someone who should not have the divided loyalties that their union 
employees had. Office work to them meant being an employee whose sole loyalty was to the company; in this way, control was unilateral. The union side did not know what to make of the new technology. They knew that technology meant fewer jobs, a lesson they learned from the plasma table, but they were not sure about what BIM work was. The union understood the traditional work that a sheet metal worker performed and thus they could relate to what was being discussed and trained on, but BIM work was something that they knew nothing of were consequently unsure about. They wanted to make sure that the members of the union were capable of performing such work, but they seemed, individually, to be frightened of it.

Given those experiences, I really wanted to know what the rank-and-file members actually thought and felt about this new world of work that I was creating for them. Were they resistant to or ready for these changes? How did their experiences with their work change? Did they recognize that their work was changing and how did they feel about those changes if they did? This led me to consider all of those workers who had been affected by the changes to work brought on by such technologies. Therefore, the goal of this study is to discover how sheet metal workers experience their work at a time when CTs are deskilling work and devaluing the need for human labor. Additionally, specifically for my union, I also inquired into whether the rankand-file members of SMART are resistant to or ready for the changes that CT has and continues to bring to the work that sheet metal workers perform. This research will provide SMART's leadership with knowledge of where the rank-and-file membership stand as it pertains to readiness for or resistance to the organizational changes needed to remain both a relevant organization and a relevant workforce. According to SMART's Constitution and Ritual, the union seeks to provide an organization that establishes and maintains desirable working conditions that enable the membership "to give a fair day's work for a fair day's pay," which 
provides the membership with "comfort, happiness, and security." To this end, relevant indemand labor skills are a key component to security, which is a desirable working condition.

As will be discussed in depth in the literature review, the current available research states several important points that relate to the impact that CT has on the worker and work in general. More specifically, the research shows the following:

1. "Developed" countries and economies are increasing their investment in technology.

2. Technology demands a more educated worker.

3. Technology skills can be correlated to wage earnings.

4. Technology causes lower skilled workers to be in less demand, thereby creating higher unemployment for lower skilled workers.

5. Technology affects workers' attitudes.

6. CTs have a deskilling effect upon work.

7. Workers who are confronted with CT have a sense of alienation from their work.

8. Technology causes an obsolescence of some work skills.

9. Technology demands higher skill levels.

10. Culture moderates acceptance or resistance to technological change.

11. Culture influences the development process.

12. Individual beliefs affect technology acceptance. 
13. Intrinsic motivation can be a determinant of technology acceptance.

14. Traditional beliefs on resistance to change hold that all resistance is of a selfish nature and should be eliminated at all costs.

15. New research shows that resistance to change is a potentially positive phenomenon and with the right engagement, could lead to more positive changes for the organization.

16. Resistance to change may signal that change resisters value the change concept, demonstrating it by maintaining the existence of the change concept, engaging with the change concept, and strengthening the change concept via ideas that enhance it.

17. Engagement with and strengthening of the change concept leads to a greater commitment to the change concept.

18. Individuals are not intrinsically resistant to organizational change.

19. Individual readiness for change centers around the individual's evaluation of the individual and organizational capacity for making a successful change, the need for change, and the benefits the organization and its members may gain from the change.

20. Organizations can employ one of three types of strategies to foster organizational change: empirical-rational, power-coercive, or normative-reeducative.

21. Normative-reeducative strategies prove to be the most effective at achieving change recipient buy-in of organizational change.

Despite this extensive body of research, there is a gap within it related to how workers in general experience their work as computerization threatens the need for human labor. The 
current research is primarily centered on corporate businesses and their employees' readiness or resistance to change, but there is little on how workers experience work that has been devalued by computerization and automation. This is especially true for labor unions and their members. Additionally, there are no studies on this on topic as it relates to building trade workers. The phenomenon of changes to work for the building trades, with their business model of commoditized labor, results in a unique dynamic for each respective building trade that is related to the impact that $\mathrm{CT}$ has upon the work which they perform. The deskilling effect and the skills obsolescence that have resulted from CT is a dynamic that could threaten the very existence of building trades unions themselves.

\section{$\underline{\text { Research Questions }}$}

1. Do workers perceive the effects that CT has upon the work they perform as being positive or negative and how do they view such positive or negative impacts?

2. Are workers resistant to or are they ready for the changes brought on by CTs?

3. How have sworkers' experiences with their work changed due to the computerization of their work?

4. How has the change in a worker's experience of his or her work changed that worker's sense of self?

\section{$\underline{\text { Research Hypotheses }}$}

This study hypothesized that unionized sheet metal workers are experiencing their work differently since CT has devalued, deskilled, or made obsolete their personal labor. Documentary analysis was used and LCA was conducted on questionnaire responses to identify emergent 
latent classes of respondents according to shared patterns of attitudes and perceptions regarding the negative impact of technology in the workplace. LCA is a statistical method used to find groups or subtypes in multivariate categorical data or continuous observed variables. LCA detects the presence of latent classes, which create patterns of association. I anticipated that at least two classes of participants would emerge from the LCA. One class would represent a subset

of participants who share feelings and attitudes about the high negative impact that CT has on the work performed specifically by sheet metal workers. The other class would represent a subset of participants who share feelings and attitudes about the low negative impact that CT has on the work that is performed specifically by sheet metal workers.

\section{Importance of Study}

The industrial revolution altered the world both positively and negatively for both society in general and the worker in particular. There was mass production of goods and services on an unprecedented level, which came with well-chronicled labor abuses. Just as the industrial revolution changed work, the present information revolution is bringing further changes to work. Work has now become abstracted, leaving the realm of the physical senses. While the industrial revolution changed work via the mass production of goods, the value of the human labor was still essential to the process because while the new machines were more productive than human labor, they still required human labor to operate them. This is dramatically different in the information age. CTs place lesser and lesser value on human labor. To be sure, human labor is needed to create software programs, but for the blue-collar worker, the story is quite different. Automation has eliminated, making obsolete, the need for human labor altogether in some sectors of the economy and has devalued and deskilled human labor. Given this, the question arises as to what the millions of blue-collar workers will do for work in the future if blue-collar 
work is automated, made obsolete, or deskilled to the point that an employer, due to market pressures, will reduce the wages and benefits of such workers. How many workers will be needed to fill the ever-shrinking number, relative to manufacturing output, of available jobs? What effect will this have on both the individual worker and society as a whole?

While the idea of organized labor is still a contentious economic argument, people like me believe that organized labor is essential to a healthier society. Given that the very nature of the work that a sheet metal worker performs is being abstracted, it is important that the union as an organization change, including wholesale changes to its organizational structures, to embrace this new reality. Therefore, this study's importance lies in its inquiry into how the individual worker experiences his or her work, which has now been devalued, and the resultant effects that this has on that worker. Finally, for me, the importance of this study also lies in determining whether the individual sheet metal worker is resistant to or ready for the changes to their work that CT brings. It is my hope that this information will be used to ensure that the skills of the rank-and-file sheet metal workers remain in demand and that the union itself remains a relevant institution for many more decades.

\section{$\underline{\text { Scope of the Study }}$}

The purpose of this research is to learn about how the individual worker experiences his or her work, which has been devalued by $\mathrm{CT}$, and the resultant effects that this has upon that worker. Additionally, this study seeks to discover whether the individual unionized sheet metal worker is resistant to or ready for the changes that CT has upon the work performed by sheet metal workers. To discover these, documentary analyses, including academic studies, media news stories, etc., were used. For the survey of sheet metal workers, it was necessary to obtain a sample from as wide an audience as possible. It was initially decided that interviewing would be 
the best format for gathering data, but with only three people agreeing to be interviewed, it was decided that data would be collected via an online survey. The online survey enabled the data to be collected from a wider pool but limited the responses to those who had access to the online survey. While this may seem to be somewhat of an obsolete issue to detail, as internet access is very widespread in America today, it is important to note that the ITI conducted a survey of sheet metal apprentices in the United States in 2013 and roughly $35 \%$ of respondents preferred that all training be done with traditional media, eschewing any electronic form of instruction. Of those who participated in the survey for this study, the majority of respondents, $82 \%$, were from Illinois and Indiana, 7\% were from states west of the Mississippi River, $<3 \%$ were from other states in the Midwest United States, $<1 \%$ was from the New England region, and 7\% were from Southern states. Due to the anonymity of the online survey, the age, sex, and race of each respondent is unknown. Finally, given that the survey needed to be completed online, the respondents that comprise this specific sample must have had some level of understanding of $\mathrm{CT}$; therefore, the results of this survey may reflect a level of confidence with CT that is biased in favor of readiness for change.

\section{Summary}

The story of technology altering industries is a constant throughout history. In the present day, CT has altered work in a dramatically different way in that it has devalued human physical labor. The simple fact is, that information technologies have eliminated the need for much of physical human labor and have deskilled and devalued much more. This is true for the sheet metal worker. CT is making inroads into sheet metal work in ways that no one had foreseen. Work has in many ways moved from the realm of the physical into the realm of the mind. This abstraction of work does not fit well into the labor-management paradigm and consequently, CT 
has made obsolete the many of the structures built around the labor-management paradigm. For the unionized building trades, and specifically within SMART, the labor-management paradigm is institutionalized in the form of the collective bargaining agreement (CBA). This structural component of SMART is obsolete as it relates to informative work and the consequences of this are stark and dramatic for the union and its members. Surely, with CT consuming more and more of the work that a sheet metal worker does, thereby abstracting that work, it is important for the institution of the union to understand and plan for this paradigmatic change. This study seeks to discover how workers experience their work, which has been devalued by CTs, and whether the members of SMART are resistant to or ready for the changes that CT brings. The importance of this study resides, in a broad sense, within the notion that human beings need to work and that work provides both emotional and financial wellbeing to the worker and his or her family. More specifically, this study is of importance to SMART and its members as this study offers insight into the attitudes and feelings of those members toward a changing economy. Furthermore, the results of this study can help SMART gain insights and illuminate pathways to embracing change should it opt to pursue such a course. 
Chapter Two: Literature Review 


\section{Literature Review}

\section{Introduction to Literature Review}

There are four primary reasons as to why computerized and automated technological advances have caused workers to experience work differently. Firstly, computerized and automated technologies have abstracted work, which is to say that work that once required human physical interaction has now changed to reduce or eliminate that physical interaction. This change to work now requires the human worker to read and understand symbols, text, or other computer-generated virtual data and to understand the value each has. Upon understanding the value of such data, a worker may then be required to alter a process via data entry into a computer. Secondly, computerized and automated technologies have caused the skills of many crafts and their workers to be deskilled or to be obsolete. Historically, a craft worker offered a social group value by what he or she could produce via his or her labor. For example, when such a social group had need for shoeing horses, a blacksmith's skills were in demand. When there was a need for customized ductwork, the bench layout skills of a sheet metal worker were in demand. Computerized and automated technologies have deskilled or made obsolete such skills on a mass level. Therefore, the skills that are required to perform work tasks have been changed to require less human labor, which results in human having a different experience with work. Thirdly, with computerized or automated technologies having eliminated many human work skills or deskilled human work skills to the point where the skills are devaluing, workers are required to have a higher level of work skills to participate in the new, more high-tech work. Workers must possess a higher level of work skills to even be able to participate in this labor. In general, a typical high school education no longer provides the work skill sets that are in demand. The last reason that computerized and automated technologies have caused workers to 
have a different experience with work is that, unlike technological advances related to work in the past where productivity in work had a corresponding increase in work opportunities, automation has led to a decoupling of productivity from employment opportunities (Brynjolfsson $\&$ McAfee, 2014). Now workers have a shrinking pool of employment opportunities, which do not value many of the work skills that such workers have and, at the same time, require a higher level of work skills from that worker. These reasons, coupled with work tasks that no longer require physical contact from the worker, have led to a different experience with work for the worker.

To summarize, the advent of computerized and automated technologies has made the production of goods and services more productive (Rotman, 2016) and this phenomenon bodes ominously for working people because unlike past advances in technology, automation has led to a different work experience for workers. In the past, technological advances have increased productivity and at the same time, employment rose relatively congruously with this productivity. However, automation is different as it decouples productivity from employment and income (Brynjolfsson \& McAfee, The Second Machine Age: Work, Progress, and Prosperity in a Time of Brilliant Technologies, 2014). Furthermore, the trend of job losses due to automation and information technologies is so alarming so as to cause The World Economic Forum to conclude that the trend portends that there could be a 5.1 million net loss of jobs between 2015 and 2020 (World Economic Forum, 2016). Therefore, with automated technologies leading to the abstraction of work, fewer jobs, skills obsolescence, and the deskilling of work and requiring higher levels of skills to operate, coupled with growing populations around the world, the worker is facing unprecedented changes with work. 
In this literature review, studies related to the thesis of this dissertation were analyzed. To begin, a Google Scholar search using keywords pertinent to the thesis was performed. The research titles from the search results were reviewed and when one was deemed relevant to the thesis, that study's abstract was read in full. After reading the abstract, I determined whether a particular study warranted further reading and had the potential to be relevant to the thesis. Once potential relevance was determined, an electronic copy of the entire study was obtained and I read the conclusion of the study. If the conclusion of a study was determined to be pertinent to the thesis, the study was read in full and analyzed to determine whether it was relevant to this study. The criteria used to determine whether a study was pertinent to the thesis of this research was whether the study concluded, either directly or tangentially, that technologies in general or automated technology specifically can be, or conversely cannot be, directly correlated to the devaluing, the deskilling, or the obsolescence of human labor skills or whether the study related to the readiness for or resistant to change in general or to technological changes specifically of an organization's members.

This literature review will discuss not only the conclusions of the relevant studies but also how and why the conclusions were reached. It will demonstrate how this dissertation fits into the gaps not covered by the existing literature and how to interpret the larger issues surrounding the topic. It will be explained how these studies relate to the context of this thesis, which focuses on the latent change to work brought on by automated technologies and experienced by individual workers in general and by unionized sheet metal workers in particular. The existing literature will be interpreted with new insights and the gaps in this previous research will be illuminated. Furthermore, new insights will show that the individual worker's labor has been made obsolete or devalued to such an extent that certain workers' skills may never be in demand again and that 
this phenomenon is particularly acute in the building trades unions, which uses a commoditized labor model. These ideas will be used to determine whether the individual rank-and-file members of the sheet metal workers' union are ready for or resistant to organizational changes to the union that are needed to maintain in-demand skills. One of the gaps in the research relates to how individual workers from a unionized workforce, with a commoditized labor economic model, experience their work when that work has been devalued, made obsolete, or deskilled and whether such a worker is ready for or resistant to organizational changes brought on by automated technologies.

Additionally, this chapter will discuss a pathway for future research. The unionized building trades, which are organizations with commoditized labor as their product, have rarely been studied in general, let alone studied in terms of what automated technologies have brought to the work of trade unions and the work experience of their individual members. However, studying a building trade union may prove to be difficult if future researchers attempt to study the unionized building trades and experienced the same obstacles I did. Specifically, my own international union refused to cooperate with this study unless they were given the raw data that would be collected, which was impossible due to my commitment to maintaining the anonymity of research participants. This was likely the main cause of the relatively low number of participants in the study. It is very likely that the number of participants would have been far greater if the international union had cooperated in the study.

Future researchers will need to attend individual local union meetings, gain access to union members via their employers, and gain permission to enter a specific construction site in an effort to interview unionized workers who have been affected by automated technologies. Additionally, future researchers could use social media sights, such as Facebook, to find social 
media groups for unionized workers that belong to an organization with such a structural model. Interviews and online questionnaires will be the best avenue for collecting data.

To correlate the existing research with this study, I determined a study to be supportive or unsupportive of my theory if it reached conclusions, either directly or tangentially, that demonstrated that technologies in general and automated technologies specifically are causal to the devaluing, deskilling, or skills obsolescence of work or if the study was related to an organization's members' readiness for or resistance to change in general or change brought on by information technologies specifically. If a study concluded that a given technology did in fact devalue skills, deskill work, or cause work skills to become obsolete, the study was deemed supportive. Conversely, if a study's conclusion was that technology in general or automated technology specifically did not devalue skill, deskill work, or cause skills obsolescence, then the study was deemed unsupportive. Additionally, if a study showed member readiness for or resistance to organizational change as it relates to information technologies, the study was deemed to be relevant to my study. In addition, the credibility of a study's conclusions and the value that its conclusions have upon this research will be discussed. To accomplish this, I chose materials and quotes from the literature that were most relevant to my thesis and discussed how they relate to my argument.

In the introduction to In the Age Of the Smart Machine, Zuboff (1988) discussed the anxiety, born of technology's reach, of workers at a paper mill. The workers foresaw their working futures "moving out of reach so rapidly that there was little opportunity to plan or make choices" (Zuboff, 1988, p. 4). They "concluded that the worker of the future would need 'an extremely flexible personality' so that he or she would not be 'mentally affected' by the velocity of change" (Zuboff, 1988, p. 4). Further lamenting, they acknowledged that there was not "any 
real choice" as most of the workers "agreed that without an investment in the new technology, the company could not remain competitive" (Zuboff, 1988, p. 4). This stark introduction into the effects of "a powerful new technology, such as that represented by the computer" (Zuboff, 1988, p. 5), which can be brought to work and the worker is illuminating for this present study. Since Zuboff (1988) contended that "there is a world to be lost and a world to be gained," (p. 5) the implications for how a worker experiences his or her work is ominous as "the sentient body loses its salience as a source of knowledge, resulting in profound disorientation and loss of meaning" (p. 6).

However dire this scenario may initially appear, Zuboff (1988) does offer an alternative where "organizational leaders ... direct their resources toward creating a work force that can exercise critical judgement as it manage the surrounding machine systems," where "work becomes more abstract as it depends upon understanding and manipulating information," and that these mark "the beginning of new forms of mastery and provides an opportunity to imbue jobs with more comprehensive meaning" (p. 6). In short, this new "world to be gained" (p. 5) is one where traditional roles and the division of labor do not resemble our past understandings. These traditional work roles are in a profound way "a world to be lost" (p. 5). Consequently, the implications of CT for the worker, whose cultural understanding of work is strictly hierarchal with a clear division of labor, portend a profound new experience with his or her work. However, unless automation makes its way fully into the construction arena, there will always be some traditional manual work to be performed by a building trade worker. I do not suggest that all work of the building trades will be eliminated; rather, it is asserted in this study that a great deal of work, as it has traditionally been understood, will be replaced by new, somewhat related work and that labor unions will likely be negatively affected by overall net job losses. 
In Giebel's (1980) dissertation, Alienation From Freedom: The Effect of the Loss of Union Power Upon the Relationship Between Technology and Work, he studied the printing industry, asserting that the results of market structural changes, due in part to technological changes, included "printers developing a new orientation toward their work... which is less satisfying" (p. 280) for the printers. Giebel's (1980) study further revealed that the printers that he studied "no longer retain a strong identity with their occupational community or local union" (p. 280). Giebel (1980) further asserted that "the result of these changes were catastrophic for the printing unions" (p. 283). With technology as an important factor in market structural changes, a labor union would be best advised to plan for technology's advent and to attempt to foresee and develop proactive strategies that best serve their members. With the three local unions that Giebel (1980) surveyed, Photoengravers, Lithographers, and Typographers, all having opted for a different strategy reactively where "none proved to be successful" (p. 288), the implications were clear and ominous. These implications seem to clearly indicate that the printers that Giebel studied had a different experience with their work and that the labor union would be wise to plan ahead if it desired to remain a relevant force for work and workers' rights in the future.

\section{$\underline{\text { Technology and Skilled Work }}$}

Zuboff (1988) asserted that technology both "creates and forecloses avenues of experience" (p. 388). The implication of this for what work means to the worker and to the worker's experiences with his or her work is dramatic in the least. To be sure, technological changes have "foreclosed" on many work experiences, including those of the sheet metal worker, but how does this necessarily relate to the story of the worker as he or she moves forward? This is particularly pronounced for the sheet metal worker and the other building trades with similar business models in a unique and important way. Specifically, since the sheet metal workers' 
union solely retails in skilled labor, the implication of "foreclosure" of any work experiences looms ominously. As this literature review will show, the structure of the labor-management divide with its division of labor as it necessarily relates to the demands that $\mathrm{CT}$ are making specifically to the sheet metal industry is "not merely outmoded, but perilously dysfunctional" (Zuboff, 1988, p. 393). CT is a dynamic that is "bound to alter the nature of work" (Zuboff, 1988, p. 7) and where CT has encroached into the domain of the blue-collar worker, the work that was once performed by such a worker using traditional methods, is necessarily altered as well.

Krueger, Autor, and Katz (1998) sought to learn about the effect that technological change, among other factors, has on the demand for workers with different educational levels and on educational wage differentials in the United States. To achieve this, they used statistical analysis, measuring “1\% Census Public Use Micro Samples," which was supplemented with the “Current Population Survey Merged Outgoing Rotation Group” (Krueger, Autor, \& Katz, 1998, p. 5). The authors concluded that their results "suggest that the spread of computer technology may 'explain' as much as 30 to 50 percent of the increase in the rate of growth of the wage-bill share of more-skilled workers since 1970” (Krueger, Autor, \& Katz, 1998, p. 27). More specific to this study, it was demonstrated that within certain industries where there was an investment in CT, this investment correlated to that industry's need for workers with skills that were upgraded to meet the demand created by CT. The idea of upgrading skills implies that base skills are not altogether eliminated but rather are enhanced or improved upon, which is a hopeful idea. However, while the idea of upgrading skills is congruent with the alteration of the nature of work, it also implies new unknown realities in the nature of that work. The implication of these 
new unknown realities of work is uncertainty, which individuals and organizations typically avoid.

While Giebel (1980) saw a downside for the individual worker and the labor union as they relate to the new paradigms of work, his study was in the past tense. His study was conducted after the effects of the new market structures had taken hold. Giebel concluded that "consideration of what might be does not appear to be appropriate, because the magnitude of the changes to printers and their unions has happened so fast that more time is needed to assess the new conditions" (p. 292). Similarly, workers who presently experience their work, which is being changed to devalue their personal labor, may find that the whole world has changed around them and while they may sense that something is happening, they may not fully understand what is occurring. This is to say that today's workers understand that work is changing, but they tend to see the changes not as being fundamental to the work itself but rather as a result of something or some other group causing it to change. This is true for most blue-collar workers; however, the story is different for the building trades unions. Since these organizations have benefited from a monopoly of power institutionalized in the CBA and consequently still remaining relevant, there is still time for the sheet metal workers' union to learn from history, such as that of the printers' union, and develop a strategy that seeks to embrace the new market structures, which seem inevitable. By developing strategies that embrace the structural changes that CT may bring, rather than assuming that CT will not impact their known working world in any negative manner, SMART's organizational fate lies within its own hands.

In "High Technology and Work," Aronowitz and DiFazio (1996) argued against what they called the "prevailing wisdom" and asserted that investments in technology by business do not lead to more permanent jobs. They further argued that such technology investments, 
primarily in the services sector, lead to new jobs that are "contingent, part-time, benefit free, and frequently temporary" (Aronowitz \& DiFazio, 1996, p. 52). This, the authors argued, will cause a shortage of permanent, decent paying jobs in the future. They theorized that with capitalism evolving from an industrial phase to a computer phase, both jobs and skills are destroyed in the process and that the natural consequence of labor saving technologies is a reduction in overall labor required. Furthermore, they differed from other researchers by arguing that the new workers that are created will become semi-skilled or unskilled due to not being involved in the mental part of the work. This study relates to my study in that the overall numbers of sheet metal workers has been reduced by technological advances and the skills needed by the average sheet metal worker has been reduced as well. This research provides a groundwork for my thesis as the work of a sheet metal worker has been negatively affected by such technologies. While Aronowitz and DiFazio's study was broad in its scope and context, my study will provide more specificity and further illumination as it engages the rank-and-file workers of the sheet metal workers' union.

Adler (1988) agreed with the conclusion that technology does destroy old skills; however, he contended that while old skills are destroyed, new skills are created simultaneously. Specifically, Adler stated that "skill has several distinct dimensions" and that automation appears to "encourage distinct shifts along these [dimensions]" (1988, p. 32). He concluded that "automation seems to undermine the commodity form of labor" (1988, p. 32). Yet, while these appear to have negative effects on the worker, Adler further concluded that there are new "trends and pressures which prefigure a new 'post-capitalist' form of organization" (1988, p. 32). These trends and pressures will lead to a different understanding of the labor-management divide, where the worker is seen as a stakeholder rather than a commodity. Adler studied the banking 
industry, analyzing "factor by factor" the 12 factors of job practices, which he derived from and compared to Bright's (1958) assessment of each factor. Adler created tables with these 12 factors and created columns showing the effects of automation on each with the results demonstrating the conclusions that he drew.

Both Adler's (1988) study of banks and my thesis focus on how automated technologies affect the work performed by workers. Our studies differed in that Alder used the banking industry for his study and I used the sheet metal workers. These two groups differ dramatically on the nature of what work each performs and consequently, my study delves into areas not present in Adler's study. My study will contribute to the larger issues around automated technologies and work by adding to the discussion with the inclusion of building trades workers.

Related to the theoretical arguments of Aronowitz and DiFazio (1996), Braverman (1974), and Adler (1988), among others, is a study by Chennells and Van Reenen (1999), which focused on over 70 studies with direct measures of technology and its effects upon skills, wages, and employment. The authors addressed three questions. Has the demand for skilled workers outstripped the supply of skilled workers? If the demand has outstripped the supply, is this due to technical change or some other factor? If the answer to the two previous questions is yes, how much of the change in unemployment and inequality can be accounted for? (Chennells \& Van Reenen, 1999, p. 12). The authors used statistical formulae to categorize their data into three tables. The first table detailed the effects of technology on skill structure, the second table detailed the effects that technology has upon wages, and the third table detailed the effects that technology has upon employment. Their results showed that related to skills, "there does appear to be considerable support for the notion of skills-biased technical change across a range of studies, and these are usually (but not always) robust to controlling for fixed affects. Secondly, 
there have been few attempts to find instrumental variables to deal with the potential endogeneity of technology" (p. 28) and "thirdly there are surprisingly few studies which try to analyze the mechanisms by which technological change translates into demand for higher skills" (Chennells \& Van Reenen, 1999, p. 28).

The results, as they relate to wages, showed that "overall, there seems evidence that the computer-wage correlation cannot be interpreted as simply the casual effect of technical change on individual or enterprise wages. More likely it reflects the fact that the best technologies are likely to be used by the most able workers who were already earning higher wages" (Chennells \& Van Reenen, 1999, p. 31). Finally, the results as they relate to employment were found to be rarely "conducted with as detailed an eye to the econometric problems involved as those investigating wages and skills" (Chennells \& Van Reenen, 1999, p. 33). This tempered the author's confidence in citing results and conclusions as they relate to this topic.

First among the authors' conclusions is that the surveys which the authors consolidated showed "considerable evidence" that technology is "biased towards skilled labour. Secondly, that there is a positive correlation between wages and innovation. Thirdly, the evidence on total employment is mixed" (Chennells \& Van Reenen, 1999, p. 33). This study relates to my study in that it examines the effects that technologies have upon skills. However, Chennells and Van Reenen (1999) cites previous studies, none of which are related to an organization with the business model that SMART, and other building trades unions, have. Including SMART, a building trades union, will enhance and further illuminate the topic of this study.

Machin and Van Reenen (1998) agreed with Aronowitz and DiFazio (1996). Machin and Van Reenen compared the changing skill structure of one organization's entire workforce and the overall employment of that organization, concluding that, among other variables, "increased 
computer usage [is a factor that has] contributed to reducing the relative demand for the unskilled" (1998, p. 1239). This conclusion was derived from statistical analysis of several data sources that was compiled into many tables and figures; the results led to the conclusion cited above. With the idea that skills and jobs being destroyed have historical support, as in the case of the Typographers, and with the deskilling effects of CT, the implications of skills obsolescence and skills devaluing for all workers in general and sheet metal workers and their union in particular is even more pronounced and, it seems, demanding of immediate attention. Indeed, "applications of industrial technology have simplified, and generally reduced, physical effort, but because of the bond between effort and skill, they have also tended to reduce or eliminate knowhow" (Zuboff, 1988, p. 48). Despite the similarities between my study and Machin and Van Reenen's (1998), there is a significant difference between studying a broad spectrum of work and the specific work of a building trades union; my study will further illuminate the topic of technology's impact on work and the worker.

For labor unions, whose sole product is skilled labor, the impact of CT on the meaning of work for the worker and on wages and benefits is a central theme. Indeed, SMART's Constitution and Ritual states:

In this age of organized effort, it is essential that those engaged at our trade must likewise organize in order to establish and maintain desirable working conditions and thus provide for themselves and their families that measure of comfort, happiness, and security to which every good citizen is entitled in return for his or her labor from a deep sense of pride in our trade, to give a fair day's work for a fair day's pay. (International Association of Sheet Metal, 2015)

Thus, with "a deep sense of pride" in one's work and "a fair day's pay" being central themes of the sheet metal workers' union, the impact that CT has upon one's sense of pride and upon a fair day's pay is worth addressing. 
Giebel's printers were "drawn to their work, and although they were well pleased with their pay and job security, they were most satisfied with the intrinsic aspects of their job" (1980, p. 282). The printers were delighted with their rate of pay but had a deeper connection to their work and this deeper connection led to personal satisfaction. The "printers were depicted as enjoying a relationship to their work, which was more characteristic of a pre-industrial craft society” (Giebel, 1980, pp. 281-282). Zuboff wrote, “A worker's sense of occupational identity was deeply marked by his or her understanding of and attachment to discrete tangible entities, such as a piece of operating equipment" $(1988$, p. 62).

If occupational identity is a socially constructed sense of self whereby one creates and maintains an identity for oneself (Christiansen, 1999), then changes or alterations to one's known occupation would likely serve to cause a sense of psychological unease or personal alienation. If, as is the case of blue-collar workers, a primary determinant in one's identity (Christiansen, $p$. 547) is manifested in physical toil and the new paradigm of work "becomes the manipulation of symbols" (Zuboff, p. 23), then it is easy to understand a person's "feelings of loss of control, of vulnerability, and of frustration" (Zuboff, p. 63). Blauner (1964) argued that among other dimensions of alienation, self-estrangement occurs when a worker views his or her work as a means to something other than self-fulfillment. This is acutely true for the sheet metal worker whose raison d'être is espoused in SMART's credo of "pride in [one's] trade," which is threatened by the very nature of CT.

With ample evidence to suggest that just such a phenomenon is occurring and will likely to continue to occur for some, if not most, of the work that blue-collar workers perform, it would seem wise for a conversation to be commenced to consider the societal implications. Giebel (1980) noted that, with the printers, "as they became less satisfied with the internal dimensions 
of their job, they were more drawn to the external. Pay became the most significant aspect of work" (p. 290). Or, as Zuboff (1988) wrote, "as the intrinsic meaning of the work dries up, its only source of motivation resides in extrinsic rewards. The operators have slowly learned to withdraw any investment of self in their work. What remains is a good paycheck, tasty tobacco, and, if one is lucky, some decent chums with whom to while away the hours of staring at the screen" (p. 273). Such alienation from work, it would seem, would prove to be highly detrimental for society in general and the worker in particular, and it may possibly be catastrophic for the labor union whose operating beliefs have identity in one's work as a central tenet of the organization.

It may be likely that the worker in general and a union's leadership in particular are unaware of the structural challenge to the division of labor implied by CT. Regardless, studies have demonstrated that skills-based technology changes are pervasive in the "developed" world. Berman, Bound, and Machin (1998) presented evidence of this phenomenon occurring as far back as the 1980s. This same phenomenon was concluded in "Workers, Wages, and Technology" (Doms, Dunne, \& Troske, 1997). While this phenomenon seems obvious in a capitalist economic system, the idea that CT poses an existential threat to traditional work and work roles and the growing pervasiveness of $\mathrm{CT}$ in work should be cause for society as a whole to address the implications for those masses who seek employment in the economic sectors most affected by this change. How much more should a labor organization consider its structural foundations and changes to its status quo? Berman et al. researched the correlation between wages and technology. To this end, the researchers conducted statistical analysis using governmental data and previous research. The authors then compiled the data into tables and figures that demonstrated the effects that technology has upon wages. Thus, Berman et al. 
concluded that there was a correlation between wages and technology. Doms et al., who studied the correlation between automated technologies and wages, occupational mix, workforce education, and productivity, used a cross-sectional analysis of workers' skills and their wages. They used data from a survey of manufacturing technology and the worker-establishment database. Additionally, they examined technologies "primarily used in the design and fabrication of products and the control of machinery and information at the factory floor" (Doms, Dunne, \& Troske, 1997, p. 259) and the worker skill level required to operate each. The authors performed statistical analysis and compiled the results of each into tables, which demonstrated a correlation between the variables. The results of their research led to the conclusion that there is a correlation between advanced technology use and increased worker skills required to operate these technologies, as well as a correlation between advanced technology use and increased worker wages (Doms, Dunne, \& Troske, 1997).

Both Berman et al. and Doms et al.'s studies relate to my research in that they focused on the correlation between automated technologies and the effects of such technology on the skill sets that workers are required to have to operate them and the effects of that technology on worker wages. The implications of these phenomena for SMART and the other building trades are directly pertinent to their organizations. This study seeks to discover the rank-and-file members' understanding of the impact of automated technologies on their work and their readiness or resistance to it. However, Berman et al. and Doms et al. studied organizations with business models that differ from that of the building trades union and SMART in particular. Whereas a manufacturing plant, for example, may offer widgets as their product to be consumed, SMART solely offers skilled labor as its product. These respective business models differed greatly; the impact of automated technologies on both the skills required to perform a work task 
and workers' wages has a different value for each organization. A manufacturing business will strive to be more competitive in the capitalist system, thereby embracing automated technologies within a business philosophy that sees such technologies as a means to greater productivity. However, for organizations with a business model that sees its workers' skills as its competitive advantage, the advent of automated technologies and their deskilling effects have a far different meaning, one with potential existential consequences.

Zuboff (1988) further detailed "a widespread belief that this new plant would require a qualitatively different kind of work force" (p. 274). Furthermore, this "different kind of workforce" does not function well in the traditional division of labor paradigm. Zuboff (1988) stated, "Their experiences suggest that the traditional environment of imperative control is fatally flawed in its ability to adequately exploit the informating capacity of the new technology" (p. 390). The implication that the traditional division of labor, which is institutionalized in the business model of SMART, is a "fatally flawed" model relative to "adequately exploiting" CT calls into question the prudence of defending such a structure. If a "different kind of workforce" will be in growing demand, then addressing structural organizational changes needed to meet that demand appears to be in order. Therefore, since CT is pervasive in "developed" economies and since $\mathrm{CT}$ creates the need for a different workforce, there is a need for society as a whole to address how work has changed and is continuing to change and for SMART to reexamine their foundational structures in order to maintain any work where CT has made inroads.

Another important area to consider, related to the how CT impacts work and the worker, is the impact that CT has upon the overall number of jobs that are available. While the assertion that CT leads to a reduction in labor may seem axiomatic, the empirical data supports this phenomenon. Giebel (1980) saw "the loss of jobs and future combined with the reduction in the 
satisfaction with work are obvious" (p. 291). Additionally, as will be explored later in this literature review, since CT has a deskilling effect upon work and "increased computer usage... [is a factor that has] contributed to reducing the relative demand for the unskilled" (Machin \& Van Reenen, 1998, p. 1239), then it seems that this is further cause for society to address what working class people will do for work and for SMART to reassess its structural paradigms. Machin and Van Reenen (1998) compared the "changing skill structure of wage bills and employment" (p. 1215) within seven industrialized nations. They collected data from governmental sources and conducted statistical analysis on it. The data was then compiled into tables and charts that showed that "there exist important skill-technology complementarities" (Machin \& Van Reenen, 1998, p. 1238) and, as mentioned above, a decreased demand for unskilled workers. This relates to my study in that it looks into the effects that automated technologies have on workers' skills and employment opportunities; however, this study is broad based and not specific to one individual trade. My study also researches an organization with a business model unlike that of a manufacturing company. Therefore, while Machin and Van Reenen's study does illuminate my study, it does not look into areas that specifically relate to SMART. My study will also enhance Machin and Van Reenen's study by providing data on this different business model type.

However, in somewhat contrast to this, Chennells and Van Reenen's (1999) third conclusion spoke to total employment and concluded that there is mixed evidence regarding whether or not CT affects total employment; however, this is not directly related to this present research. Important, and to extrapolate through, is their conclusion, which strongly implies that the skill sets of the worker, provided that technology is impacting those skill sets, are changing and if there is a change to the skill sets needed by the worker, the definition of what it means to 
be a worker is changing too. Furthermore, specifically to the building trades union, if there is a reduction in the number of total employment jobs for their workers, the impact on the union could eventually prove to be terminal. For to maintain an organization that offers high wages, pension funds, and health and welfare funds, there is an obvious need for a multitude of participants in that organization.

Chennells and Van Reenen's study, coupled with the previous studies, supplied ample evidence that the phenomenon of technology demanding higher skill sets and higher educational levels than what was once required, occurs at all levels of industry, which means that there are serious implications for society as a whole and specifically for trade organization whose only product is skilled labor. For the building trades union, if the once categorized skilled labor becomes obsolete or the work that once required such skilled labor becomes deskilled, what does that mean for the organization and the individual people who make up that organization? This study is important in that it shows that the empirical evidence suggests that technology will have a total systemic impact on skills, wages, and employment opportunities. For the individual worker who has to compete with other workers for work and the organizations that sell what once was skilled labor, the implications seem staggering.

Another aspect of work that is impacted by CT is wages. In the aforementioned study by Krueger et al. (1998), the evidence showed that the overall trend of increased use of CT has led to wage inequalities between those workers with upgraded skills and with those who have not upgraded their skills. Chennells and Van Reenen's (1999) also concluded that there is empirical evidence of a correlation between CT and wage inequalities. If CT deskills labor and labor is what one's product is, then it seems that not addressing at least the potential impact that CT could have on one's labor would be negligent at best. 
In “Technology, Employment and Skills: An Interpretive Framework” (Vivarelli, 2013), the author discusses the qualitative and quantitative effects of technology upon employment. The author focused on macroeconomic analysis related to technology and unemployment and researched several areas, including an "introductory discussion of the process which starts from the innovation investment and develops into the innovation output with its possible impact on the demand for labor" (p. 67); a "focus on the economic theory put forward by classical and modern economists for giving account of the employment impact of technological change" (p. 67); and "how wage flexibility can (or cannot) respond to the insurgence of 'technological unemployment"” (p. 67) and "skills-biased technological change"(p. 67).

Vivarelli (2013) began with the theoretical framework by which he built his argument, namely that there are two sides to technological change. First, product innovation leads to both job creation and job destruction. While job creation and job destruction do overlap, they each have a tendency towards their respective ends. Vivarelli offered figures, which showed, in the case of process innovation, that such innovation leads to "technological unemployment" (2013, p. 70). In his section on "the compensation mechanism 'via a decrease in wages'," which presented a "demand-for-labor" framework, Vivarelli argued that "assuming free competition and full substitutability between labor and capital, technological unemployment implies a decrease in wages" (2013, p. 72). However, he does then argue that "this should induce a reverse shift back to more labor-intensive technologies" (Vivarelli, 2013, p. 72). To balance this last point, Vivarelli presented the economic framework of the compensation mechanism "via increase in incomes'," which is in direct contrast to the compensation mechanism 'via a decrease in wages" framework. Here a Fordist mode of production where "unions take part in the distribution of the fruits of technological progress" is presented (Vivarelli, 2013, p. 73). 
However, after an extensive review of potential possibilities centered on the "compensation mechanism," the author argued "on the whole, this compensation mechanism has been strongly weakened in the new institutional context" (Vivarelli, 2013, p. 75). In the author's third section, he expanded upon the previous argument on the compensation mechanism via decrease in wages. He uses figures to show his conclusion, which is that there is "severe doubts on the possibility to counterbalance the possible labor-saving effects of innovation” (Vivarelli, 2013, p. 78) by using a decreasing wage strategy. In fourth section, he addressed the skills-biased nature of technology, using tables to support his conclusion that with process innovation occurring, "technological unemployment [will be] disproportionately adverse to the unskilled portion of the labor force" (Vivarelli, 2013, p. 80).

Vivarelli's study relates very well to my study in that it offered a reasoned framework to understand the nature of technological advances and their effect on employment. Furthermore, the idea that the unskilled sectors of the labor force are being particularly affected should be cause to consider this phenomenon. Vivarelli's study offers direct reasons for SMART to address what technology means to itself as an organization and it should cause SMART to consider organizational change. However illuminating this study is, though, it offered only a macro view of the issue and was not specific to SMART's circumstance; my study will help to enhance the theories presented by Vivarelli (2013).

In summary, regarding the effects of technology on the skill sets of workers, workers' wages, and employment opportunities, the literature, with few exceptions, demonstrated the following conclusions.

1. "Developed" countries and economies are increasing their investment in technology. 
2. Technology demands a more highly educated worker.

3. Technology can be correlated to wage earnings because a greater skill set is required to operate these technologies.

4. Technology causes lower skilled workers to be in less demand, thereby creating higher unemployment for those workers with lower skills.

The aforementioned studies provide a clear path into this present study. To elaborate, since there is empirical data showing that the United States, a developed country, is increasing its investment in technology, a study on how workers experience their work that included a labor organization whose sole purpose is to supply skilled labor to a market that is increasing its investment into technologies has merit. Furthermore, this present study is supported by the second conclusion listed above. More specifically, since new CTs are emerging within all industries, the evidence supports the need for increased education for the worker. This point has profound implications for society as a whole and the worker in particular. The idea that training will need to evolve in society to support $\mathrm{CT}$ will be interesting to witness and this is especially true for the sheet metal industry, which markets itself as an alternative to college (The International Training Institute for the Sheet Metal and Air Conditioning Industry, 2015).

Finally, the last conclusion holds stark implications for workers in general and for many of the members of the sheet metal union in particular. Not all workers are alike and for those that are on the lower end of the skill spectrum, a computerized trade may prove devastating. If higher educational levels are required in order to be employed as a worker in the future, then those workers may find it difficult to find employment. For organized labor, this initially could cause the building trade unions in general and the sheet metal union in particular to realize quite a 
shock since the union's income is derived from the members working and high unemployment would cause tremendous stress on the resources of the union. For all of these reasons, this present study fits well within the field of inquiry into how the worker is experiencing his or her work, which has devalued their individual human labor, and whether the individual sheet metal worker is resistant to or ready for the changes brought about by CTs. For the sheet metal industry, learning how the rank-and-file members of the sheet metal union want for their leadership to move forward in light of technological changes is worthy of inquiry.

\section{Technology and the Worker}

Thus far, I have reviewed and discussed the empirical data and how the literature demonstrates, among other things, that there is a correlation between technology's implementation leading to a demand for higher skill sets and how technology causes some skill sets to become deskilled or obsolete. Now I will turn to the literature related specifically to the worker in general and to how the worker resists or embraces technological changes.

As an overall treatise on technology, the worker, and society, "Adapting Automation to Man, Culture, and Society" (Sheridan, Vamos, \& Aida, 1983) sought a human perspective to the phenomenon that automation brings to work. The study looked into the dynamics of automation and human culture with an eye towards both the positive and negative impacts that automation brings to work. The authors showed that as the required skill levels increase, the workers who do that work demanded to be trained in it. While technology does reduce the overall quantity of workers needed to perform any work task, the workers who do perform that work have higher skills than their predecessors did. The authors also concluded that for some well-educated workers, there is no economic demand for their work; the implications of this for the blue-collar workers are pronounced. 
Sheridan, Vamos, and Aida (1983) cited previous studies, offered a reasoned critique, and then extrapolated to reach their conclusions. While this was not a controlled study, it nonetheless relates to my study in that it focuses on the impacts of automation on human beings. With the labor union in general being an organization that is centered upon work as it pertains to the human being, the ideas of Sheridan et al. are directly applicable to my study. Additionally, my study will bring specificity to the topic of automation's impact on human beings, whereas Sheridan et al. do not provide such details.

Regarding alienation of work from the worker, Sheridan et al. (1983) discussed that the worker has less contact with, is more distant from, the work has to be done, including direct bodily contact with work and physical processes that the worker must control. The worker is "not only separated by space, but also desynchronized in time" (Sheridan, Vamos, \& Aida, 1983, p. 610) from the work that is performed. All of this leads to a loss of human dignity by the worker due to the deskilling effects of technology.

While Giebel (1980) contended that structural issues were primary, this phenomenon was present for the printers that he studied. He concluded:

In a relatively short period of time, workers who experienced a great deal of satisfaction with their work and who felt security and pride in their occupation have found these to be transitory. They were ill-prepared for the severity of these changes and this has further confounded their former position in terms of individual success and the affirmation of self-worth; it is debilitating for them to come to grips with the problems associated with the new circumstances. (Giebel, 1980, p. 292)

Zuboff (1988) recorded the same phenomenon with the mill workers that she studied. She offered one potential scenario where: 
As more tasks must be accomplished through the medium of information technology....the sentient body loses its salience as a source of knowledge, resulting in profound disorientation and loss of meaning. (Zuboff, 1988, p. 6)

This is a bleak picture that CT brings to work and the worker. If, as has been previously mentioned, the commodity of the worker in general and sheet metal worker union in particular is skilled labor, then automation's impact on that commodity appears to be profound and should serve as cause for a proactive strategy to adapt and cope with the inroads that CT is making on work.

“The Economics of Has-Beens" (MacDonald \& Weisbach, 2004) sheds important light on the plight of workers as they relate to technology. That study considered any individual's human capital investment to be risky in light of several factors beyond the individual's control. It concluded that "technological innovation has had a substantial impact on the productivity and welfare of many workers" (MacDonald \& Weisbach, 2004, p. S307). While the study centered on the dynamics of older versus younger workers as they relate to technology, it did not wade into the dynamic of how the individual worker, whether younger or older, experienced the new reality of work or whether these workers were resistant to or ready for the changes. The authors used statistical analysis to arrive at their conclusions. While this study does provide sufficient context related to skills become obsolete, it does not consider workers' experiences with their work, including the individual's readiness for or resistance to changes.

MacDonald and Weisbach (2004) did note that there are statistics that suggest a correlation between skill obsolescence and wage depreciation, which, it seems, would indicate negative feelings and possibly resistance to change from the "has-been" workers. Finally, with the conclusion from their study showing evidence that a willingness to adapt to changes from 
new technology is a factor in maintaining one's human capital relevancy, this present study is supported in its view that workers are experiencing their work differently with that work having devalued their human labor. If, as these authors concluded, the forces of a technological advancement "makes obsolete the human capital of most of the workers" (MacDonald \& Weisbach, 2004, p. S308), then this would mean that a corporation would find itself in the situation of eliminating many jobs that were once available to workers. The widespread implications of this on the working classes are ominous and profound. How much more, then, should a labor union, whose sole commodity is skilled labor, do to address the issue of skill obsolescence resulting from CT?

Yet another study that provides a foundation for this present study is "Technology, Alienation, and Job Satisfaction" (Shepard, 1977). Shepard (1977), drawing his conclusions from existing studies, explored the relationship between technology and the worker's sense of alienation from his or her work as well as the relationship between technology and the worker's job satisfaction. While Shepard offered a well-rounded critique of the subject, his conclusions offer support to this present study. One supporting conclusion is that technology "affects the nature of work" (p. 15). Furthermore, Shepard's work concluded that, as of the writing of his study, the evidence showed "that technology and associated job characteristics are a prime determinant of work attitudes and behavior" (1977, p. 16). Thus, with technology's role as a prime determinant of worker attitude and work behavior, this present study on how workers experience their work and, for the sheet metal workers' union, whether the individual sheet metal worker is resistant to or ready for the changes brought by CTs is well supported. However, this study, like the others did not speak to the organization of a building trades union. Shepard discussed the idea that work-related job alienation has a spillover effect into other parts of a 
person's life. For the labor union which purports to concern itself with the whole of its members'

lives, such a spillover effect would have negative consequences. Relatedly, Zuboff pointed out:

The critical point is that the workers who draw sustenance from developing their competence seek measures that they believe will reflect their skills. These are the measures against which they want to be judged, and the reflections of competence provided by such judgments are critical to their own feelings of value.

Throughout Piney Wood, operators complained, "They are not letting me do my job." For them, their jobs had been related specifically to pieces of equipment; since they no longer were able to use familiar skills, they had lost the certainty that "I can do a good job." (1988, p. 300)

Another study offers a different perspective. In "The Impact of Technological Change on Older Workers: Evidence from Data on Computer Use," (Friedberg, 2003) the author sought to understand the impacts of technological change on older workers and the results of that study reveal pertinent information for this present study. Regarding the results of that study, the author offered one conclusion, which was that "workers acquired computer skills as needed" (p. 527). The author also concluded that there is possibly a link between skills upgrading and delayed retirement by older workers, which proved to be true for all workers except the "oldest." For this present study, it is informative in the sense of how the workers attitudes toward their work experiences, especially related to readiness for or resistance to change, might be realized as the results are learned.

Friedberg also researched the challenges faced by older workers as a result of the changes to their work brought on by CTs and she argued that age alone does not explain why older workers use the computer less than do younger workers. The data from her tables showed a clear pattern from which the author concluded that "rates of computer use were remarkably similar for all but the older workers . .., suggesting that most workers acquired computer skills as neededeven when they had long been out of school" (Friedberg, 2003, p. 527). 
This illuminates my study in that it suggests that the older members of SMART will learn new computerized skills, should SMART embark upon such an organizational change, and that they are not inherently opposed to learning new skills. However, this study cited data that speaks to a traditional top-down business model, which has a different culture than does a democratically structured labor union business model. Mandating the use of new technologies is simpler in traditional corporations where all it takes is a mandate from the corporate heads. The unionized building trades business model is different and consequently has different dynamics to consider. Therefore, my research will create data that can be used to further Friedberg's research.

The evidence suggesting that workers who possessed computer skills chose to delay their retirement clearly implies that workers who upgrade their skills possess a higher level of job satisfaction. It seems fair then to deduce that those workers who do not adapt to technology by upgrading their skills possess a lower level of job satisfaction, thereby leading to such workers being unhappier overall. This evidence also speaks to the possible plight of the worker. If a worker has the sense that his or her skills are out of date, it is certainly possible that he or she would possess an overall lower sense of self; when extrapolating this to the whole of society, the implications are large. If, as in the case of the sheet metal workers' union, by no fault of its own it finds that its work has changed from skilled labor to less-than-skilled labor, the relevance of that organization, it follows, is lessened. Furthermore, since the members of the sheet metal union have a great deal of pride regarding the skills that a sheet metal worker currently possesses, deskilling those skills implies that the organization as a whole becomes less in demand and relevant. If being a sheet metal worker connoted a less-than-skilled worker, the effect would be devastating not only to the self-esteem of the individual member, but it would mean that the organization would be less relevant as a whole. 
However, the authors of "Advanced Manufacturing Technology and Work Simplification: An Empirical Study" (Wall, Clegg, Davies, Kemp, \& Mueller, 1987) did not reach the same conclusions. Specifically, among other conclusions, the authors stated that adoption of technology by the manufacturing companies that they researched did not result in an overall loss of skill by those manufacturers' labor forces (Wall et al., 1987). Wall, Clegg, Davies, Kemp, and Mueller (1987) do concede that the results of their study cannot "refute the general deskilling argument" (p. 248). It is important to note that while this last study offered general insight into the relationship between technology and the worker, it did not speak to the dynamic of commoditized labor, which is a structural component of SMART.

Related to organized labors, one limitation from these cited studies is with regards to the division of labor. These studies looked at companies that could force implementation upon the workers that they employed simply by management decree. When considering the idea of a labor union and the CBA process, the ideas of implementing change normally takes a different form. Many changes to work, the work environment, etc. are subjected to the negotiation process within the collective bargaining process. With the organizational structure of the labor union established to preserve its contracted labor jurisdiction, implementation of technological changes would likely prove to be more difficult than by a simple management decree. Furthermore, within each local SMART union, all CBA contracts must be ratified by a majority of members present at the contract meeting. This is true even if the elected leadership of a local sheet metal union had negotiated an acceptance of CT that would result in job losses. In this case, the rankand-file membership could veto the negotiated contract of the union's leadership. Therefore, while these studies can shed light in a general sense on workers and their attitudes toward 
implementing technology, they do not take into account the unique circumstances of a private sector building trades labor union.

In "Employment Protection, Technology Choice, and Worker Allocation" (Bartelsman, Gautier, \& Wind, 2011), the authors researched the relationship between technology adoption and employment legislation. More specifically, the authors were interested as to why there was a divergence in productivity between the United States and the EU beginning in the mid-1990s. The authors hypothesized that this phenomenon was in part due to the differences in employment laws between the United States and the EU. Using data collected from earlier studies and conducting extensive statistical review of that data, the authors concluded that regardless of "industry riskiness," (the higher the risk, the greater the intensity of advanced technology usage), the greater the cost a company incurs to fire or otherwise eliminate jobs leads to "lower employment" (Bartelsman, Gautier, \& Wind, 2011, p. 35).

This is particularly illuminating to a building trades union with their unique model of organization. The CBA is a vehicle that the union can use to establish a cost to eliminate jobs. This study shows that companies prefer to continue using lower risk technologies rather than incur costs for job elimination. For a building trades union, such as SMART, this is hopeful news and could provide a means whereby the union could seek to slow the tide of jobs elimination associated with technology adoption. However, this study was also conducted on business with a different structural model than the building trades union; my study will provide insight into how such a structurally constructed organization will address the phenomenon of technology eliminating jobs and how employment elimination costs affect such an organization.

The review of literature related to technology and the worker, while accounting for differences, resulted in the following conclusions: 
1. Technology affects workers' attitudes.

2. Computerized technologies have a deskilling effect on work.

3. Consequently, the workers have a sense of alienation from their work.

4. Technology causes some work skills to become obsolete.

5. Technology demands higher skill levels.

6. Workers acquire skills on an as-needed basis.

7. Labor laws regarding the cost to eliminate jobs affect technology adoption.

The conclusion that CTs deskill work, it seems, is the most profound in its implications for the individual worker and how he or she experiences his or her work. Indeed, most industries have already experienced this and the sheet metal industry has experienced this with the obsolescence of the bench layout personnel, which I discussed in this study's introduction. If the arc of technological progress has not yet completed its path within the economy and work, then the implications for workers, especially related to how they experience their work, is stark. Where the impact of CT on work ends, what it means to be a worker, and how a worker will experience work are questions that are deeply important to society as a whole. For the sheet metal workers union, the implications may prove to be devastating for the union as a whole and for its members. If the next wave of $\mathrm{CT}$ reduces the numbers of jobs available to workers, as it did to the sheet metal workers with the advent of the plasma table, then sustaining a society that can find employment for the working class may prove to be extremely difficult and for an organization that relies upon mass numbers to support its pension funds, health and welfare funds, it may prove to be impossible. For the labor union, this possibility alone is cause to study 
the implications of technology on its claimed jurisdictional work. Finally, while the cited studies provided illumination on technology and the worker, there is a gap in the research as it pertains to how the worker experiences his or her work, which has devalued his or her human labor.

\section{Literature Regarding Adoption of Technology}

Pertinent to this present study is the idea of adoption of technology. There are many dynamics that can affect the adoption of technology, including culture, beliefs, and mandate; all of these dynamics are at play for the worker. Additionally, since technology has already dramatically altered the career landscape of what it means to be a worker, it naturally follows that adoption of technology is thematic. The focus of this section of the literature review is on workers adopting technology. With the dynamics of commoditized labor and technology deskilling such labor, adoption of technology by those that are the commodity, i.e., the labor force, seems to be imperative. Here too, there was a wealth of studies to draw from and those studies that were reviewed provided ample foundation for this present study.

How culture affects the adoption of technology has been widely studied. In "A ThreePerspective Model of Culture, Information Systems, and Their Development and Use" (Kappos \& Rivard, 2008), there were three conclusions reached that spoke directly to this study. Specifically, the authors found that "culture moderates the relationship between the characteristics of the [information system] and acceptance and resistance" (Kappos \& Rivard, 2008, p. 620). This conclusion is foundational for this present study. If the attitudes and behaviors of an individual worker in general are adverse to change, the implications for such a worker seem negative. As it relates to the sheet metal worker, this means that if the sheet metal workers union is resistant to change, as was evident from the story of the business managers, then the implications for the long-term well-being of that labor union also appear to be negative. 
If the culture of the sheet metal union is greatly shaped by its leaders and those leaders are averse to adopting emerging technologies, then it seems that the deskilling effect will be profound.

The second conclusion from that study worth discussing is that "culture influences the development process" of technology systems (Kappos \& Rivard, 2008, p. 620). If the individual worker opts to not engage with emerging the CT or the culture of SMART is such that workers do not engage with emerging technology, then the individual worker, or the union as an organization, has no ability to affect the development process of that technology. It is important here to consider the discussion that I had with the two business managers. Accompanying the patent was a business plan to develop the technology into working status. The United States patent enabled the unionized sector of the sheet metal industry to completely control the development of the automated technology for the sheet metal shop; however, the culture of the union was such that two of the leaders opted for a path that secured their personal self-interests over adopting an emerging technology. In fact, the General Executive Council of SMART chose not to pursue implementation of the patent. Therefore, the conclusion that culture participates in the development of the processes of technological systems, clearly shows, specifically related to SMART, that the decisions of the leadership of the union has chosen to react to whatever may come at a future time from that development process. This same principle applies to the individual worker.

In the same study (Kappos \& Rivard, 2008), the role of culture and its effects on information systems was also addressed. The researchers used a three-perspective concept of culture that included integration, differentiation, and fragmentation, which were expressed in visible manifestations, items such as artifacts and practices, and ideation manifestations, the values, beliefs, and assumptions held by members of a collective (Kappos \& Rivard, 2008, p. 
604). After defining what they meant by culture and how culture is manifested in an organization, the authors conducted a literature review and categorized the existing literature into two categories: synthesis and derivation of propositions (Kappos \& Rivard, 2008, p. 607). Their research found that culture influences the development process of an information system. Culture moderates the relationship between the development process and the information system characteristics; between the information system characteristics and user acceptance and resistance; and between the information system characteristics and the use process. Information systems use has an influence on the culture of an organization itself (p. 607).

This study relates to my thesis in that it illuminates the effects that organizational culture has upon informational technologies acceptance by the members of an organization. For SMART, the culture is such that there is a long-standing veneration of its history. The labor unions of the American Federation of Labor (AFL) before it merged with the Congress of Industrial Organizations (CIO), of which SMART has its roots, have a longstanding tradition of being skilled craft laborers and the members of these unions strongly identify with the work that they perform. Indeed, to be a union sheet metal worker is a source of pride because of not only pride in the work one does but also because of pride in the history of the union and the battles that the union fought and won. In fact, it is common to see vehicle bumper stickers or t-shirts being worn that say "Labor Unions: the folks that brought you the weekend." The point to understand is that there is a strong sense of history within the building trades unions and especially for SMART, which informs the organizational culture of the union. Therefore, understanding how culture is affected by information technologies and how the culture of SMART will affect the acceptance of technologies is very pertinent to my study. However, here too the gap in this research is on the type of organization being studied. The literature is 
extensive on the organization of a top-down corporate structure but lacking in terms organizations that are democratically structured. My research can shed light on how organizational culture is influenced by information technologies and how such technologies are accepted in a democratically structured organization.

More personal than culture is the individual. Important to the individual is belief and specifically belief about acceptance and adoption of technology. One study supports the notion that an individual's perception of the usefulness of a technology and that technology's ease of use plays an important role in adoption of a technology (Agarwal \& Prasad, 1999). For the individual worker, these implications are positive. If the beliefs of the working classes are such that they feel as though adoption of technology is important for the their well-being, and the well-being of their union in the case of SMART members, then adoption will come more organically. Additionally, if workers believe that adopting such new technologies is relatively easy, then they will be more ready to embrace such technological changes. However, if the belief of the workers is such that they individually perceive that a new technology is not useful for their work or if they believe that it will be difficult to use, then adoption of that technology becomes more difficult. Zuboff (1988) spoke to this point:

How people feel about themselves, each other, and the organization's purposes is closely linked to their capacity to sustain the high levels of internal commitment and motivation that are demanded by the abstraction of work and the new division of learning. (p. 401)

In "Are Individual Differences Germane to the Acceptance of New Information Technologies?" (Agarwal \& Prasad, 1999), researchers sought to discover what individual differences caused individuals to adopt new technologies. The researchers hypothesized the following. 
1. Ease of use and usefulness beliefs fully mediate the influence of selected individual difference variables on attitude and usage intentions (p. 369).

2. Ease of use and usefulness beliefs about an information technology innovation are more positive for technology providers than for technology workers (p. 371).

3. The length of tenure in the workforce is negatively associated with ease of use and usefulness beliefs about an information technology innovation (p. 371).

4. Level of education is positively associated with ease of use and usefulness beliefs about an information technology innovation ( $p$. 371).

5. The extent of prior experience with similar technologies is positively associated with ease of use and usefulness beliefs about an information technology (p. 372).

6. Participation in training on an information technology innovation is positively associated with ease of use and usefulness beliefs about that innovation (p. 372).

To test their theses, the researchers sent out over 450 surveys to a Fortune 100 information technology vendor in the Midwestern United States. They received a $49 \%$ response rate of usable surveys (p. 372). These surveys consisted of eight items all using a 7point Likert scale. The statistical analysis of the survey data led the researchers to several conclusions. They concluded that "individual differences drive the acceptance of new information technologies through their influence on beliefs about new IT" (Agarwal \& Prasad, 1999, p. 383). Furthermore, the researchers also concluded the following.

[There was] support for the technology acceptance model as an adequate and parsimonious conceptualization of acceptance behavior and the salience of usefulness and ease-of-use beliefs. In addition, we have demonstrated the feasibility of viewing the process of belief formation as essentially one of learning; consequently, we show that learning theories provide a rich theoretical foundation for identifying potential influences on beliefs" (Agarwal \& Prasad, 1999, p. 383).

This study relates to my thesis in that it provides a foundation into how the beliefs, educational level, career length, etc. all affect how an individual sheet metal worker may accept or resist information technologies that are emerging within the sheet metal trade. However, this 
study also studied a corporation with a top-down business model. Within this structure, new information technological innovations can be imposed from the top of the structure down to those who work for that corporation. SMART is different in that it is more democratic in its structure. Being democratic in structure, the mandating of information technology acceptance becomes more tenuous as those who may be in a position to attempt to mandate such acceptance may find themselves voted out of office and consequently out of the position to mandate any such change. My research will determine whether the rank-and-file member of SMART is aware of a need to accept new information technologies and whether they are ready for or resistant to the changes to the trade that will be brought about by information technologies. The data gained from my study can help to further illuminate Agarwal and Prasad's study by filling in the gaps cited above.

Another study supporting the conclusions that perceived usefulness and perceived ease of use are important determinants of adoption of new technology comes from the University of Michigan (Davis, 1989). In "Perceived Usefulness: Perceived Ease of Use, and User Acceptance of Information Technology," Davis acknowledged in his study that the dynamic of an individual's intrinsic motivation is not well accounted for in the research that he reviewed. Intrinsic motivation is important to this present study since the institutionalized structure of obtaining work is one where the individual worker's ability to be employed is in large part determined by that individual worker's work ethic. Indeed, while the assessment of what constitutes a "good" or "bad" work ethic can be subjective, the structural system in place within the competitive market is such that the individual employer is the entity with the power to make that determination and the power to choose whether to employ an individual worker. Thus, the worker's intrinsic motivation primary determinant of whether the individual worker is employed. 
Additionally Davis (1989) studied the correlation between "perceived usefulness and ease of use" (p. 333) and the acceptance and usage of new technologies by people who were tasked with using new information technologies. In this study, Davis conducted both field and lab studies where he created multi-item scales that "were used to generate 14 candidate items for each construct," (1989, p. 323) which was derived from past literature. Interviews were then conducted to assess the semantic content of these constructs. Finally, 10 items were selected for each construct to yield the testing scales. His analyses demonstrated that there was a "significant correlation" (Davis, 1989, p. 333) between perceived usefulness and ease of use of a technology and user acceptance of that technology. The correlations that were realized when analyzing these studies were significant to draw such a conclusion.

This study relates to my thesis in that it speaks to the concept of technology acceptance by people who may otherwise be adverse to accepting technologies. If the survival of SMART does, in part, depend upon accepting technologies that have not historically been tools used in the sheet metal industry, then understanding that users will accept technological changes if they perceive the technology as useful and easily learned will enable SMART to evolve to include skill sets not yet present in its organizational plans. Davis' (1989) study was conducted on subjects who were in a different business model than that of the unionized building trades, which has skilled labor as its marketable product. When technologies deskill or cause skills to become obsolete altogether, the acceptance of technologies has a different meaning for an organization that is solely peddling skilled labor. My research can add to Davis' research because it explores that market and will further illuminate the concept of user acceptance of information technologies in areas that Davis did not study. 
In the structure where the individual worker knows that he or she must please his or her superiors, which creates a culture where the individual worker works under the aura that one must be motivated to work in order to find regular work and not be laid-off. This systematic structure is not unique to the industries of the West as a whole but is also in place for the unionized building trades including SMART. For within the building trades model, a contractor hires labor from a local union hall, which is the structure for all of the building trades, leading to competition between the members of an individual trade union becoming a structural component to its culture. Thus, intrinsic motivation becomes a structural component of the system that the building trades, including the sheet metal industry, operate under.

In conclusion, there are four important themes in this section that are related to this present study as it relates to adoption of technological change. Additionally, the gap in research is the same as cited above. Namely, research has not been conducted on how workers experience their work with that work devaluing the individual's human labor. Related to the members of the sheet metal workers' union, the dynamic of technology adoption imbues a new structural element, that of survival, which would be cause for intrinsic readiness for change. However, this may not be present as was evidenced by my conversation with the two business managers.

The conclusions from this section are:

1. Culture moderates acceptance of or resistance to technological change.

2. Culture influences the development process.

3. Individual belief effects technology acceptance.

4. Intrinsic motivation can be a determinant to technology acceptance. 


\section{Literature Specifically Related to the Unionized Workforce}

It is important to consider the systems and culture of the building trades unions and, specifically, the sheet metal workers union when reviewing the literature. As was discussed previously, the culture and structural systems of the building trades are ones with dynamics that influence whether technology is adopted or resisted. For, if the structure of the unionized sheet metal industry is one where the individual sheet metal worker's labor is commoditized, then the economic laws of supply and demand and the economic dynamics of competition are structural. The institution of the labor union may be adverse to the dynamics of supply and demand and competition for the benefit of its members, but those structural dynamics are supreme as long as the power to hire the commoditized labor (the worker) resides with the entity (the contractor) that chooses to use (hire) the labor that is supplied by the local union. As Zuboff wrote, "The union contract became the most important means for institutionalizing workers' instincts for selfpreservation, as rationalization routed out the ordinary graces with which the workday had been laced" (1988, p. 46). The CBA, the union contract, is as it relates to the information economy, a relic of an industrial economic model of the past. For sure, while much of what a sheet metal worker still presently does for work can fall under an industrial economic model, the inroads that CTs have upon that work continues to grow.

It is here that this literature review focuses on existing research related to a unionized workforce. It is important to remember that the building trades', which includes the sheet metal workers union, structures differ from a company union model or a public sector union model. There are studies to draw from, but they are fewer in number than a general review of technology as it relates to work as a whole. Apart from Giebel's (1980) study, which has been discussed already, there are two studies that are worth noting. 
The first of these studies sought to discover whether a unionized workforce influenced the diffusion of technology (Keefe, 1991). In this study, "Do Unions Influence the Diffusion of Technology?" Keefe (1991) discovered that while a unionized workforce is more likely to be using advanced technologies, there is no supporting evidence that this finding is endogenous to the unionized work force. This is important to the present study in light of the discussion that I had with the two business managers. Important in that account, and supported by Keefe's findings, is the concept that while the two business managers were apparently resistant to the implementation of a robotic sheet metal shop, their responses were such that they accepted such a fate accompli and, importantly, offered no responses that would prevent technology from emerging in the sheet metal industry as a whole in the future. It was as if they knew that this technology would eventually be realized and with its realization, there would be major job losses. Keefe's research is foundational to this study as it appears to support what Samuel Gomper's leadership has set in place foundationally and what labor unions operate under today. Nevertheless, Keefe's research demonstrated no empirical evidence between a unionized workforce and acceptance of technology.

Keefe (1991) reviewed the existing literature regarding unions and their effects on the diffusion of manufacturing technologies and conducted a survey of "835 establishments in 23 metropolitan areas" (p. 265). Keefe concluded "that union status has no apparent effect on the use of advanced manufacturing technology" and that "historically, American unions have been most concerned with protecting their members' employment and income security, and not with preventing change or impeding management initiatives for modernization" (Keefe, 1991, p. 273). These conclusions were derived by the author after the results were compiled into tables and analyzed. The results showed that while union manufacturing plants may indeed be more likely 
to be using automated technologies, this was the result of the size of the manufacturing plant and operating on shift work and not related to its unionization status.

This study relates to my study in that it is directly related to the dynamics of labor unions and advanced technologies. The conclusions reached are a positive for the story of labor unions because the results show that unions' have priorities that do not preclude the acceptance and diffusion of advanced technologies. For SMART, this provides a hopeful framework to build upon. However, this study does not address the whole story that my research seeks to discover. Namely, while Keefe (1991) concluded that unions have mostly been concerned with "protecting employment and income security" and that they are not inherently adverse to preventing changes brought by advanced technologies, the concept of what unions will do when the modernization changes mean a lack of employment and income security is not considered. My study does provide insights into how the rank-and-file membership of SMART feels about and accepts such changes brought about by advanced technologies. The results of my study provides a greater understanding of whether SMART's rank-and-file membership are ready for or resistant to the changes brought about by such technologies. Therefore, Keefe's study (1991) provides a basis for understanding that the members of a labor union have no inherent bias against advanced technologies per se but that should any resistance to change brought about by advanced technologies may be due to other variables unrelated to the organization itself.

Somewhat related to Keefe's (1991) research is the work of Delaney, Jarley, and Fiorito (1996) who studied many national unions in the United States. In "Planning for Change: Determinants of Innovation in U.S. National Unions" their results showed that unions with a proactive approach to technology tended to engage in "innovative behavior" and that there was a correlation between heterogeneous unions and innovative acceptance (Delaney, Jarley, \& Fiorito, 
1996). However, Delaney et al. (1996) also noted some regressive results, including the lack of a correlation between a democratic union and innovation facilitation and, interestingly, that a more democratic union tended to be less accepting of innovation. Furthermore, they suggested that the American legal system is supportive of regressive behavior by labor unions (Delaney, Jarley, \& Fiorito, 1996).

Delaney et al. (1996) seek to better understand determinants of innovation within the national unions in the United States. To this end, Delany et al. used existing literature but also conducted research of their own using surveys and interviews. Delaney et al. coded the responses and interviews and systematically analyzed the results. They discussed both the descriptive and regression results of their study. The descriptive results showed that the associations among the innovation variables are strong and positive (Delaney, Jarley, \& Fiorito, 1996, p. 607). For regression results, Delaney et. al presented the results of their statistical ordinary least squares analyses, which showed that the "results [were] generally consistent across the Perceived Innovation and Innovative Tactics equations ... however, the pattern of results is somewhat different in the Innovation Norms equations, where signs on the size coefficients reverse" (1996, p. 607).

From the data, Delany et al. (1996) asserted that there were three implications. The first was that "the results confirm that union characteristics are associated with union innovation," (Delaney, Jarley, \& Fiorito, 1996, p. 610) where union characteristics are defined as the union's membership population, rationalization, centralization, democratic structures, and membership heterogeneity. The second assertion was that "some characteristics especially salient in unions and often ignored in the organizational literature (such as democracy) may have important influence on unions' innovation" (Delaney, Jarley, \& Fiorito, 1996, p. 611). Here Delaney et al. 
argued that there are specific business structure constructs within labor unions, which have not been studied adequately, that are not present in traditional corporate models. The third and last assertion was "it may be fruitful to examine innovation within unions across specific occupational groups (such as nurses in the American Nurses Association and nurses in the Teamsters [union])" (Delaney, Jarley, \& Fiorito, 1996, p. 611).

Delaney et al.'s (1996) study relates very well to my study in that it takes into account the structural differences present in the labor union business construct. Many labor unions in the United States have indeed innovated as necessity has imposed upon them. This is especially true for labor unions such SMART. For labor organizations like SMART, the need to innovate and change could be a matter of survival for the union. Their study, however, does not address my thesis that computerization and automation is devaluing, deskilling, or causing skills obsolescence and resulting in the worker experiencing work differently. My study fills in the gap not addressed in this study as it addresses the issue of changes to skills and what it means to be a sheet metal worker.

In conclusion, there are four important themes in this section that are related to this present study as it relates to adoption of technological change. However, as mentioned above, the gap in research lies in resistance to or readiness for change within the commoditized labor model of a labor union, which has not been studied. The conclusions from the cited literature are:

1. While a unionized workforce is likely to be using advanced technologies, there is no evidence that this is intrinsic to the unionized workforce.

2. Unions with a proactive approach to technology led to innovative behavior by that union.

3. There is no correlation between a democratic union and innovation facilitation. 
4. The more democratic unions tended to be less accepting of innovation.

\section{$\underline{\text { Resistance to Change }}$}

Resistance to change has long been recognized as an important determinant for change, including organizational change, efforts. Indeed, Schein (1998) asserted that resistance is regularly viewed by managers as an enemy of change and there is ample research to draw from regarding this traditional view of organizational resistance. Furthermore, the traditional management prescription for organizational resistance has been simple: eliminate it. However, there is new research illuminating the phenomenon of resistance to change and in it, the ideas of managerial prescriptions for change via change agents has come to be seen as being an integral part of the resistance problem itself.

Firstly, though, it is important to further address the traditional managerial prescriptive theory of change management. As was mentioned above, there is ample research on organizational resistance to change. One such study is "Resistance To Change: The Rest Of The Story," which argues that the traditional theoretical presupposition was from a "change agentcentric" view where it was presumed "that resistance is an accurate report by unbiased observers (change agents) of an objective reality (resistance by change recipients)" (Ford, Ford, \& D'Amelio, 2008). This view stems from the Taylorism philosophical framework that managerial prescriptions are derived from a scientific objective reality, which is still, to this very day, engrained within the understanding of what it means to be "good" management. Indeed, "in the hundred-odd years that management has been around, it has colonized work life and staked a claim to a universal ideology, spreading to all corners of the globe, infiltrating every aspect of our lives" (Addleson, 2011, p. 211). Thus, resistance to managerially decreed change prescriptions, via change agents, are inevitably unwarranted and detrimental and "there is no 
consideration given to the possibility that resistance is an interpretation assigned by change agents to the behaviors and communications of change recipients, or that these interpretations are either self-serving or self-fulfilling" (Ford et al., 2008, p. 362).

Ford et al. sought to "address the failure" of previous research where organizational change agents were seen as unbiased agents who dealt with the "objectively real resistance of change recipients" (p. 362) rather than considering the change agents as contributors to the resistance itself and the consequences of that contribution. Ford et al. sought to reconstruct the concept of resistance to change as a social construct by both the change agents and the change recipients. They reach the conclusion that resistance is socially constructed by examining and analyzing the existing studies and critiquing them with the added sense that the change agent being human will add to the dynamic of the resistance to change (Ford et al., 2008). Ford et al. argued that "the contributions of change agents to resistance goes beyond the labeling that results from their own sense making to breaking agreements and violating trust, misrepresentation and other communication breakdowns, and their own resistance to change" (2008, p. 365)

This article relates to my thesis in that since resistance to change will invariably occur should SMART embark upon organizational change; thereby, those charged as change agents, those elected leaders of each local union and possibly the international union's executives, will need to understand that they will be co-constructors of any resistance to change that will occur. Knowing this beforehand will enable the change agents to better plan and anticipate resistance when it occurs. Yet while Ford et al. (2008) illuminated the phenomenon that both the change agent and change recipient co-create resistance to organizational change, there is a supposition that the change agents are not subjected to be re-elected to their leadership, and consequently change agent, positions by the very change recipients that the individual change agent is charged 
with securing change from. In the case of the union leadership who would be in the role of change agents, this means that not only are the change agents co-creators of resistance and resisters of change but that their role as change agent is potentially fluid and certainly not a secure position, as it is subjected to the desires of the change recipients. Indeed, within a short period of time, should the change recipients for whatever reason fail to reelect a union leader, this union leader would find himself or herself no longer a change agent but a change recipient. This adds a dynamic not considered by Ford et al. Therefore, while it is illuminating to consider that the change agent and change recipient are co-creators of resistance to change, the concept of resistance is not fully considered within the business model of a labor union such as SMART. In this situation, the resistance created by the change agent has an added dimension and meaning, with the change agent having to consider the implications of change from the perspectives of both the change agent and the change recipient. The change agent has to not only secure the change desired but do it in such a manner that the change recipients are satisfied with the change agent to the point that they are willing to reelect him or her to the position that includes the change agency. This may prove to be a real tightrope walk for the change agent in such an organization.

In contrast to the traditional views on resistance to change, newer theory say "that resistance can play a useful role in an organizational change effort" (Waddell \& Sohal, 1998). Furthermore, Waddell and Sohal asserted that resistance is driven not by selfish reasons but rather by several social factors including rational, non-rational, political, and management factors. (1998, p. 544). They conclude that resistance should not be seen as adversarial because of the useful role that resistance can play towards organizational change. Likewise, "[change] recipient reactions can have value for the existence, engagement, and strength of a change, 
serving as an asset and a resource in its implementation and successful accomplishment" (Ford et al., 2008; Knowles \& Linn, 2004).

In “Resistance: A Constructive Tool for Change Management?", Waddell and Sohal (1998) referenced several existing studies thematic to organizational resistance to change and concluded that while "the theoretical understanding of resistance is well advanced, it is apparent that this knowledge has not impacted common perceptions of management and therefore has not transferred into the development of solid resistance management techniques" (p. 546). They further concluded that the "classical adversarial approach remains dominant" (Waddell \& Sohal, 1998, p. 547) because of a lack of solid resistance management techniques in practice. This is important to my thesis as SMART will invariably encounter resistance to any organizational change that will be attempted; should the union's leadership take an adversarial approach, the results could potentially be far different from the results that were realized in the studies cited by Waddell and Sohal. It is important to remember that the structure of the union is different from that of a traditional labor-management paradigm, which is an area where there is a gap in the research. While the leadership of the union does have a level of organizational control, this control is not absolute, as all leaders are subject to reelection to their positions or a higher one and consequently, those who may resist organizational change could conceivably vote out any leader attempting to change the organization. Resistance to organizational change in this circumstance could easily lead to a loss of a position of leadership within the organization. Therefore, the level of buy-in from the rank-and-file membership of the union has a different importance than that of the more typical corporate setting. This means that anticipating and planning for resistance will likely require, as the studies cited by Waddell and Sohal show, SMART's leadership to take a more measured, systematic pace and to ensure that any 
organizational change advocated is not simply for change sake but rather for the survival of the union. Taking such a measured approach will ensure that the SMART organizational change will be more meaningful and beneficial to the SMART membership as a whole.

To say it a different way, Waddell and Sohal's (1998) review centered on management techniques that should be employed for change in an organization where the classical organizational structure resembles a pyramid. This differs from the management of a labor organization wherein the management is required to be reelected by the membership of the organization every few years. In this organization, the organizational chart would more resemble a circle in that the leadership directly answers to those that they have authority over. This means that the management of each local SMART union will always need the consent of their local membership, thereby adding a different dynamic to the management of organizational change. Resistance to organizational change by the membership of a local SMART union can, as is shown in the review by Waddell and Sohal, be a stabilizing and beneficial dynamic but in the context of a labor union, those being managed can have veto power as to whether organizational change occurs at all. My study of a labor union's rank-and-file membership fills one gap in this area of research.

Regarding the demonstration that one valus a change initiative by maintaining the existence of that change initiative, "new conversations have difficulty competing with already existing conversations that are well practiced and habituated, not because the new conversations are without value but because they suffer from the liabilities of newness, inexperience, and unfamiliarity (Ford et al., 2008; Barrett, Thomas, \& Hocevar, 1995). Simply put, those who are resisting changes and discussing those changes are maintaining the existence of the change proposal. This phenomenon shows that the change resisters demonstrate deference to an 
acculturated idea and that the change concept, while unfamiliar, is of enough value to merit continued discussion rather than categorical dismissal, thereby maintaining the existence of the change initiative.

Regarding the value of engagement, Ford et al. (2008) and Piderit (2000) see resistance as a possible form of engagement with change. Ford et al. further asserted that resistance "in some cases, reflect a higher level of commitment than acceptance, because some resistance is thoughtful" (2008, pp. 368-369). To put it in simple terms, the idea that resistance is a positive occurrence, in that it demonstrates that change resisters are engaging with the change concept, is akin to the existence value discussed above. If change resisters are unfamiliar with a concept, but they are engaged with the idea, wrestling with its implications, then it demonstrates that they do see some value in the concept and do not simply dismiss it as nonsensical.

In "Rethinking Resistance and Recognizing Ambivalence: A Multidimensional View of Attitudes Toward an Organizational Change," Piderit (2000) conducted a review of the existing scholarly literature and concluded that the existing research was limited in that it failed "to take the good intentions of resistors seriously and for the varying emphases in conceptualization of resistance" (p. 792). More specifically, Piderit argued that past research revealed "three different conceptualizations of resistance: as a cognitive state, as an emotional state, and as a behavior" (2000, p. 785) and that "any definition focusing on one view at the expense of the others seems incomplete" (2000, p. 786). Therefore, Piderit sought to integrate all three conceptualizations of resistance and to seriously consider resisters' "good intentions," which Piderit believed was a more complete framework within which to conduct future research.

This article relates to my research in that having as whole a conceptualization of resistance to change as is possible will enable the union's change agents to better prepare and 
anticipate any desired changes. As I previously stated, resistance will occur if and when the union chooses to embark upon organizational change and the understanding that resisters to change can have good intentions should prove to be very beneficial for the union as a whole and the change agent in particular. Additionally, recognizing and planning for all three conceptualizations of resistance will enable the individual union change agent to be more empathetic, thereby creating an environment for change recipients that can feel less judgmental and adversarial.

Yet here, as before, the manager/subordinate divide is set within a traditional corporate structural model where the manager possess the power to coerce, in one form or another, organizational change and not within a building trades business model where the union's leadership is democratically elected every few years. This dynamic changes the variables that contribute to resistance to change as any change agent that the union leadership uses may find himself or herself terminated from the position of change agent and consequently find himself or herself as a change recipient. This dynamic will likely alter the understanding of resistance to change as the models studied thus far have a clear dichotomy between the change agent and the change recipient. If the change agent understands that his or her circumstance as change agent could be quickly altered so as to cause him or her to become a change recipient, the conceptualization of resistance by that change agent will differ from a change agent that is in a traditional corporate business model where coercive power is assured. Additionally, the dynamic for the change recipient is different in the business model of the labor union. In the labor union, the change recipient has the understanding that organizational power is granted to the leadership, and consequently, to the organizational change agent by the consent of the membership. This 
alters the dynamics of how a change recipient resists change in all three conceptualizations discussed in this article: cognitive, emotional, and behavioral.

In "Success and Failure in Organization Change: An Exploration of the Role of Values," Burnes and Jackson (2011) researched the role that values, or more specifically values alignment, plays in organizational change. To achieve this, Burnes and Jackson used a "method based upon Graves' emergent cyclical levels of existence theory (ECLET)" (2011, p. 143) to determine the values system of a group by using a values test. The value system of the intervention used with each group, which was determined using a qualitative examination of the description of the intervention approach and its agreed objectives, and the effectiveness of the intervention, which contained both quantitative and qualitative feedback data was collected after the intervention (Burnes \& Jackson, 2011, pp. 143-44). Burnes and Jackson studied two groups. One was a project team consisting of 11 members who work with an English national charitable organization and the second was a management team consisting of 13 members of a privately owned marketing organization; both were located in the northwest of England (2011, p. 143). The results of each group were compiled into tables and bar charts and then statistically analyzed. The results showed a mean average and deviation that supported the proposition of the authors. Burnes and Jackson concluded that there is support for their "proposition that value alignment may play a significant role into whether change interventions are accepted by members of an organization and in the intention of those members to respond and implement change" (2011, p. 158).

This study relates to my study in that it researches value alignment as an important factor in a change initiative. The leadership of SMART, as has been previously mentioned, will need to plan for values alignment of the rank-and-file member of the union. They will need to discover 
the values of the membership as a whole and of the various subsets within the union. Planning for a change initiative will need to account for the individual's values as well as the group's values. This point will need to be planned for with particular care. However, despite the fact that this study has commonality with my study, it does not address the specifics of the type of organization that building trades unions are. Specifically, and as I have previously discussed, SMART has an organizational structure that differs in important ways from a traditional company or corporate business model. With the leadership of the building trades unions having to be elected by the membership on a regular basis, change by decree is a more tenuous proposition. Researching values alignment of an organization such as SMART will illuminate the present research by offering evidence from this type of organizational structure.

In the "Overcoming Resistance to Change and Enhancing Creative Performance," Hon, Bloom, and Crant (2014) studied the correlation between resistance to change and individual member creativity. Hon et al. used a sense-making perspective of how contextual cues may help the possible negative effects that employees' resistance to change can have upon their individual creative performance (2014, p. 920). Towards this, Hon et al. hypothesized that “employees' resistance to change will be negatively related to their creative performance" $(2014$, p. 922), that "modernist climates will moderate the effects of employees' resistance to change on creative performance such that the negative relationship between resistance to change and creativity will be lower in climates that emphasize modernity" (p. 926), that "empowering leadership will moderate the effects of employees' resistance to change on creative performance such that the negative relationship between resistance to change and creative performance will be lower under empowering leaders" (p. 926), and "coworker help and support will moderate the effects of employees' resistance to change on employee creative performance such that the negative 
relationship between resistance to change and creative performance will be lower when employees receive more help and support from their coworkers" (p. 927).

Hon et al. (2014) collected data from three industries in China: high technology, manufacturing, and service sector jobs. A survey was used with a 7-point Likert-type scale where resistance to change, modernity climate, empowering leadership, coworker helping and supportive behaviors, and employee creativity were all measured. Control variables were considered and these measures were analyzed and aggregated. Tables were created with the data showing support for the hypotheses. Hon et al. concluded that their research supported the "view, indicating that modernity climate, empowering leadership, and supportive coworkers serve as important contextual cues for shaping employee creativity" (2014, p. 936). They concluded "that leaders who foster trust-based relationships and promote employees' sense of autonomy and coworkers who provide support and assistance also help ameliorate the negative effects resistance to change might have upon employees' creative performance" (Hon et al., 2014, p. 936).

This study relates to my study in that it offers evidence in support of the notion that the individual sheet metal workers sense-making perspective is cued by antecedents that are within the control of the union's leadership. Knowing of a more conducive environment that mitigates resistance to change, thereby enhancing member creativity, will enable the union to effectively plan for any desired organizational change. My study, however, differs from this study in that there are potentially cultural differences between Chinese organizations and an American building trades union. Additionally, this study was performed on a more traditional company structure where the manager/subordinate structural component was present, which differs from the structure of SMART as has been previously discussed in this research. 
It has been asserted that "resistance is a form of conflict. And since conflict has been found to strengthen and improve not only the quality of decisions but also participants' commitments to the implementation of those decisions" (Ford et al., 2008; Amason, 1996). The idea is that those who are resistant to change but are engaged with the change concept through honest critique may potentially provide a superior change idea and active participation in the change definition will lead to greater commitment by those resistant to the change. In short, "involvement in the learning, planning and implementation stages of a change process significantly influences commitment to change an apparently lowers resistance (Waddell \& Sohal, 1998).

In "Overcoming Resistance to Organizational Change: Strong Ties and Affective Cooptation," Battilana and Casciaro (2013) theorized that relationships between influential organizational members who are "fence-sitters" and organizational change agents who seize the opportunity to coopt such ambivalent organizational members provide the change agent with the means to increase the probability of organizational change. To this end, Battilana and Casciaro had two theories. First, they hypothesized that "a change agent's strong ties to potentially influential fence-sitters increase the likelihood of change adoption" (Battilana \& Casciaro, 2013, p. 821) and second, they hypothesized that "the less the change diverges from the institutional status quo, the more a change agent's strong ties to potentially influential resisters increase the likelihood of change adoption" (Battilana \& Casciaro, 2013, p. 822). To test their hypotheses they used "multimethod longitudinal data on 68 change initiatives conducted at the NHS in the United Kingdom" (Battilana \& Casciaro, 2013, p. 822), which was collected from more than 600 organizations, categorized as administrative units, primary care service providers, or secondary care service providers. Battilana and Casciaro gathered data via participants' resumes, 
interviews, human resource records, and surveys. They then measured the "outcome of the change agent's initiative as a degree to which the organization had adopted it after 12 months of implementation" (Battilana \& Casciaro, 2013, p. 824). Telephone surveys were conducted after one year and the results of that survey compiled into a Likert-type scale from one to five, with one equaling strongly disagree and five equaling strongly agree. With the dependent and independent variables compiled, tabulated, and statistically analyzed, Battilana and Casciaro concluded that "strong ties to potentially influential fence-sitters increase the likelihood that an organizational change will be adopted, irrespective of how divergent the change is" and that "the effects of strong ties to potentially influential resisters on change adoption are contingent upon the extent to which the change diverges from the institutional status quo" (2013, p. 833).

This study relates to my study in that it is highly likely that there will be resistance to organizational change by some members of SMART. This will likely occur at both the administrative and the rank-and-file level. Knowing that leaders will emerge within change resisters will enable SMART's change agents to work closely with such members and seek to coopt their resistance. Furthermore, knowing that the change initiative has a greater likeliness of success if that change initiative is closely aligned with the status quo of the culture and organizational norms of SMART will enable the planning of a slow and more gradual plan for change. However, this study was not conducted on an organization with the structure that is present in SMART. The National Health Services (NHS) in the United Kingdom is a very large monolithic organization with a bureaucracy to match its size, whereas SMART, as has previously been discussed, is a smaller organization with a democratic structure.

In “Ambivalence Toward Imposed Change: The Conflict Between Dispositional Resistance to Change and the Orientation Toward the Change Agent," Oreg and Sverdlik (2011) 
researched the proposition that two factors jointly contribute to an individual's experience of ambivalence when an organization imposes change. In a secondary study, Oreg and Sverdlik researched the individual's personal orientation to change with his or her relationship with the change agent. Specifically, Oreg and Sverdlik had two hypotheses. The first was that:

employees' orientation toward the change agent will moderate the relationship between dispositional resistance to change and ambivalence such that among employees with a positive orientation toward the agent, the relationship between dispositional resistance to change and ambivalence will be positive, whereas among employees with a negative orientation toward the agent, the relationship between dispositional resistance and ambivalence will be negative. (Oreg \& Sverdlik, 2011, p. 340)

The second was that "there will be a quadratic, inverse U-shaped relationship between support and ambivalence" (2011, p. 340). Oreg and Sverdlik (2011) tested their first hypothesis with three field studies. In the first study, which was conducted on an organization within the defense industry, surveys containing a 7-point Likert scale, where one equaled strongly disagree and seven equaled strongly agree, were used. Statistical analysis was then conducted to tabulate the results.

In their second study on their first hypothesis, Oreg and Sverdlik (2011) directly measured the effects of individual's ambivalence on an educational organization, which was in the process of relocating. Questionnaires with a 6-point Likert scale, with one equaling strongly disagree and six equaling strongly agree, were used. Here too the results were statistically analyzed and tabulated. The third study of the author's first hypothesis was conducted on an Israeli electrical company. In the third study, 150 questionnaires were disseminated and 89 that were returned were deemed usable. A Likert scale questionnaire was also used, with one 
equaling strongly disagree and six equaling strongly agree, Interestingly, while the results of the first two tests showed a correlation, as hypothesized, between employees' positive or negative orientation with the organizational change agent and the employees' ambivalence towards the change, the results of the third test did not support the hypothesis. This, Oreg and Svedlik explained, may have been due to the fact that the change was imposed not by the organization of the electric company but by the Israeli government. To test the second hypothesis, Oreg and Svedlik "conducted polynomial regression analysis by regressing ambivalence on both support and the squared value of support" (2011, p. 345). The results supported their hypothesis.

SMART will also benefit from the results of this study. Knowing that there is a relationship between the rank-and-file members' orientation to the change agent should be cause to empower change agents who are generally well liked and/or respected by the membership. This should enable SMART to better plan and execute a change initiative. However, there are significant differences between this study and my study. First, there is likely a cultural difference between Israeli corporations and an American building trades union. Secondly, as discussed previously, the companies studied are not organizationally structured the same way SMART is. Therefore, my study will add to the research on Oreg and Svedlik's (2011) hypotheses.

The conclusions drawn from the literature on resistance to change asserts the following:

1. Traditional beliefs on resistance to change were such that it held that all resistance was of a selfish nature and should be eliminated at all costs.

2. An adversarial approach to resistance to change remains dominant in managerial techniques used. 
3. New research shows that resistance to change is a potentially positive phenomenon and, with the right engagement, could lead to more positive change for the organization.

4. Resistance to change may signal that change resisters place value on the change concept by maintaining the existence of the change concept by engaging with and strengthening the change concept via ideas that enhance it.

5. Engagement with and strengthening of the change concept leads to a greater commitment to the change idea.

6. Resistance to change is socially constructed.

7. Values alignment plays a role in change adoption.

8. Change agents' relationship with organizational members affects change adoption.

In summary, data from the cited research related to resistance to change demonstrates that there are many workers who, while demonstrating resistance toward changes to their work brought about by CT, will, when presented with an honestly democratic plan to address these changes that the workers are resistant, maintain the existence of the change concepts, engage with the ideas, and strengthen any needed changes to an organizational change plan. This is important for a society that is experiencing such changes.

\section{$\underline{\text { Readiness for Change }}$}

A different construct than resistance to change is readiness for change. Readiness for change differs from resistance to change in several distinct ways. Of these, "some researchers have argued that individuals are not naturally resistant to change-rather, they resist the imposition of change, or the way change is imposed to them" (Choi \& Ruona, 2011; Fuegen \& 
Brehm, 2004; Knowles \& Linn, 2004). This is a very different presupposition than resistance to change is, with very different outcomes. Indeed, with a resistance to change presupposition, as was discussed above, the view leads to the concept that resistance is dysfunctional in its natural states. With the concept of readiness for change, however, 'individuals' negative reactions to change are not necessarily dysfunctional obstacles or liabilities to successful change. Rather, they may serve as the legitimate source of information regarding the implementation of change" (Choi \& Ruona, 2011, p. 50; Ford et al., 2008; Klein, 1985; Knowles \& Linn, 2004; Piderit, 2000; Waddell \& Sohal, 1998). Therefore, the concept of readiness for change provides a more holistic approach to organizational change. Furthermore, while researchers have defined individuals' readiness for change in differing ways, they "all agree that individual readiness for organizational change involves an individual's evaluation about the individual and organizational capacity for making a successful change, the need for change, and the benefits the organization and its members may gain from change" (Choi \& Ruona, 2011, p. 51; Armenakis, Harris, \& Mossholder, 1993; Eby, Adams, Russell, \& Gaby, 2000; Holt, Armenakis,, Feild, \& Harris, 2007; Jansen, 2000). Therefore, an individual who may be expressing negative responses to change may in fact be expressing these ideas for positive reasons. It may be a simple case of cautiously honest questions to the change proposal.

With the concept of readiness for change having been established, it seems best to turn to the change strategies used by organizations. In the study "Individual Readiness for Organizational Change and Its Implications for Human Resource and Organization Development," these strategies can be classified into three categories: empirical-rational, powercoercive and normative-reeducative (Chin \& Benne, 1985). Empirical-rational strategies assume "that people are rational and that they will follow their rational self-interest once it is revealed to 
them" (Choi \& Ruona, 2011). Some research has shown that empirical-rational strategies may not work without normative-reeducative efforts to alter change recipients' beliefs, values, and attitudes" (Choi \& Ruona, 2011, p. 58). Regarding power-coercive strategies, Lewin (1997) asserted that a change recipient required changes to his or her values, beliefs, and normative orientations and that this reeducation is not possible via coercion. Therefore, under powercoercive strategies, the underlying goal is conformity and the change recipient may conform without introspective reflection or reeducation of one's beliefs, values, or normative orientations. Normative-reeducative strategies, the research shows, have demonstrated more effectiveness in fostering individual readiness for change than the other two strategies (Choi \& Ruona, 2011). While Choi and Ruona (2011) proposed that normative-reeducative strategies were the most effective at fostering individual readiness for change within an organization, they further proposed that "individuals who perceive their work environment to have characteristics associated with a learning culture are more likely to have higher levels of readiness for organizational change" (p. 63). They further proposed that a learning culture within an organization moderated the relationship between normative-reeducative strategies and individual readiness for change (Choi \& Ruona, 2011, p. 63).

Choi and Ruona (2011) conducted a review of existing literature as it relates to resistance to and readiness for organizational change. Choi and Ruona specifically focus on "change implementation that [is] based on the normative-reeducative change strategy and [organizational development] approaches as an ongoing organizational effort to enhance organizational health and capacity through fostering the learning culture" (2011, p. 48). Additionally, they conducted a systematic compilation and analyzation of existing studies and concluded that three propositions emerge from those studies. The three propositions are: 
- Individuals who experience normative-reeducative change strategies are more likely to have higher levels of readiness for organizational change than those who experience either empirical-rational strategies or power-coercive strategies (Choi \& Ruona, 2011, p. 60).

- Individuals who perceive their work environment to have characteristics associated with a learning culture are more likely to have higher levels of readiness for organizational change (Choi \& Ruona, 2011, p. 63).

- A learning culture moderates the relationship between normative-reeducative strategies and readiness for change - specifically, the relationship between normative-reeducative strategies and readiness for change is more positive in situations where the learning culture is stronger (Choi \& Ruona, 2011, p. 63).

This article relates to my study in that the conclusions reached by Choi and Ruona (2011) provide a roadmap for the planning of organizational change that SMART may choose to pursue. This is particularly valid with the union's business structure being democratic as it makes sense for the planners of organizational change to embrace a normative-reeducative strategy in lieu of empirical-rational strategies and power-coercive strategies. Yet while these conclusions do provide a roadmap for planning of organizational change for SMART, this research was also conducted with the presupposition of a traditional organizational power structure where the organizational power is distributed to managers and not to change recipients. The democratic structure of the union's business model creates a variable that will affect the individual member's readiness for organizational change. Having the power to alter the union's leadership provides the change recipient, or rank-and-file member of a local union, a level of control over the change agent, which is unknown in a traditional corporate model. Therefore, this article may be enhanced or countered by including studies of organizations with a more democratic business structure. Finally, to have a fuller understanding of change implementation strategies and resultant resistance to or readiness for organizational change, future research will need to include organizations with a more democratic business structure. 
In “A Theoretical Framework of Organizational Change,” Jacobs, Witteloostuijn, and Christe-Zeyse (2013) sought to create a framework with which to analyze barriers and enablers of organizational change. Jacobs et al. analyzed internal change processes "in a larger cultural and institutional framework, focusing on differences across societies" (2013, p. 776), where they framed the process as an "input-throughput-output" model (2013, p. 776). Starting with the input component of their theory, Jacobs et al. argued that while an organization may at its inception be aligned with its external environment, the alignment weakens as the organization ages, "requiring serious effort to keep pace with the changing environment" (2013, p. 780). Here the organization must develop insights into the possible environments of the future and the organization's weaknesses. Jacobs et al. discussed frameworks around how an organization may wish to address perceived changes that are needed as it related to throughputs. They discussed a comprehensive approach to addressing organizational change, citing numerous previous studies. Finally, Jacob et al. discussed the outputs component of organizational change. They discussed how the ultimate goal of organizational change is to enhance organizational performance and how organizational change can be realized as positive, neutral, or negative. Jacobs et al. "emphasize[d] the critical role of two important mediating effects: the impact of organizational change on external legitimacy and internal identity" (2013, p. 786). They argued that without careful execution, "organizational change is very likely to lead to external legitimacy erosion and internal identity conflict" (Jacobs et al. 2013, p. 786).

Jacobs et al.' theory and theoretical framework are very important for SMART and other building trades in America as they offer light into where the union currently stands. SMART was instituted in the year 1888 and during the period immediately following the industrial revolution. Abuses of workers have been well chronicled, as has the rise of labor unions as a response to 
such abuses. The alignment of the organization of the labor union with the environment at that time can certainly be seen as fitting. However, fast-forward 130 years and one can clearly see that the environment where the labor union sits has changed. This can lead to the conclusion that the labor union is not as fit to its environment as it once was. Regardless of the rhetoric that unions choose to employ, many of the abuses of the past have been remedied by societal changes and the force of law. The concept of "internal identity conflict" can be seen as applying to the American building trades union. Many "old-timers" within the building trades lament the lack of commitment from the younger workers. Many younger members are seen as not committed to the cause of the union or unionism, as only being in it for the money. Jacobs et al.'s research offers illumination to my study as it provides a theoretical framework for SMART to consider organizational change; it offers a well-reasoned starting point for this. However, as a theoretical framework, it does not offer any specific conclusions into a study on a building trades union such as SMART; therefore, my study will provide illumination where this study ends.

The conclusions from the literature regarding readiness for change are:

1. Individuals are not intrinsically resistant to organizational change.

2. Paradoxically resistance to change is a source for positive change to an organization.

3. Individual readiness for change centers around the individual's evaluation about the individual and organizational capacity for making a successful change, the need for change, and the benefits the organization and its members may gain from change.

4. Individuals may be expressing negative responses to change for positive reasons. 
5. Organizations can employ one of three different strategies to foster organizational change: empirical-rational, power-coercive, or normative-reeducative. Normativereeducative strategy proves to be the most effective at achieving change recipients to buy into organizational change.

6. A learning environment positively effects change adoption.

7. Organizational change, if not executed carefully, can lead to external legitimacy erosion and internal identity conflict.

In summary, it is likely that the majority of the rank-and-file members of SMART have a readiness for the changes that $\mathrm{CT}$ is bringing and will continue to bring to the sheet metal industry. The leadership of SMART would be wise to embrace a learning culture, eschewing a coercive strategy towards change. Indeed, if the trend of deskilling and job task obsolescence within the sheet metal trade continues, which is likely, then SMART would be wise to embrace rather than resist changes brought forward by digitization. The hopeful news is that the majority of the rank-and-file members seem ready for this change. The institution of the union should embrace a normative-reeducative strategy to usher into these types of changes in the short-term future.

\section{$\underline{\text { Summary and Conclusion of Literature Review }}$}

Research informs us that investment in computer technology is increasing in developed economies and that this technology demands a more educated worker with higher skill sets. We also know that technology is correlated to wage earning, that it causes lower skilled workers to be in less demand, that it affects workers' attitudes, and that it has a deskilling effect on the work that is to be performed. Research also tells us that technology leads to workers feeling alienated from their work and to the obsolescence of some work skills. We also know that culture 
moderates acceptance of or resistance to technological change and that culture influences a development process of technology adoption. The research informs us that an individual's beliefs and intrinsic motivations affect whether the individual accepts or resists technology. We also know that while a unionized workforce is more likely to use advanced technologies, there is no evidence that this phenomenon is intrinsic to the union itself. Unions with a proactive approach to technology saw innovative behavior from the members of that union. Furthermore, the research informs us that there is no correlation between a democratic union and technology acceptance. In fact, the opposite was discovered; the more democratic the union, the more resistant to innovation that union was. Resistance to change may in fact be a positive phenomenon for organizational change concepts, which will be an important dynamic should SMART develop a plan for organizational change. Furthermore, we know that individuals are not intrinsically resistant to change and that what seems to be negativity from an individual may in fact be sense making of a proposed change and not necessarily individual resistance to change. We also know that individual readiness for change is centered on an individual's evaluation of his or herself, the organizational capacity for making a successful change, the need for change, and the benefits the organization and its members may gain from change. Finally, we know that individuals may be expressing negative responses for positive reasons and that the most effective change strategy an organization can employ is the normative-reeducative strategy.

The study of workers' relationship to the dynamics of technological change has been studied to great lengths, but research has not been conducted on a building trades union and their commoditized labor. In such an organization, the dynamics of technological change can have an existential meaning. If the advancement of technology within the sheet metal workers union is such that there will be a massive net loss of employment, then the implication that technology 
brings for the sheet metal workers and of the union is stark and ominous. This study began when there was a gap in the research. Namely, there are no current studies that address the workers' experiences with the increasingly digitized nature of their work, which has devalued human labor. There is also no study available on the resistance to or readiness for change in a building trade union, specifically the sheet metal workers union, whose sole commodity is skilled labor. Nevertheless, the topic is sufficiently important to examine from both a practical and theoretical perspective. 
Chapter Three: Research Method 


\section{$\underline{\text { Introduction }}$}

With the emergence of the postmodern era, the very ideas of truth and discovering truth have been challenged, which has important implications for scientific research. In the received view of science, authority is presumed upon scientific research and methodology by the orthodox scientific community (Woolgar, 1996). To elaborate further, the received view of science states that the classical approach to science with the subject/object divide is the only accepted approach to scientific inquiry, thus claiming authority on what equals science and what equals fraudulent science. However, with the rise of postmodern thinking, contrasting ideas to the received view of science have emerged; it is no longer universally accepted that research be constrained by the subject/object dichotomy. The present scientific inquiry was conducted using the relational constructionist approach.

This research does not look or feel different from the traditional classical scientific method. However, the difference is in the epistemic approach. Relational constructionism asserts several key differences from the classical scientific approach. Of those differences, it is important to note that "distinctions between science and philosophy, between 'discoveries in nature' and 'rational justifications' are to be understood as local to a particular community and in a particular historical moment” (McNamee \& Hosking, 2012, p. 31). Herein lies my approach.

Since I am employing both qualitative and quantitative research methods, shouldn't I acknowledge that this is an empirical, positivistic study? In addition to acknowledging that the study is empirical, I assert that while the similarities to a claimed empirical study are noticeable, there are important differences to consider. I acknowledge that the collected data may have been biased and the questions posed to the so-called study group may have been generative or cogenerative. To further elaborate, I acknowledge that the questions asked may have in fact 
influenced, altered, or co-created the response. To put it another way, I recognize that the research has not necessarily discovered a truth, but rather, this research has possibly co-created a truth. Therefore, while this research uses methods that may be palatable to the orthodoxy of science, due to my usage of traditional methods, I maintain that my methods are possibly generative and local to a particular community and historical moment.

With the previous points regarding the philosophical approach to research being established, this study uses a mixed-method design due to having two distinct components. Firstly, a descriptive design using documents and various analytical methods was used for the qualitative portion of the study. Secondly, a cohort design using an online questionnaire for sheet metal workers was used for the quantitative portion of the study.

\section{Quantitative Research}

\section{Cohort Design}

To test my hypotheses, a questionnaire was devised to collect and analyze how the members of SMART were experiencing the phenomenon of devalued labor. The questionnaire used was achieved by employing an online survey and subject interviews. I chose an online survey in light of three variables. The first is the ubiquity of the Internet, the second is the accessibility to the Internet in the United States, and the third is the geographical area covered in the study, namely the entirety of the United States, with participants in the study residing in various cities throughout the country.

Regarding online surveys and their validity, several studies have suggested that their value is equal to traditional survey methods. For example, online surveys are as reliable as traditional surveys, which were delivered via the United States Post Office mail service. This is 
not without potential pitfalls, but with mindful integrity towards the process, reliability can be realized (Van Selm \& Jankowski, 2006). Furthermore, after a well-rounded critique of the strengths and weaknesses of online surveys and with a caution to consider the limitations of online surveys and the interpretation of the results when employing these surveys, Kaye and Johnson (1999) concluded that online surveys "can be excellent vehicles" to use (p. 335). The topics of validity and reliability will be discussed in more detail below.

\section{$\underline{\text { Participants }}$}

Data were obtained from a sample of 111 unionized sheet metal workers. All participants are sheet metal worker and members of SMART, the international sheet metal workers union. A convenience sample was generated by contacting the business manager of each respective local union listed below and asking that business manager to send a mass informational email inviting participation to the online survey. The business managers who agreed to this sent a mass email to all of their members who had an email account on file with that local union. The numbers of members who received and responded by taking the survey, relative to the total membership of the local unions is not known; therefore, the response rate, while likely low, is also not known.

While SMART has members in the transportation industry, only building trades local union members were surveyed. It is important to establish that the building trades' local unions consisted of members who work primarily within the construction industry. More specifically, they are mostly workers who are employed to install Heating, Ventilation, and Air Conditioning (HVAC) systems and service these same HVAC systems. In contrast, the transportation industry workers operate transportation vehicles such as airplanes, trains, and buses. These members of SMART were part of a separate union, the United Transportation Union (UTU), until they merged with the Sheet Metal Workers' International Association in 2011. These members had a 
wholly different system, if any, of apprenticeship and work experiences, which are unfamiliar to me. Therefore, I did not pursue these members as survey participants.

Local union members representing different areas of the country were also asked to participate in the survey. These included members from the local unions for the following locations:

- Northern California, including San Francisco, Oakland, San Jose, and surrounding cities and suburbs

- Western Washington, including Seattle, Tacoma, and surrounding cities and suburbs

- Chicago, Illinois metropolitan area, including eleven counties that are served by two separate local unions;

- the entire state of Indiana, including Indianapolis, South Bend, Ft. Wayne, Evansville, Terra Haute, and Gary

- Eastern Pennsylvania, including Philadelphia and its surrounding cities and suburbs

To achieve participation I contacted the administrative offices of these local unions and requested that a link to the online survey be sent to every member who was signed up to receive email from that local union. Accompanying the link was an introduction from me regarding this research, the nature and intent of the research, the commitment to privacy, and the requirement that participation be completely voluntary.

For members who opted to participate in the survey, their job classification could be that of apprentice, journeyman, foreman, general foreman, or superintendent, which are the standard 
job classifications for sheet metal workers throughout the building trades. Members could be either male or female; however, according to the United States Department of Labor Bureau of Labor Statistics, estimates as of the year 2012, a sheet metal worker is far more likely to be male (96\%) than female (4\%) (Statistics, 2015). Finally, participants could be aged 18 to beyond retirement age; this differs from local union to local union but is generally around 62 years of age.

\section{$\underline{\text { Instrumentation }}$}

This research used the online survey website SurveyMonkey as the platform for data collection. I opened an online account at SurveyMonkey and then proceeded to develop a 12question survey titled "Sheet Metal Workers and Computer Technology." After an initial word of thanks for participation in the survey, the introduction to the survey informed participants that "the survey is designed to learn how sheet metal workers view issues related to CT's impact upon the sheet metal industry." The 12-question survey asked participants to select one prewritten statement that best described their thoughts or feelings related to technology's impact upon the sheet metal trade, or, if one of the prewritten phrases failed to best describe a participant's thoughts or feelings, the participant could write their own personalized response.

To summarize the questions, participants were asked about how they felt about the impact that CT had on the jobs and the work that a sheet metal worker performed, both now and in the future. They were also asked what impact CT had upon the relevancy of their individual skills and how their skills would be impacted by technology. Additionally, the survey asked participants whether they had already taken steps to learn the new technology and how each participant felt the union's leadership should or should not embrace these technological changes. Finally, the participants were asked about how they felt the whole construction industry would 
be impacted by CT. LCA was used to extract the data to determine whether the sample set was resistant to or ready for the changes that CT brings to the work that a sheet metal worker performs.

\section{$\underline{\text { Instrument }}$}

The online survey was structured as a Likert scale fixed choices with an option for the participant to offer a response that is not fixed. The online survey correlates to a paper survey, which was structured to ask the same questions using the same Likert scale items. The survey was not used in any pilot testing but was reviewed by my advisers and work colleagues to determine a valid correlation between the Likert scale fixed choices and member readiness or resistance to change; it was determined that the validity of the data was present. For example, the relationship between the participants whom the data showed to be ready for change also showed a correlation with having already learned new computer skills.

There have been several studies testing the reliability of online surveys with the results indicating that online surveys are equal in reliability as traditional mail-in surveys (Deutskens \& Wetzels, 2006; Kaye \& Johnson, 1999). Consequently, the choice of this tool, SurveyMonkey, does in fact consistently measure the data that it is intended to measure, which, as will be discussed later, is demonstrated by the internal consistency of the participant responses.

\section{$\underline{\text { Research Procedures }}$}

After I wrote the survey questions and they were positively reviewed with my advisors, I sent emails to the Business Managers of Sheet Metal Workers' local unions throughout the United States. These included the following local unions:

- $\quad$ Local 105 Los Angeles, California including much of Southern California 
- $\quad$ Local 104 San Francisco, California including much of Northern California

- $\quad$ Local 66 Seattle and Tacoma, Washington area

- $\quad$ Local 16 Portland, Oregon and the western Oregon area

- $\quad$ Local 67 Austin, San Antonio, and Waco, Texas including the central and southern Texas areas

- $\quad$ Local 265 nine counties in northeastern Illinois excluding Chicago, Cook, and Lake Counties

- Local 73 Chicago, Illinois including Cook and Lake Counties in Illinois

- $\quad$ Local 20 the entire State of Indiana

- $\quad$ Local 19 Philadelphia, Pennsylvania including eastern Pennsylvania, southern New Jersey, and the State of Delaware

- $\quad$ Local 28 New York City and Long Island New York

When reviewing the local unions in the list above, it is important to consider that the vast majority of members work within urban and suburban settings. While it is true that most rural areas in the United States are the claimed jurisdiction of the SMART local unions, the vast majority of work is performed in urban areas. Larger cities comprise the majority of construction spending relative to rural areas. Therefore, the members of any building trades union are more concentrated in such urban areas. I sought to have respondents from as diverse an area as is possible. Including members from both the East and West Coasts of the United States and including the middle of the country was determined to be the best scheme to ensure as diverse a 
response as could be possible. Some locals were not selected due to them not having adopted any digitized technologies in their training programs.

Of the above list of Sheet Metal Workers' local unions, several were not able to participate in the survey, stating that their particular local did not use email to communicate with their membership. The survey was made available online beginning July $21^{\text {st }}, 2014$, and closed on October $13^{\text {th }}, 2014$. There were 111 responses collected, with the last response recorded on August $12^{\text {th }}, 2014$. Consideration was given to ensure that every union member who chose to participate in this study did so voluntarily. Specifically, each Business Manager of the respective local union was given the following script to use as the message to their respective local membership.

Dear Brothers and Sisters, I am writing to you today to ask you to participate in a research project. SMART member Michael Keane is working on his PhD and is researching technology and its effects on the sheet metal industry. Member Keane is a research student in The Netherlands. In his professional career, he works to train members of the SMART union on how to use technologies that are used in the construction industry, but he does recognize that all technologies can have both a positive and negative effect on the lives of workers.

Please be reminded that while I recommend that you participate in this research, your participation must be $100 \%$ voluntary. To participate, please click the following link to take an online 12 question survey.

http://www.surveymonkey.com/s/HKZ6M3G

If you have any questions or comments please email Michael Keane at [email address] or call him at [telephone number].

Fraternally, [Business Manager] 
Below is a list of where the survey participants were located in the United States. This information was obtained from the participants' Internet Protocol (IP) addresses when they took the survey on SurveyMonkey.

- 1 participant from California

- 2 participants from Florida

- 2 participants from Georgia

- 43 participants from Illinois

- $\quad 48$ participants from Indiana

- 1 participant from Kansas

- 2 participants from Kentucky

- $\quad 4$ participants from Missouri

- 1 participant from New York

- 1 participant from North Dakota

- 1 participant from Ohio

- 2 participants from South Carolina

- 1 participant from Texas

- 2 participants from Virginia 


\section{$\underline{\text { Measures }}$}

Data consisted of self-reported responses to a 12-item survey designed to investigate the attitudes and perceptions of sheet metal workers regarding readiness for or resistance to changes to the work of the unionized sheet metal workers. I created the survey after I made note of several concerns that I had received from rank-and-file sheet metal workers regarding what BIM meant to each of them personally. When I was tasked with giving presentations and conducting seminars on such new technologies, members would routinely ask about their individual skill sets and advanced training during the question and answer portions. Oftentimes, the members would express a level of fear regarding their own relevance as a sheet metal worker. These ideas were discussed with my advisors, and they agreed that the concerns expressed would form a good basis for the survey study. The questions, as detailed in chapter one, were written for an online survey using a Likert scale response format.

\section{$\underline{\text { Data Analysis }}$}

The fundamental analytical tool used in this study was latent class analysis (LCA). LCA was used to identify participants with similar patterns of responding to the survey items (Hagenaars \& McCutcheon, 2002). LCA provides the probability of a particular participant belonging to an unobserved latent class by assessing the pattern of observed responses. Latent classes were calculated by maximum likelihood analysis using an Estimation-Maximization algorithm in which 500 multiple start values for estimated model parameters were considered (McLachlan \& Peel, 2000). The most parsimonious model (1-class) was fit first, followed by sequentially increasing the number of classes to five latent class models, with the choice of the best fitting model based on three criteria: the Bayesian Informed Criterion (BIC) statistical fit index (Raftery, 1995), with lower values indicating better model fit (Li \& Nyholt, 2001); the Lo- 
Mendell-Rubin likelihood ration test (LMR-LRT) for mixture distributions (Lo, Mendell, \& Rubin, 2001), with a significant LMR-LRT (i.e., $p<.05$ ) indicating a model with $\mathrm{k}$ classes significantly improved over a model with k-1 classes; and entropy, in which values approaching 1 indicated clear delineation of classes (Celeux \& Soromenho, 1996). LCA was implemented using Mplus version 7.3 (Muthen \& Muthen, 1998-2015).

While the results of the data will be detailed and discussed later in this paper, as an example, Figure 1 shows how SurveyMonkey organizes the data from the online survey.

\section{Q1 Which statement best describes your thoughts and feelings about the impact of computer technologies on sheet metal workers' jobs?}

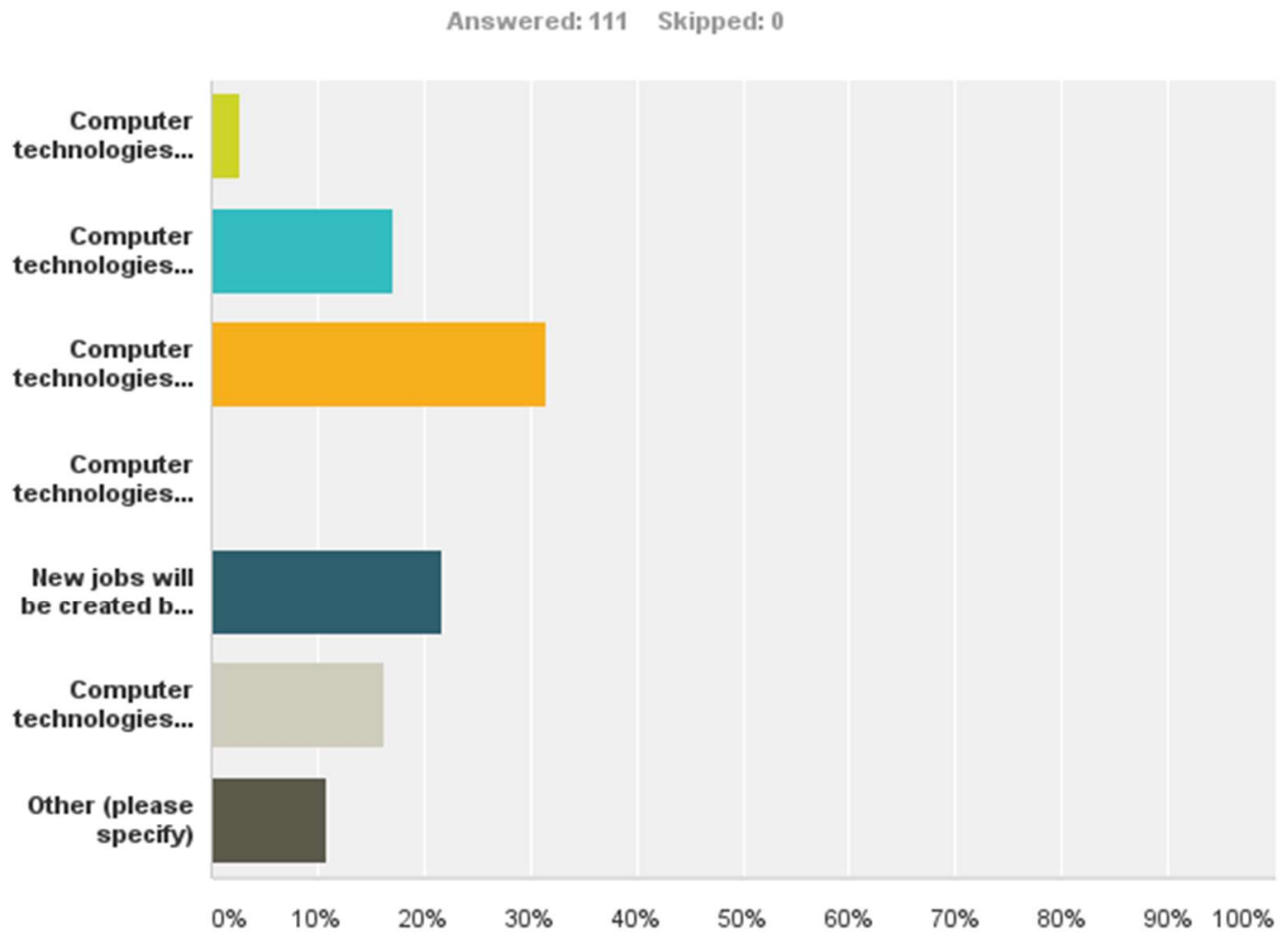

Figure 1. SurveyMonkey chart 


\section{Ethical Considerations}

The anonymity of each survey participant was paramount. Firstly, SurveyMonkey allows each survey creator the option of creating a survey that where responses are anonymous or one where responses are not anonymous (SurveyMonkey, 2015). I created the online survey for this research with responses anonymized. Additionally, apart from the aggregate data, the confidentiality of the data has been strictly maintained. Furthermore, each participant's anonymity will also be strictly maintained, including after this study is made public.

\section{Limitations of the survey part of this research}

There are at least three notable limitations to the quantitative portion of this study. Firstly, this study only included SMART members who had access to the internet and who had an email address on file with his or her local union. I would like to note that while I was working at the ITI, I was tasked with conducting a survey of the then current apprentices throughout the United States, inquiring as to whether each respective apprentice would prefer electronic training over traditional physical book and classroom training. While the results of that study are strictly anecdotal, it showed that approximately $35 \%$ of all apprentices who responded to that survey were either completely opposed or strongly opposed to any form of electronic education or training. Therefore, the idea that many SMART members shun various forms of electronic training does lend to the idea that this survey was limited to a subset of SMART members who embrace such technologies.

The second limitation is the geographical location of the survey respondents. While a wide geographical locational demographic was actively sought, the participants were mostly from two areas. Both of the areas are within the Midwestern United States. Perhaps, if the 
SMART members from the high-tech areas of California, e.g., San Francisco, were to have participated in the research, the results might have shown a higher readiness for change than the current results show. Either way, the demographic profile of the research participants is such that it is not clear that they are representative of their unions' workers. Also, while the IP addresses indicate a larger respondent population from suburban and urban areas, it is not know where each individual respondent resided.

The third limitation to this portion of the study is the overall number of participants that took the survey. While interviews were actively sought before the online survey was conducted, very few members opted to be interviewed. Interestingly too is that a relatively small number, less than $2 \%$ of possible respondents, chose to participate in the anonymous online survey. In my experience, many members of various local unions seem to fear retribution by their respective union leadership should that member fail to toe-the-line on any given subject and this may, in part, account for such a low participation rate. Whatever the reasons may have been for this phenomenon, it provided data of the state of SMART organization. However, that data is not pertinent to this study. Finally, while latent profile patterns were clearly visible from the survey data analysis, this research would have been enhanced by greater participation from the SMART members.

\section{$\underline{\text { Summary }}$}

Having been a member of SMART for over 25 years at the time that this data was collected, I have had many experiences in the culture and organizational behavior of my own local union. When I worked at the ITI, I learned the cultures and organizational behaviors of many other local union chapters. As I detailed earlier, it is common that a rank-and-file member demonstrates trepidation at giving any position for fear of possible political retaliation. 
Therefore, I was not expecting greater than a 5\% response rate and I am not at all surprised at the less than $2 \%$ response rate that was received.

Data collection was made significantly easier by utilizing the internet and an online survey without compromising the integrity of the data. This study used the anonymous response feature of the online survey tool SurveyMonkey to ensure the privacy of the participants. The study group encompassed a wide swath of unionized sheet metal workers throughout the United States. These participants were contacted with the request to participate in this research study by emails, which were sent to them by their own local union. Participation was $100 \%$ voluntary and completely anonymous.

\section{Qualitative Research}

\section{Descriptive Design}

Descriptive design research was used to establish that the phenomenon exists (Bickman \& Rog, 1998). Since descriptive design cannot necessarily speak to the why or the implications of a phenomenon, in this case workers having a different experience with work, it is my hope that having established such a dramatic change in how workers are experiencing work, further studies are conducted and public policies debated to explore the societal implications that this phenomenon causes.

\section{Document Analysis}

Documents are "social facts" (Atkinson \& Coffey, 2004), which contain words and possibly images. Therefore, raw data that has been recorded is data that has not been interfered with by a researcher. Yet, while all documents may not be suitable for research purposes, a systematic procedure was used to "find, select, appraise, and synthesize data contained in 
documents" (Bowen, 2009, p. 28). Document analysis is a systematic procedure for the evaluation of documents and the collection of data (Bowen, 2009). For this research, both print and electronic documentation with evidence that workers are experiencing work differently was collected, systematically analyzed, and then organized into categories to demonstrate the occurrence of the phenomenon.

\section{$\underline{\text { Interpretive Phenomenological Analysis }}$}

Interpretive phenomenological analysis (IPA) was used to analyze the documentary data collected. IPA is seen as one of the least demanding methods of qualitative research (Madill, Gough, Lawton, \& Stratton, 2005). However, this critique may be mistaking the lack of rigor of IPA for flexibility (Larkin, Watts, \& Clifton, 2005). Yet, while IPA may be difficult to properly perform and consequently not be suitable to be used in all studies, "research in its image can be very powerful when it is carried out with the requisite care and commitment" (Larkin, Watts, \& Clifton, 2005, p. 103). Therefore, to approach the data analysis using IPA with the requisite rigor, two aims are considered (Larkin, Watts, \& Clifton, 2005, p. 104). The first aim is to faithfully understand and collect the participant's understanding of his or her individual world as expressed in the documentation. This aim, however, can never achieve a first person accounting; rather, it is a construction of both the participant and the researcher and therefore the objective is to produce a coherent and informed third-person accounting that describes the participant's view as faithfully as possible (Larkin, Watts, \& Clifton, 2005, p. 104). The second aim is to interpret the co-constructed accounting into theoretical concepts (Larkin et al., 2005, p. 104); in this study, workers are experiencing their work differently since CT has devalued, deskilled, or altogether made obsolete their labor and consequently this structural change to work, which many workers are unaware of, is a cause of unease and anxiety in workers. 


\section{Data Collection}

There were numerous news organizations available to me to search for data and an online Google search yielded numerous other new stories and personal interviews to draw from. In this information age, it is easy to use online search tools to access any television broadcast news programs. I watched hundreds of hours of television news programs to find news stories that are relevant to this study. Then, upon documenting a collection of news stories that were deemed in need of further analysis, I performed a Google search to find the relevant broadcast aired news stories online. Additionally, a Google search was conducted using key words and phrases, such as "work and automation" and "workers experiencing work differently due to automation," to discover additional relevant data.

\section{Summary}

For the qualitative portion of this research, a descriptive design method using document analysis via IPA was used. Using descriptive design, I sought to document the phenomenon of computerized automation altering work and consequently how workers experience their work. To demonstrate the occurrence of this phenomenon, document analysis of printed and electronic documents, including interviews and news stories, was conducted using IPA to collect, systematically analyze, and then organize into categories the data that demonstrated this

phenomenon. Observation of broadcast news programs and Google searches using keywords were used to find the specific relevant data used in this research. 
Chapter Four: Research Findings 


\section{Quantitative Research Findings}

\section{$\underline{\text { Introduction }}$}

To better understand the technological change dynamic for the individual sheet metal worker and the unionized sheet metal industry in America as a whole, it helps to first understand the business model that the individual sheet metal worker works within, which has many dynamics inherent to it. It is certainly true that the individual sheet metal worker's readiness for or resistance to technological change is shaped by his or her personal experiences with the business model that the sheet metal industry operates within. Therefore, it is best to remind the reader of the main actors that establish the framework wherein the individual sheet metal worker plies his or her trade. They are:

- The Union

O In this research, this is SMART.

- The local SMART union

○ The individual sheet metal worker

- The Contractors

○ Including Sheet Metal \& Air Conditioning Contractors' National Association (SMACNA)

- The local SMACNA chapter

- The individual mechanical or sheet metal contractor (Contractor)

- Contractors are not required to be SMACNA members

- The individual sheet metal worker

Each of these actors create different dynamics that affect the nature of the system that constitutes the structural business model that all unionized building trades sheet metal workers operate under within the United States.

The first dynamic to discuss is the fact that by joining the union, the individual worker is not ever guaranteed work. In fact, many members, euphemistically labeled "hall rats" by those members who do find regular employment, go months or even years without regular 
employment. Some may find only seasonal work. This means that some rank-and-file workers may only find employment 4-6 months yearly, some even less. During the "Great Recession," which began in 2008, many went years without working in the sheet metal industry. A structural dynamic where work is not guaranteed for any individual rank-and-file member is institutionalized via legal agreement between labor and management by means of the CBA, or union contract. Here, it makes sense to note that the individual rank-and-file worker is never employed by the union, but rather, by the individual contractor. This means that for the individual rank-and-file worker, he or she must join the union to be eligible to work within the unionized industry at all, but must please his or her contractor to be employed or to maintain employment. For those rank-and-file members who have found favor and trust from a contractor, they do find regular, steady employment. These workers are euphemistically labeled "company men" by those members who are not in the same situation. In this system, the contractor has the power to hire, lay-off, and fire the individual worker, and, in most cases, doesn't need to establish a cause for the layoff or firing; a simple lack of work, as defined by the contractor, is sufficient reason to end the employment of the individual worker. The CBA guarantees the right of the contractor to operate his or her business in any manner of his or her choosing to the extent that, when it comes to CBA defined labor tasks, the contractor must employ a member of the local union to perform these tasks. Essentially, under the CBA, the contractor agrees to only hire a rank-and-file union member to perform CBA defined labor tasks and the local union agrees to supply a competent person to perform these labor tasks. This is the very nature of the commoditized labor model discussed above. This means that for the rank-and-file worker who wishes to be regularly employed, he or she must perform these labor tasks to such a quality and productivity level that the contractor deems him or her to be of such a value that the contractor 
opts to maintain that person's employment with his or her company. The net result of this is that the individual rank-and-file members of the local union are, to a large extent, in competition with each other for the same jobs.

The second dynamic to discuss is competition for jobs. As discussed above work is not guaranteed for the worker and except for extraordinary times when work is in overabundance, there are fewer jobs available from the contractors than there are workers to perform these jobs. This, of course, creates guaranteed unemployment for some workers. To be sure, there are some rank-and-file workers who are content to work less than full year's employment, but they are in the minority. Thus, while each member has pledged loyalty to the union as a requirement of membership, the union is incapable of guaranteeing work for the member since the CBA establishes that work is gained only by employment by a contractor. Consequently, pleasing the contractor becomes essential for employment and, thereby, to some extent, dividing the loyalties of the member.

It is important to note that the individual contractor is not compelled to agree to the CBA; rather, the agreement is voluntary. Now, while this is literally true, in many cases, contractors feel as though this is not true in practice since, there may be legal requirements external to the CBA that are established by a state, city, or other municipality. For example, should a contractor opt to perform work within a certain municipal jurisdiction, the contractor must abide by certain practices that in effect require that contractor to agree to a CBA. Regardless, the underlying fact is that each contractor must agree to the CBA, which is another dynamic to consider.

Each individual contractor is, in the vast majority of cases, a small business. There are a few exceptions, but even those large contractors within a large metropolitan area, are typically small businesses. It is helpful to understand that the contractor who competes for business within 
the construction industry does not operate under the corporate model that requires steady, monthby-month growth, but rather, is subject to the highs and lows of the construction market. In many cases, they are "mom and pop shops" with less than 10 office staff. The point to be made here is that there is a dynamic present whereby each company is subjected to a competitive market. Consequently, should the contractor fail to be competitive enough, that company will go out of business. Therefore, the nature of the competitive market in the construction industry is such that, for the contractor, securing the most productive labor force as is possible is essential.

As is the case in many industries, labor is the most volatile economic variable. Indeed, within the construction industry, from the contractors' perspective, those who are hired to perform CBA defined labor tasks are the defining variable for the viability of the business. Thus, there is incentive for the contractor to keep and maintain those union workers who they have deemed to be productive for their businesses. To this end, many contractors offer incentives to these workers. Extra pay, paid vacation time, paid time off for holidays, and a company paid vehicle are just a few incentives offered to the union workers whom the company wishes to entice to stay with their business. Additionally, many contractors have deemed it a better financial decision to pay their "regular" workers overtime pay rather than hiring another worker from the union hall at straight time. It is important to note that a union worker is equally free to quit any job and is in no way compelled to work at all.

One CBA defined position is that of superintendent. While the CBA may not require a superintendent to be present at each contractor, for those that it does require, the superintendent's duties include management of the labor force, (union members employed,) at the contractor. The superintendent is frequently the person who decides which rank-and-file members are deemed worthy of regular employment at the company and which members are not. The superintendent 
is required to be a union member, but answers directly to the contractor. The CBA defines a higher wage rate for the superintendent and the working conditions are such that the person employed as superintendent rarely engages in the physical labor aspects of the trade. Indeed, the construction trades oftentimes require the individual worker to work in the atmospheric elements. If it is 20 degrees or 100 degrees Fahrenheit, the work must still be performed and the worker must work in these conditions. However, the superintendent, being a management position, oftentimes does not require physical toil in these, or any other, circumstance. Therefore, the member who finds his or herself in the superintendent position has at least financial and physical incentives to please his or her employer, the contractor, thus, dividing his or her loyalty furthermore.

The picture of the superintendent should be made clearer. Since, as was stated above, the superintendent's duties include management of the company's unionized labor force, and with the dynamic of pleasing his or her contractor being constant, the superintendent is in the situation where he or she has incentive to secure a productive workforce. However, the operative word here is productive. To be sure, each business must be financially solvent to exist, but the level of productivity and, consequently, profitability are in part determined by the labor variables used. When all that is known is a profitability at level $\mathrm{X}$, then while the company can strive for profitability at level $\mathrm{X}+1$, it is confined to its understandings to what is known. Perhaps, the real profitability could be $\mathrm{Y}$, which is, in this example, $\mathrm{X}$ times 2 . The contractor never really knows whether $\mathrm{Y}$ is achievable and, provided they are profitable, they may be contented to a certain point. For the contractor, achieving profitability $\mathrm{X}$ is the minimum requirement and if this is achieved with the labor force employed, ways to enhance that profitability can be pursued. 
While the exact details of a company's balance sheet may not necessarily be shared with the superintendent, maintaining a workforce that ensures profitability $\mathrm{X}$ is paramount. This is to say, that for the superintendent to be deemed as a competent superintendent by the contractor, he or she must maintain a workforce that consistently delivers at least profitability $\mathrm{X}$ for the contractor. This dynamic, perhaps for some economics theorists, would be seen as a determinant towards the superintendent acting in a selfless manner and this is largely true but selfish behaviors do also arise. Indeed, in many cases superintendents act on self-preservation instincts. Securing a labor force "team" can mean those deemed to be productive, but can also mean a team that will cover each other's backs, a clique; including the superintendent's back. Of course, it could include both: a productive team and a clique. It is not uncommon that the superintendent established fiefdoms, which include "toadies" within the company's regular work force and, while not overt, blacklisting occurs too. These can be thought of as "unions within a union," as is voiced by some members. While this may be construed as a harsh critique, it is not intended to be so. I understand that for many in the superintendent position, what has been described is how it has always been done and such a superintendent is merely continuing with the management technique which has been employed for decades. For some, they would never consider this improper. Additionally, there are dozens of superintendents who opt against establishing cliques. This is not to paint with an absolute brush, only to establish a dynamic that is present for many rank-and-file workers.

For the rank-and-file member within such a clique, there is incentive to maintain the status quo. With knowledge that the superintendent has one's back, ensuring that this superintendent remains in power is critical for regular employment. However, for the rank-andfile member outside of such cliques responses can be varied. Among such responses 
ambivalence, anger, resentment, and the hope of joining can be a few of the feelings that a worker could have. Of course, there are those superintendents and company "regular" workers who find no inconsistency of loyalties with being a company man and a union worker, or by "blacklisting" those workers deemed unsuitable for employment and, indeed, to some extent this can be plausible. Such members will often say, "This is a business and we need to be profitable and such workers cannot be productive. Thus, they deserve to be unemployed." However, in this context, such workers elevate their senses of productivity and profitability to the level of standard, (likely due to the fact that they have been deemed to be profitable by the company that they work for). With all of this said, it is important to understand that for the member who wishes to be regularly employed there oftentimes is present the dynamic of cliques to contend with. To be inside a clique is to submit to its rules. To stand against such cliques is to be outside of it, with all that entails.

It is important to further discuss the nature of membership in a building trades union. Like any organization the local building trades union and its international union, to a larger extent, is a group of individuals who unite for a stated purpose. In this case, the organization of the building trades union is a group of individuals who unite for the purpose of collectively standing together to legally negotiate with the individual contractor what work tasks are determined to be deemed as covered work and to negotiate the wages, benefits, and terms and conditions for performing these tasks. (It is important to note that while the concept of the purpose of the organization of the union is described above as standing together to negotiate with the individual contractor that in fact the union leadership negotiates with the local SMACNA chapter, which is representative for all of the local area contractors.) Therefore, the local building trades union, as well as its international union, is a group of individuals who are organized labor 
to perform a certain skill and, consequently, within the Capitalism system, this labor is therefore commoditized; that is, a skilled worker (labor) is the product that the union offers to the marketplace.

For SMART unions, the local union's leadership is elected members and while in fact, the leadership is elected democratically by the rank-and-file members, there is a certain level of disingenuousness to saying this. At the international level, the leadership, while being members, is elected by those people that are elected to office of the local union and not by direct vote of the membership as a whole. Here too, there is disingenuousness to the process. At the local SMART union, the offices of Business Manager and Business Agent(s) are the most powerful elected positions. Like the American political system with its parties with a slate of candidates, in the local union's elections there also are slates of candidates. One slate would be an opposition group and another slate would be one that the current Business Manager will field. However, in many cases and unlike the American political system any alternate, non-incumbent slate has limited access to resources that enable serious opposition. Here, the power of incumbency is particularly pronounced and oftentimes includes incumbent leaders "grooming" younger members whom regularly attend the union meetings for succession. This is a common practice. This, in many cases, leads to a string of unbroken leadership from members within the ruling clique who have all learned to toe the line for the incumbent platform. Additionally, and this is true at the international level too, one tactic used is by an incumbent Business Manager, or General President at the international level, is to win reelection and then after a short period of time retire from the position. This, by the constitutional rules and procedures of the union, requires that the ruling board or council appoint a successor to the position, which, usually, ensures continuity from the ruling party. Here, too, cliques are dominant. To be sure, changes to 
leadership have occurred, but only as an exception to the rule. This phenomenon is important as it relates to the dynamic of the local union who negotiates the CBA with the local contractors' association.

It cannot be understated that while there is a long history of continuity by the ruling party within a local union that it still is the local members who vote for the union's leaders. It is important to point out that attendance to a union election is required to vote for the union's leadership. In many cases, the local union will have multiple voting dates and locations to accommodate the membership. For there are many locals who cover a large geographical area. That being established, the rank-and-file members still must show up to vote and while elections usually see a far more robust turn out than the average meeting voter turnout can be disappointing. However this may be, it is important to discuss the typical union meeting. The typical union meeting is attended by less than $10 \%$ of the membership and, in fact, for some locals, a $10 \%$ turnout would be considered to be good. Of those who do turnout at these local union meetings, many of the rank-and-file members are not a company's "regular" workers, rather many are members who may be looking for work. Perhaps in these situations, these workers attend the union meeting due to these workers' needs to find work and they attend in the hopes that the union can deliver some positive news regarding employment. Regardless, though, many of the rank-and-file voices that are present at the union meeting have a certain understanding of the structural systems (oftentimes from outside any of the discussed cliques) and, consequently, they hope to steer the leadership in a direction more in line with their experiences within the industry. With this as the majority of voices being heard by the leadership at a union meeting, the directions opted by the leadership may in fact represent a certain singular understanding of what the rank-and-file member's wants and needs are. 
Regarding specific employment of the worker, the local union is the place that a contractor would call to hire needed workers. (While this is not exclusively true, as a contractor may call an individual worker directly should the CBA permit it, it is generally true that should more labor be required, that the contractor contact the union hall. Here the Business Agent can steer work for his or her comrades and allies. Perhaps the specific rules forbid such practices, but this occurs nonetheless.) This dynamic is such that the individual rank-and-file member can find his or herself having to ally with the ruling leadership to find work. For, if a contractor calls the union hall to find additional workers, it behooves the worker to ensure that he or she is in good graces with the Business Manager and Business Agent(s) should the worker desire the leader to send the work his or her way; a fiefdom can arise here too. While not every worker that is unemployed is outside of the various cliques described and none of these descriptions thus far are absolute, these are an accurate description of many of the dynamics that structurally create the system where the rank-and-file sheet metal worker finds that he or she is working within the unionized building trades. Add to this the deskilling effects and skills obsolescence that CT brings and this context will help the reader better understand the data from this research.

In summary, the rank-and-file member must pledge loyalty to the union, but the union cannot guarantee work for the member. Therefore, the member can find his or her loyalties divided between the union and the contractor that hires him or her. Add to this the dynamic pressure of competition for a job. Indeed, it is the norm that there are more workers in a local union than there are jobs available, guaranteeing unemployment for some. Couple this competition with the overall competition that each individual contractor business has for construction projects and the need to be perceived as productive and profitable is pronounced for the worker. Added to these, the worker often times must attempt to find favor with the 
company's superintendent who is a fellow union member. Additionally, if a worker does find favor with a contractor's superintendent, the pressure to repeat and maintain productive and profitable levels is constant. For the superintendent, the need to create and maintain a work force, which can maintain these levels, can lead to blacklisting and cliques of fellow members. For those workers on the outside looking in, adopting certain behaviors, including a de facto pledge of loyalty to the superintendent is in order. For those on the inside of such a clique, maintaining the status quo is paramount.

Of course, the local union must and does serve its members, for if it failed to do so, the union itself could possibly disappear. Thus, it must always be thought that the leadership of the local union, while potentially self-seeking regarding their political life, always acts in what they see as the best interest of their members at any given point of decision making. However, this may be, it appears that, in many cases, the union's leadership operates subconsciously with the understanding that the whole of the system is structured in an industrial economic model and has a scientific understanding of management. The idea of measuring and controlling inputs and outputs is an axiomatic understanding that both the labor leaders and management, the contractors, operate under. While the contractor side feels the pressures of the information economy more acutely, their understandings are still colored by their long experiences in doing battle with the union, which is shaped by the industrial economic model. The union recognizes the deskilling effects of $\mathrm{CT}$, as they need to look no further than the plasma table and its subsequent jobs elimination for proof, but the union's leadership is captive to its known paradigm of the industrial economy and a sense of scientific management. In the middle of all of this is the rank-and-file union worker, both within one of the cliques and without who feel the pressures, perhaps unknowingly, of a changing industry and wonder what it all means for 
themselves and their families. Indeed, having a job, paying one's bills, and scraping by a living will always be a constant pressure upon all workers within a capitalist system. Understanding these structural systems that are present provide guidance for analyzing the data as it relates to the rank-and-file sheet metal workers readiness for or resistance to change.

\section{$\underline{\text { Results of Quantitative Findings }}$}

Unionized sheet metal workers from throughout the United States completed an online survey for this research. They answered a questionnaire about their thoughts and feelings regarding the impact of the nature of CT on their work and trade. Additionally, they responded as to how they thought and felt that their union's leadership should respond to the encroachment of technology on their work. This section of the research will detail their responses. Additionally, out of the thousands invited to interview for this research, only three people consented to do so. For that reason, I cannot prescribe much importance to the interview data. However, there were noteworthy interview responses, the substance of which is detailed immediately below.

The people who interviewed for this research held beliefs that were supportive of the majority responses of the online survey. In response to the question regarding the impact of technology on the sheet metal trade, the interviewees shared the following:

The best way to put it is, get on board or be left behind. That's it. [The members] should get educated with technology but, they don't. Building Information Modeling is coming, it's here and it's only going to get bigger. If you can't electronically know where to put a piece of equipment or a hanger, because that's what BIM is all about, then you're not going to be on the job or you'll be a pair of hands on the job.

Technology's been a big help to us. It has reduced man hours and reduced mistakes. Nowadays, you can do a lot more. You're more productive. It has made us more compatible with the other trades I guess. We have to keep up with the 
Joneses we don't have any choice. It's either that or we relinquish all the drawing to somebody else. You can't stop technology.

It might lead to less jobs but more efficient and more accurate. Because there's less chance for human error. But, overall, it's going to help us be competitive. It's here to stay, and it should be. It could be less man hours in the long run [,but] we don't know the full impact yet; time will tell.

Regarding the impact CT has on the specific work that a sheet metal worker does, the interviewees said:

For the average worker, probably not much change yet but for the lead man, yes, he'd better have the laptop with him or, some of the foremen I see now have the, uh, I-Pads. [Others] will probably be led by someone who's computer literate.

We are looking at, to a certain degree I think we are looking at a reduced volume of sheet metal that going to go into buildings in mechanical systems. We need to start looking at what other opportunities are out there for sheet metal workers to do. Something outside the box. Not just relying on HVAC as our bread and butter. Any new technology that comes along that we haven't yet thought of, I mean, we have to look at, as new technology comes down for heating and cooling buildings we're going to have to look at all that technology and say 'where do we fit into this picture and how do we garner some of that work.'

I see it taking over more and more, especially for records. I don't see that ever changing now. As far as laying out and stuff like that you've got to have somebody that knows that because what if the machine breaks down. These jobs are under a contract, they've got to be done in a certain amount of time. I believe it's going to be there forever. You're going to need less though. I think technology is going to keep advancing, they're going to come out with, uh, new ways to do things that's going to be faster and more efficient and more cost effective and that's all for us good because, especially if we come up with it, because that puts us ahead of the game with, uh, the people that are non-union that don't have it.

Regarding the relevancy of sheet metal skills, the interviewees offered the following responses:

The older generation are a little bit more mechanically inclined. If I point out, if I asked them to point out $1 / 8$ " on the tape measure, this computer savvy guy has a 
rough time. I know how to measure a job, I know how to size ductwork. Remember, there's an old saying; garbage in garbage out. Just because you know AutoCAD doesn't mean you know what you're doing. I know what I'm doing with HVAC.

I think [the] sheet metal skills are critical to, you know, even if the guys just a field guy because we don't have any shop guys any more, you know, most of the shop stuff is concentrated in a few shops and most places will have one good guy that he keeps around the shop that helps do the estimating, take-offs and if they need a fitting right away or something. But, the guy in the field still needs to know how something is made in order to make sure that it's something possible to make it. He needs to have an idea of, of, uh, how air flows through a duct and what sizing requirements need to be. Those skills are essential.

Skills are going to, you know, we have all our skills that are working with sheet metal in which there's no computer or, uh, machine or robot that can replace that. Especially for the field. But, as far as the shop, I see it probably taking over some jobs in the shop some times. It's got to be. It already is with layout and stuff. Look at that. That's just in the last 20 years.

In response to how computer technologies have and will continue to affect the number of

jobs available to the sheet metal worker, the interviewees responded with the following:

Net jobs will be losing. We will need less sheet metal workers on a jobsite. [The union] will shrink. Percentagewise, I would tell you that we'd lose $30 \%$. If they're on top of things, um, they have to go after other ventures. They need to go after other work.

Maybe we do more Detailing now than we did 20 years ago. Now-a-days you can do a lot more and you're more productive. Does it add man-hours? Only if we're Detailing more, I guess. I don't know if it's increased the man-hours.

When I started my apprenticeship everything was laid out by hand. A few years into my apprenticeship or just as I became a journeyman, plasma tables came on the scene. Uh, and I saw, you know, where you'd have five or six guys in a shop doing the layout work, uh, it went down to one or two guys in the shop once the plasma tables came out. It didn't make sense if you had any kind of fabrication shop not to have one in your shop.

I'm not sure if it's going to increase our employment opportunities or put some people out of work. I don't really know. I mean, I guess so far it's probably helped us overall. It's just hard to tell what the impact is right now because the economy has been so bad the last six years. So, it's really hard to tell how much, 
um, it's either been a plus or minus as far as jobs. Because you don't really know what you can attribute the, uh, unemployment rate to if it's through, uh, advances in technology or if it's just because the economy's been so bad. I think it's probably, right now, it's more or less break even.

Regarding how those interviewed felt about how the union's leadership should act toward computer technology, the responses were as follows:

They should be all over it, and they are [at my local union.] They should embrace it. It's the way to go because if you don't embrace it, then the non-union, who do embrace it, will take over the jobs anyways, that you thought you were going to keep; because you didn't embrace it. Survival.

We have to embrace them and we uh, to a certain degree we have to sell them. We have to sell them. We have to sell them to a lot of people. Um, we have to sell them to our contractors. Uh, that makes them more competitive so they can get more work, so that we can employ more guys and get more man-hours. We have to sell them to our guys. Because once our contractors start using them, our guys are going to have to know how to do it in order to be productive. Um, we have to sell them to the end user that our guys are smarter and faster and our technology is quicker than someone else who might be doing this same kind of work.

I expect them to, um, keep us abreast of the educational aspects of it at the hall. I mean I'm hoping, I guess some locals are in much dire worse shape than mine. There, where they can't, you know, some may even close their schools and stuff because they don't have money. I mean, that's going to hurt. That hurts overall. Not just them but, everyone that's union. They need to embrace it. Create a fund that, you know, keep the money growing for technologies as far as, uh, educational. You know, we're at the point of no return. It's like we're not turning back on electronics in, uh, the field and everything else as far as, uh, drawings and everything else. It's just going to keep going.

We will now discuss the results of the online survey. Question 1 inquired upon the individual's thoughts and feelings about the impact of CT on the sheet metal worker's job. The results were mixed. Of that mix, $31.5 \%$ of respondents, the highest response rate to that question, acknowledged that CT would indeed replace some of jobs, but they thought or felt that the skill level of the sheet metal worker was too advanced for CT to replace much of the work that a sheet 
metal worker does. The second highest response rate, $21.6 \%$, thought that new jobs would be created, but they felt that CT would cause a net loss of work/jobs for the sheet metal worker. The third response rate, $17.1 \%$, saw the impact of $\mathrm{CT}$ as being more profound than the previous two groups of respondents. These respondents felt that CT would replace a great deal of work that the sheet metal worker performs but that CT could not replace all work performed by the sheet metal worker. The fourth group of respondents, with $16.2 \%$ of the responses, saw a zero growth scenario for their work; the respondents felt that new jobs would be created and that the current membership would be trained to do that work. The fifth group of respondents, those who chose "Other," will be detailed last. The sixth group of respondents with $2.7 \%$ of the responses saw CT replacing more and more work into the future. Next, none of the 111 respondents felt that CT could not replace their work/jobs. All 111 respondents felt that CT could, in part, replace some work that a sheet metal worker performs.

The 12 respondents who chose the "Other" option responded to the question as follows:

1. "While computer technologies create new jobs, some may lose his or her job but that will open up other opportunities to train members for those jobs."

2. "Technology cannot replace hands on shop work or field installs."

3. "The choice just above this is truly my best choice to this answer. But my $50+$ years in the trade, $25+$ of which was as a JATC instructor, tells me that convincing my journeyman brothers on re-training is a "really" tough sell."

4. "I think computer technologies are going to enhance our careers as long as we receive proper training." 
5. "Computer technology will make us more efficient and competitive if used properly. We must evolve to embrace this technology, but not let it hinder us. It has it place in our trade, but it is not a cure-all."

6. "Doesn't have anything to do with what I do"

7. "Technological advances only help the unionized sheet metal industry, by having the latest technology, companies are able to stay competitive, and go after more work to keep more workers employed."

8. "It's not that the technologies are replacing our jobs, but the technologies are making shop and field jobs easier which in turn reduces hour for the industry."

9. "More jobs have been lost and will continue to be lost due to incompatible software and no training."

10. "Computer technology is the future. Learn it or be left behind, period."

11. “Computer technologies cannot install, service or maintain equipment. They will aid in energy efficient design however."

12. "Some jobs will be lost, but others might open up."

Analyzing these 12 "Other" responses listed here, most can be categorized into one of the preselected categories from the survey. More specifically, the response captured in Points 2, 6, and 11 can be viewed as fitting into the response group that sees sheet metal workers' skills as being too advanced for $\mathrm{CT}$ to replace. This increases that response count from 0 to $3(2.7 \%)$. The response captured in point 12 , which shows some hope that while CT will cause job losses, other 
job opportunities may be created. Therefore, this response could be categorized with the fifth preselect answer, which brings that selection's total response count to $25(22.5 \%)$. The responses for Points 1, 4, 5, 7, 8, and 10 all impart the sense that jobs will be lost, but with training, workers will be able to find work in a new type of computerized work. Therefore, these answers can all be classified with the sixth preselect answer, which expresses the same sentiment. These additions of these responses increased the response count from 18 to 24 (21.6\%). The response captured in Point 9 shows pessimism and therefore can be categorized with the first preselect answer. This increases the response count from 3 to 4 (3.6\%). Finally, the response in Point 3 does not seem to fit into any category and therefore it is excluded from the categories.

Five of the six preselect answers, those that chose "Other" were excluded as I attempted to reclassify these into one of the six preselect answers, all imply a deskilling or skills obsolescence effect that CT has upon the work performed by a sheet metal worker. The first three preselect answers clearly show that $\mathrm{CT}$ will replace work performed by a sheet metal worker and consequently, this means that the sheet metal skills that were once in demand are in less demand or not needed altogether. The fifth and sixth preselect answers are not as direct as the first three preselect answers at demonstrating skills devaluation or obsolescence, but nonetheless, they also imply the same. Creating new jobs regardless of whether a net gain or loss of overall work is realized means that new skills are required. While the fifth preselect answer, with its "net jobs lost" language meaning that skills will be devalued or obsolete, the sixth preselect answer is more nuanced. The sixth preselect answer clearly implies that new skills are needed, but this in and of itself does not necessarily mean that other skills are devalued or obsolete. However, the answer that no one will lose his or her job because of training to the new skills does imply that skills will at least be devalued. To further elaborate, this is not to say that 
skills of the sheet metal worker have been necessarily made obsolete, but that they have been devalued. Even if such skills are still required to perform the work of a sheet metal worker, the preselect answer implies that the quantity of workers needed to do this work is lessened. Therefore, if skills are more common among workers, the less scarce such skill are, and this necessarily means that such skills hold lesser value as finding a worker with such skills is more easily obtained.

To analyze the data from this question about the thoughts and feelings that sheet metal workers have as to whether their skills are devalued or made obsolete, the results are very one sided. Excluding the respondents reclassified into the fourth preselect answer and the respondent from the "Other" category, which could not be classified (a total of 4 respondents), all remaining respondents (107 out of 111, or 96.4\%) expressed some sense that CT has a deskilling and/or a skills obsolescence effect upon the work performed by sheet metal workers. Data analysis on the readiness for or resistance to change of the sheet metal worker will be addressed in the LCA section. 


\section{Sheet Metal Workers' and Computer Technology}

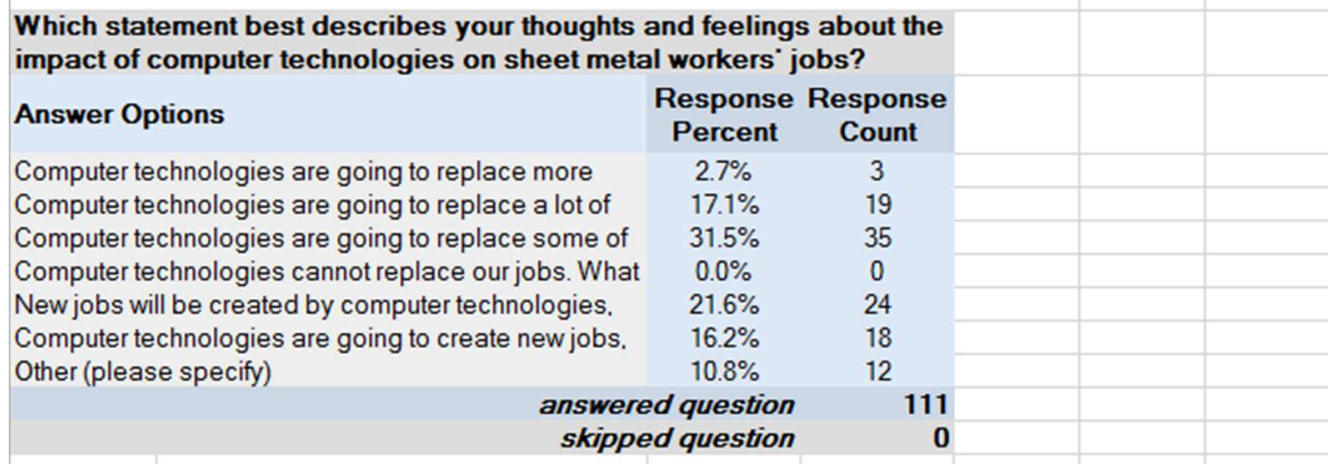

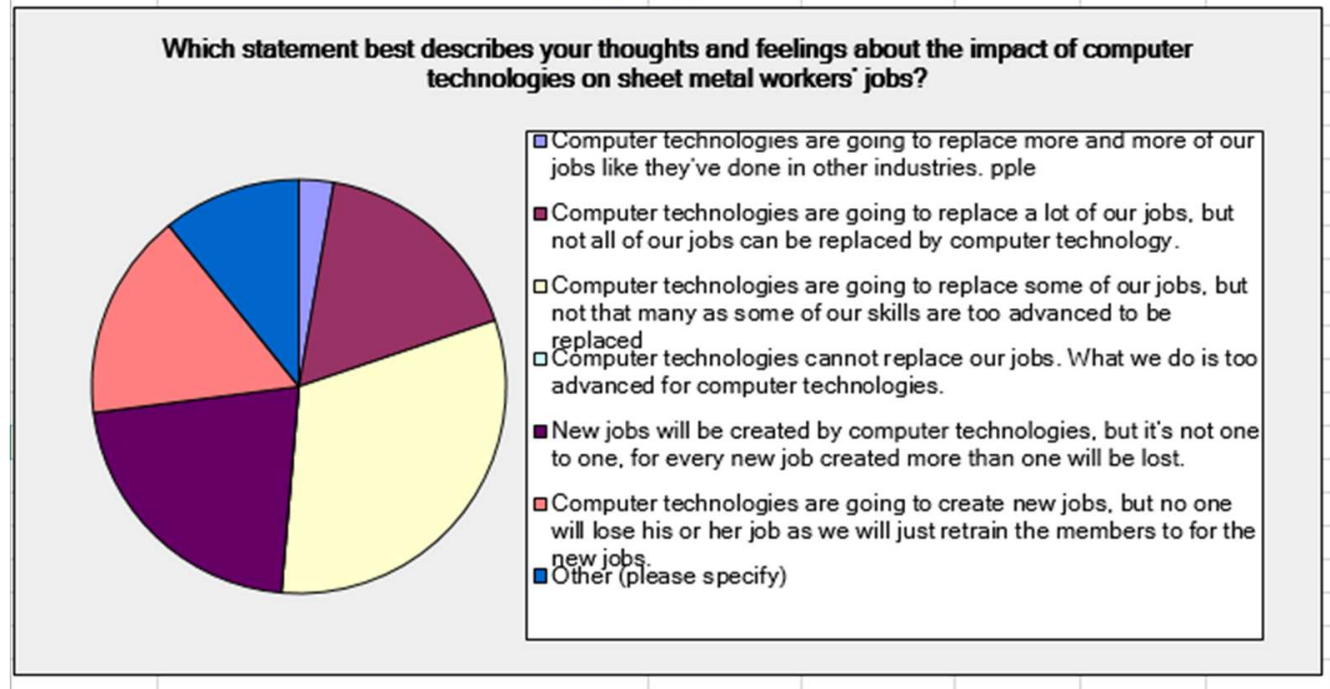

Figure 2. Question 1 SurveyMonkey Results Chart

Question 2 asked the respondents about the impact CT has had on his or her job. Fifty respondents (45\%) saw the impact of CT as somewhat positive and that $\mathrm{CT}$ would replace some but not all of the work performed. Thirty-eight (34.2\%) felt that CT would have a very positive impact upon the work that each performed and that CT would enable these respondents to perform their work in better ways. Ten respondents (9\%) said CT had a somewhat negative impact upon their work, with it replacing many of the work tasks that they used to perform. Eight respondents $(7.2 \%)$ felt that $\mathrm{CT}$ was irrelevant to the work that they performed. Four respondents $(3.6 \%)$ chose to respond without a pre-written answer. These will be detailed later. One 
respondent $(0.9 \%)$ saw CT having a very negative impact upon the work that is to be performed, with CT replacing most or all of the job tasks that the sheet metal worker is to perform.

The respondents who chose the "Other" option responded as follows:

1. "Older cad operators like myself are losing jobs with work slowing down, while the younger workers are being kept on for their newer computer skills."

2. "Doesn't have anything to do with what I do."

3. "Technology has created new opportunities for myself, and has increased the quality of the product and increased the efficiency at which the products are fabricated."

4. 'It will create more work for service technicians but decrease work for sheet metal workers."

The response in point 1 demonstrates a pessimistic view of the impacts on CT upon that individuals work. Therefore, it is added to the fifth preselect answer which is a very negative impact. This causes the response count to rise from 1 respondent to 2 and causes the response rate to rise to $1.8 \%$. The response in point 2 demonstrates a neutrality regarding the effects of CT on that individual's work and, therefore, it is added to the third preselect answer which is also neutral on CT's effects upon the worker's work. This causes the response count for that answer to rise from 8 to 9 and the response rate rises to $8.1 \%$. The response in point 3 demonstrates a very positive expression of what CT means to that respondent's work and, therefore, it is added to the preselect answer 1 which also states that CT has a very positive impact upon a worker's work. This causes the response count to rise from 38 to 39 and the response rate rises to $35.1 \%$. Finally, the response in point 4 does not fit into any preselect answer and therefore no additional 
adjustments to these preselect answers will be made. However, the answer in Point 4 suggests both a positive impact for some workers and a negative impact upon other workers.

In this question three of the five preselect answers, "Other" is reclassified, express a devaluing or obsolescence of work skills; preselect answers 2, 4, \& 5. Combining this data shows that the respondents see CT's impact upon their personal skills much more positively than they do for the trade as a whole. Whereas $96.4 \%$ of the respondents expressed that CT does devalue or make obsolete the skills of a sheet metal worker on the whole, when it came to CT's effects upon the respondent's personal skills this effect was reduced to $55.9 \%$ of the respondents. While the majority of respondents see a devaluing or obsolescence of skills caused by CT, $34.2 \%$ of the respondents feel no devaluing of their personal skill sets. 


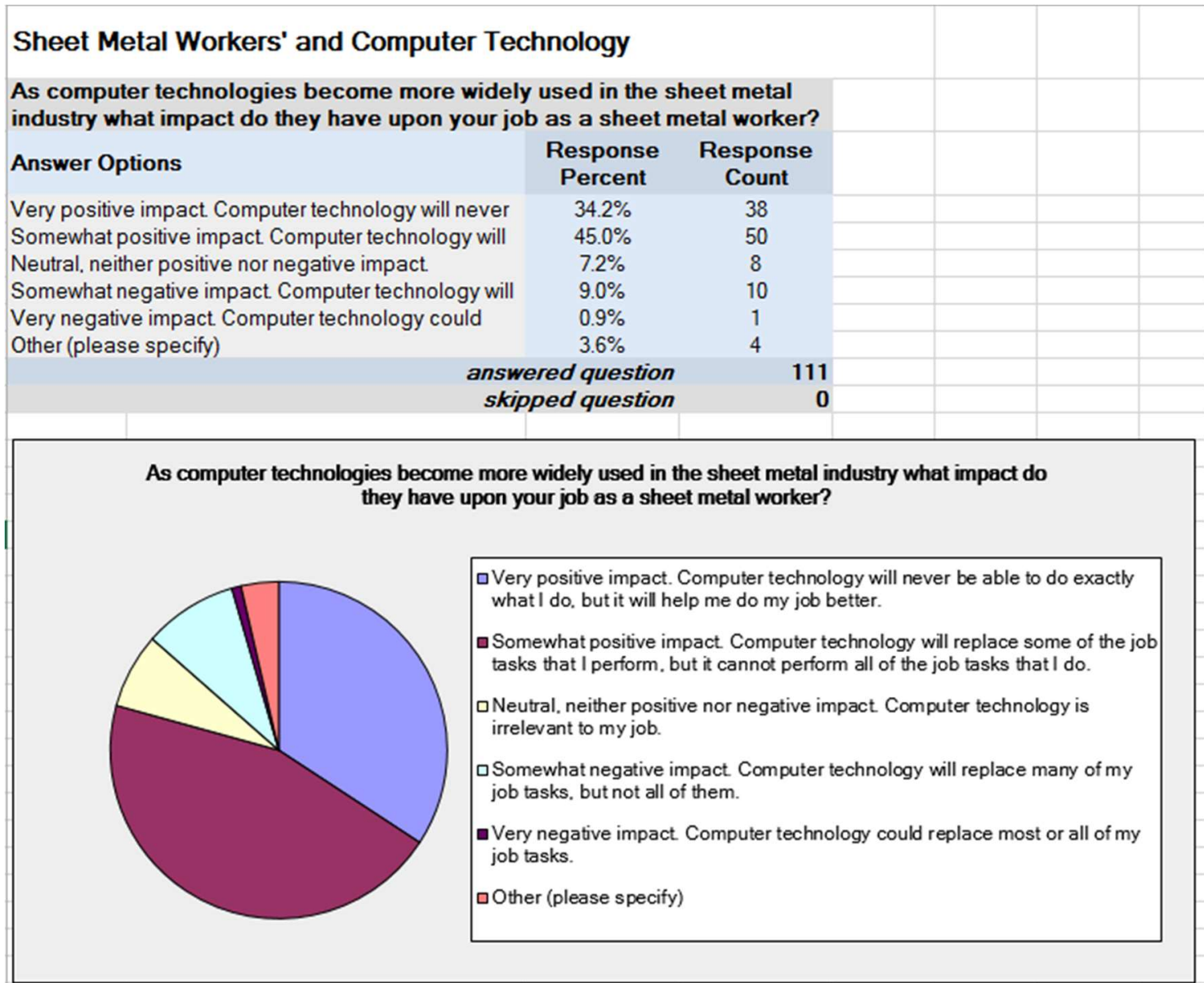

Figure 3: Question 2 SurveyMonkey Results Chart

Question 3 asked respondents for their thoughts and feelings regarding the relevancy of their sheet metal skill set. Seventy respondents (63.1\%) saw their skill sets as being very relevant and needed. These respondents felt that CT did not perform the skills that each respondent possessed. Thirty-four respondents (30.6\%) felt that their skill sets remained somewhat relevant, but that CT was causing their skill sets to become less and less relevant. Five respondents (4.5\%) chose the "Other" option. Two respondents $(1.8 \%)$ had a much bleaker stance on the relevancy of their skill sets. These respondents chose the option that held that their skills are not very 
relevant or needed as CT does most of what their skill level requires. Finally, none of the respondents felt that CT could do everything they do at their skill set level.

The details of the "Other" responses are as follows:

1. "My skills work well with computer technology. I work in the commercial vent side of the industry and lay out skills have been replaced with technology."

2. "Doesn't have anything to do with what I do."

3. "The skills I have are needed to help the technology be the most efficient."

4. "Most work is physical and coordinating with other trades."

5. "Sometimes, often we are asked to design, layout stuff the programmer couldn't imagine. Sometimes the power goes out."

The responses in point 2, 3, and 4 all express the feelings that the respective respondent felt that his or her individual skills were very relevant and therefore, these three have been added to the first preselect answer which states that the respondent feels his or her skills are also very relevant. This causes this first preselect answer's response count to increase from 70 to 73 and its response rate to increase to $65.7 \%$. The response to point 1 demonstrates confidence in the relevance of that respondent's skills but also expresses that CT has replaced some skill sets. Therefore, this response is added to the second preselect answer which expresses the same sentiments. This causes the response count for preselect answer 2 to rise from 34 to 35 and the response rate to rise to $31.5 \%$. The response found in point 5 is indeterminable and therefore, it is not added to any preselect category. 
In light of the previous responses, which demonstrate that the respondents to some degree see the skills of a sheet metal worker being deskilled or made obsolete, here the results of the responses show that the majority of respondents see the deskilling/obsolescence effect as not particularly acute to their individual skills. They are in effect saying that $\mathrm{CT}$ is devaluing the skills of a sheet metal worker in general and for some of us we are feeling that effect, but the effects are not too pronounced at this point in history. With 73 of the 111 , or $65.8 \%$ of the respondents feeling that their sheet metal skills are very relevant and needed, this conclusion is drawn.

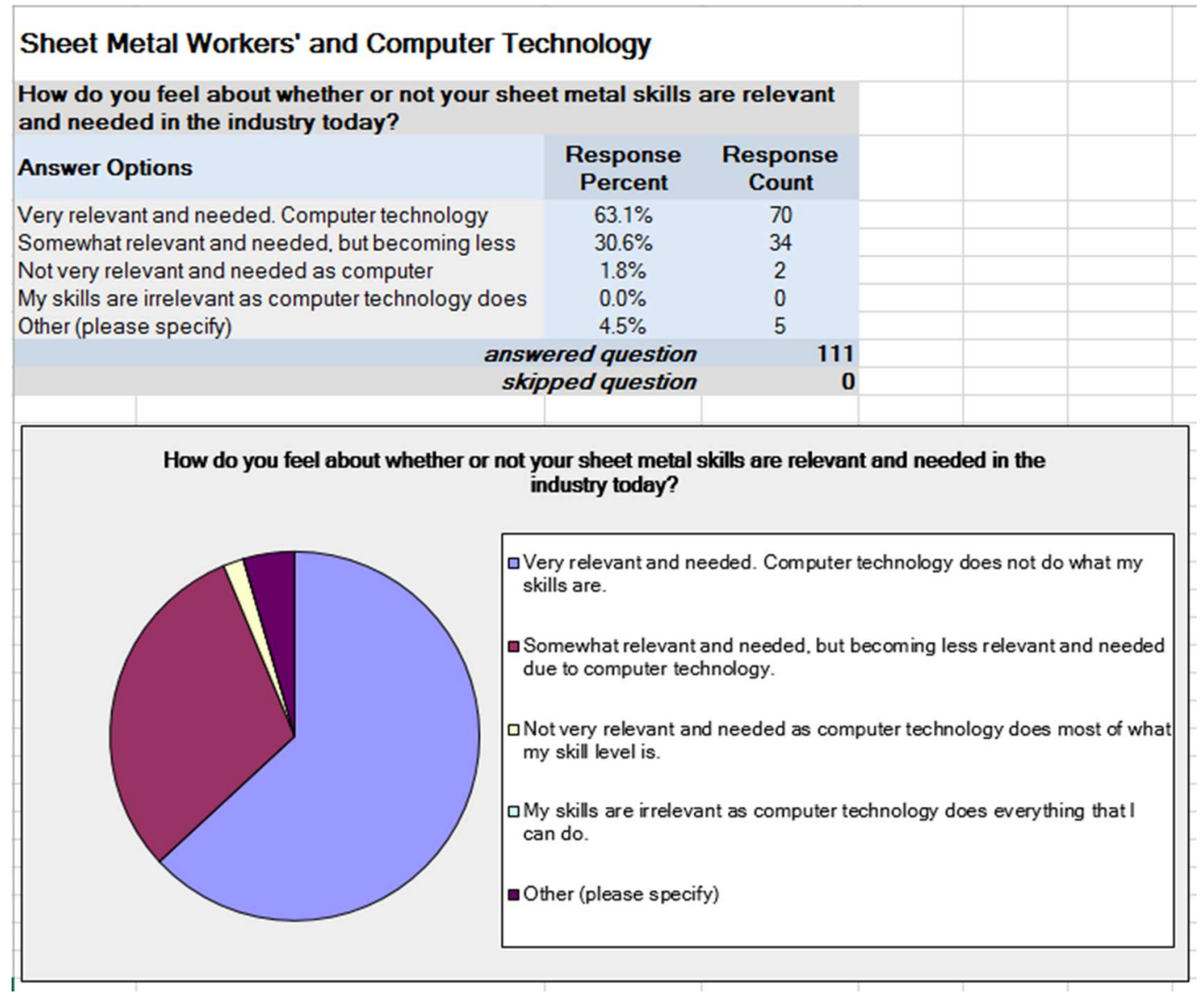

Figure 4: Question 3 SurveyMonkey Results Chart 
Question 4 asked the respondents how they felt about the impact CT would have on their job in the future. Fifty-two respondents (46.8\%) felt that CT would have a somewhat positive impact upon their job, with these respondents acknowledging that CT will replace some of the work that they do in the future but that CT would not replace all of the job tasks that these respondents performed. Thirty-eight respondents (34.2\%) saw CT having a very positive impact upon the work that they perform. These respondents felt that CT would enable them to perform their work in a better way. Ten respondents $(9 \%)$ felt that CT would have a somewhat negative impact upon their work in the future, with CT replacing many of the job tasks that these respondents now perform. Six respondents (5.4\%) felt that CT was irrelevant to the work that they perform. Four respondents (3.6\%) chose the "Other" option. One respondent $(0.9 \%)$ felt that CT would have a very negative impact upon their work in the future. This group thought that CT could replace most or all of the job tasks that this group performed.

The detailed responses from the group that chose the "Other" option are as follows:

1. "See answer to question \#2."

2. "Technology will only enhance my future, as it will always take a good sheet metal worker to make the technology work."

3. "It will replace some people but not all, humans will always have to be there, but any job loss is bad."

4. "Very positive as I am a service technician."

The responses in points 2 and 4 demonstrate a very positive outlook regarding how those respondents saw the impact that $\mathrm{CT}$ will have upon their respective work. Therefore, these two responses are added to the first preselect answer, which is that $\mathrm{CT}$ will have a very positive 
impact upon work, and this causes the response count for this to rise from 38 to 40 and the response rate rises to $36.0 \%$. The response in point 3 demonstrates a somewhat positive feeling regarding CT's impact upon that workers work and therefore has been added to the second preselect answer and this causes that response count to rise from 52 to 53 and the response rate to rise to $47.7 \%$. Regarding the response in point 1 , it is indeterminable and therefore it cannot be added to any preselect answer grouping.

Question 4 changes the focus from the present to the future. Here the respondents show a sense that their personal skills will suffer at least devaluing caused by CT. Only the first preselect answer to question 4 offers a sense that the individual worker's skills will be unaffected by CT. Forty of the 111 or $36 \%$ of the respondents feel as though their skills will remain at least equally valued as they are now in the future. However, 64 of the 111 or $57.7 \%$ of the respondents do see at least some of their skills being devalued in the future. 


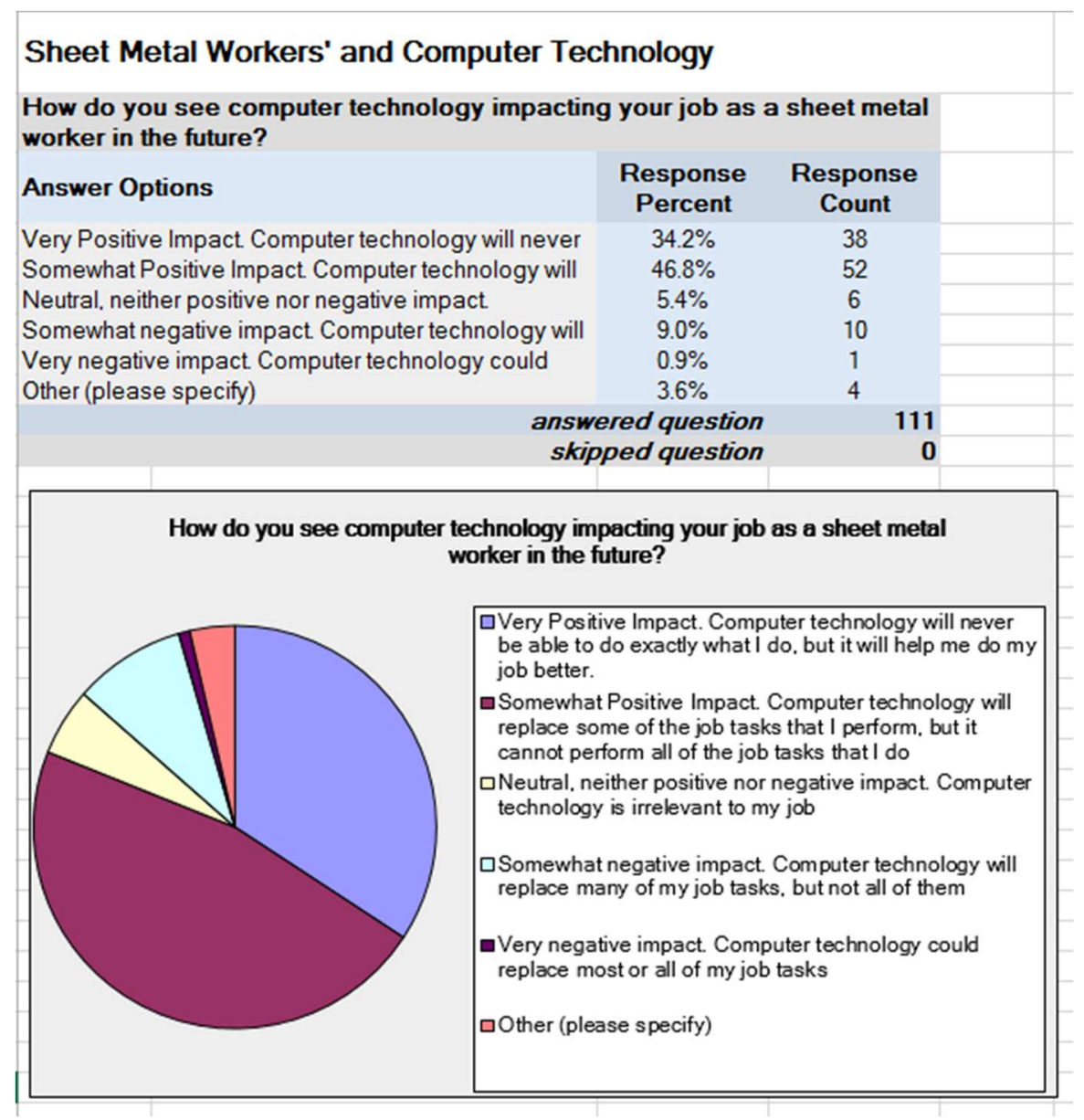

Figure 5: Question 4 SurveyMonkey Results Chart

Question 5 asked the respondents how they foresaw their skills being changed by greater usage of CT. Seventy-two respondents (64.9\%) said that their skill sets would be somewhat changed. This majority felt that they would need to learn new CT related skills to perform their respective work tasks in the future. Twenty-two respondents $(19.8 \%)$ felt that their skill sets would largely be changed. This group of respondents felt that they would need to learn many new CT skills to perform their work in the future. Ten respondents $(9 \%)$ felt that their skill sets would not be changed at all in the future as they felt that CT could not perform the work that they will need to perform in the future. Four respondents $(3.6 \%)$ felt that CT is irrelevant to their 
respective work that they perform. Two respondents $(1.8 \%)$ felt that their skill sets would be completely changed to perform the work that they will be doing in the future and that these respondents would need to learn a great amount of new CT related skills to perform their respective work. One respondent $(0.9 \%)$ chose the "Other" option; the response is detailed below:

1. "More local training needs to be available for the latest industry programs, again the younger workers are getting the in-office training while the older worker is being put out on the street, companies are forgetting that we have valuable skills in and out of the office"

There is obviously only one "Other" response and it demonstrates the sense that for this particular worker the effects that CT has had on his or her work are negative. It is expressed that he or she is "being put out on the street" which suggests a negative impact. However, it does leave open the possibility that work can obtained outside of the office. Therefore, this is added to the largely changed preselect answer, which causes that answer's response count to rise from 22 to 23 and its response rate to rise to $20.7 \%$.

Question 5 can be coupled with question 4, but it differs in scope. Question 4 asks the respondent how he or she feels towards what quality of impact $\mathrm{CT}$ has upon that respondent's job in the future, whereas question 5 asks how much of an impact the respondent sees his or her skill sets being changed. With these as differences, the two questions still touch upon how the respondent sees his or her future in light of CT's impact upon personal work skills. Regarding how the respondents feel about the level of impact that CT has upon his or her skill sets 97 of the 111 respondents or $87.4 \%$ (found in preselected answers $2,4, \& 5$ ), feel that their current skill sets will require at least some enhancement. Here too these responses imply that the respondent 
acknowledges some level of skills devaluation at least. If new skills are needed to do the work of a sheet metal worker, then this necessarily means that the old skills are not sufficient, at least in part, to perform the work tasks that a sheet metal worker is to perform. This means that the old skills have lost at least some of their value.

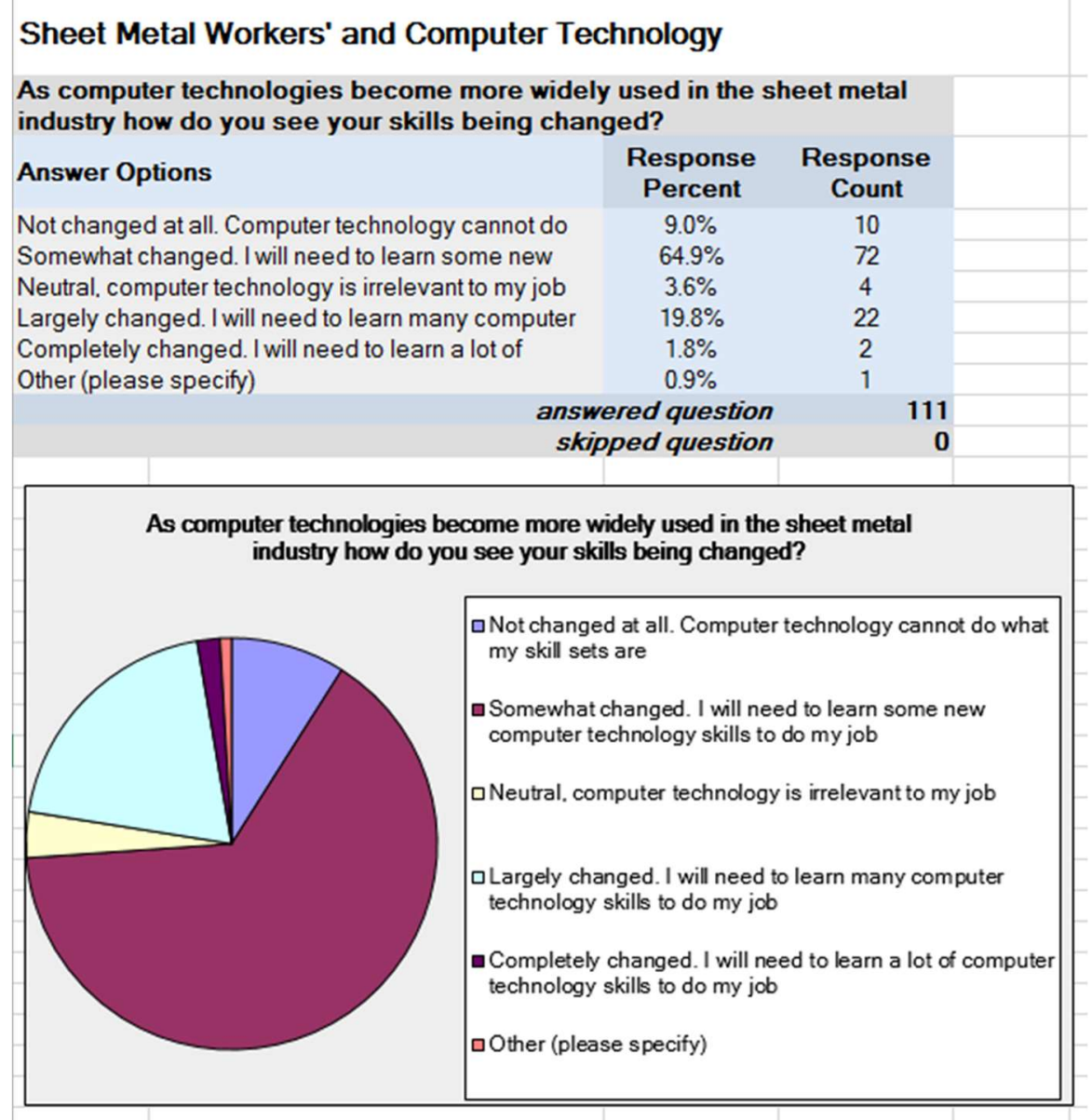

Figure 6: Question 5 SurveyMonkey Results Chart

Question 6 asked respondents about learning experiences related to CT that helped each to perform their work tasks better. Forty-four respondents $(39.6 \%)$ responded that they indeed had learned new CT, which enabled them to perform their work tasks better, and that the learning was done on their own. Twenty-eight respondents $(25.2 \%)$ answered that they had indeed 
learned new CT, which enabled each to perform their respective work tasks better, and that this learning was provided by their respective employers. Eighteen respondents (16.2\%) answered that they had learned new $\mathrm{CT}$, which helped each to perform their work tasks better, and that they learned these new skills by attending training provided by their respective local union's Journeyperson upgrade training program. Nine respondents (8.1\%) answered that they have not learned new $\mathrm{CT}$ and that they have never had an opportunity to do so. Eight respondents (7.2\%) chose the "Other" option. These responses will be detailed below. Four respondents (3.6\%) answered that they have not learned new CT that enabled each to perform their work tasks in a better manner. However, these respondents also answered that they did indeed have the opportunity to learn CT skills, but each chose not to partake in such learning.

The details of those respondents who chose the "Other" option are as follows:

1. "On the job training."

2. "I think your survey only addresses the impact on shop work it still takes boots on the concrete to install the product."

3. "I am retired 20 years ago so I have seen technologies with the duct machine, it made more jobs for workers."

4. "Yes, hands on, learn as I worked made me a much better detailer / cad operator, more formal training would have better served me."

5. "To my understanding, the new computer skills that are offered are not intended to help me do my job better, but rather to help me do a different job within the industry." 
6. "Both the second and third choice from above."

7. "Yes, I have taken skills that I have and learned from opportunities I have been given by my employer."

8. 'I've learned skills through the apprenticeship program and my employer has provided me training."

The responses in points 3, 4 and 7 demonstrate that all three respondents learned new CT skills while working at their employment and therefore are added to the first preselect answer which corresponds with an employer providing CT training. This causes that preselect answer's response count to rise from 28 to 31 and its response rate rises to $27.9 \%$. However, the response in Point 8 suggests that this respondent learned CT skills through his or her employer but, also through his apprentice training. Therefore, one half of the response will also be added to the first preselect answer, which obtaining training via an employer, and this causes the response count for this to rise from the adjusted 31 detailed above to 31.5 and the response rate rises to $28.4 \%$.

The second part of the response in point 8 is that the respondent learned new training in apprenticeship school. This training is formal and via the training center and, while it cannot be determined conclusively here, such training is more often than not identical to journeyperson training. However, since the training is formal and via the local union's training center and that journeyperson training is also via the local union's training center, this second part of the question is added to the second preselect answer, which is that the respondent received formal training via the training center. This causes that response count to rise from 18 to 18.5 and its response rate to rise to $16.7 \%$. However, the response in point 6 states that the respondent received CT training as a journeyperson via night school. Half of this response is therefore added 
to the second preselect answer and this causes its response count to rise from the adjusted 18.5 detailed above to 19 and its response rate rises to $17.1 \%$.

The second part of the response in point 6 is such that it is added to the third preselect answer; namely, that CT skills have been learned individually by the respondent. This is added to that response count and response rate which causes each respectively to rise. The count rises from 44 to 44.5 and the response rate rises to $40.1 \%$. The responses to points 2,3 and 5 do not suggest any correlation to any of the preselect answers and therefore they are not added to any category.

Question 6 cannot be correlated to the respondents' feelings regarding skills devaluing and skills obsolescence directly. However, this question does add support to the studies related to adoption of technology, which I cited in the literature review. Specifically, these results support the findings that "ease of use and usefulness beliefs fully mediate the influence of selected individual difference variables on attitude and usage intentions" (Agarwal \& Prasad, 1999). As can be seen in the respondents who learned new computer skills on their own. Individuals who take learning new technological skills upon themselves are supportive towards the usefulness beliefs of these respondents being correlated to usage intentions. Furthermore, these results are also supportive to the correlation between perceived usefulness and the acceptance of new technologies (Davis, 1989) within the sheet metal trade. 


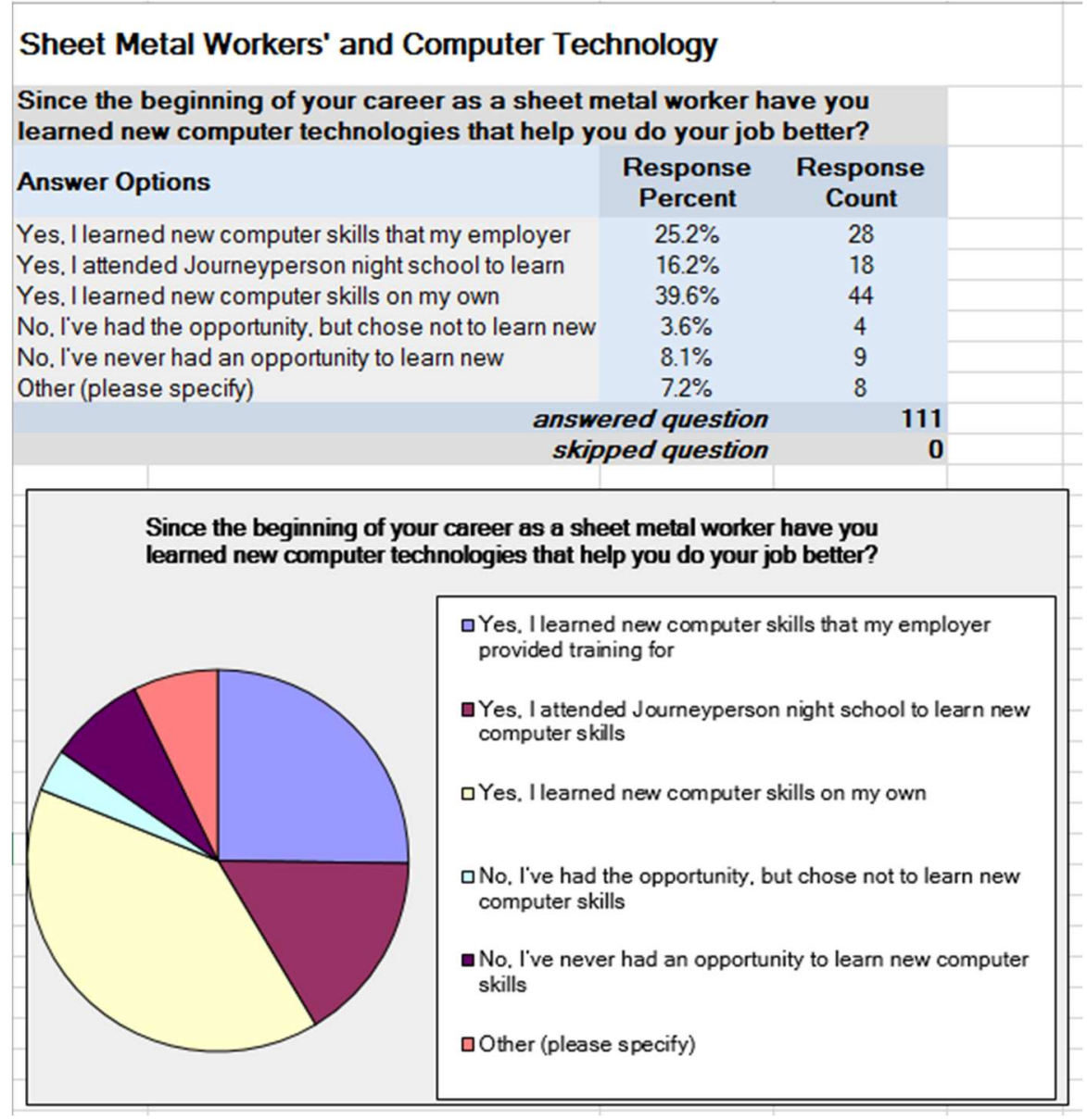

Figure 7: Question 6 SurveyMonkey Results Chart

Question 7 asked respondents how they would feel if their work as a sheet metal worker changed to the point where they were required to learn new CT. Fifty-four respondents $(48.6 \%)$ answered that they felt very positive about such a situation and that each was not worried about such a prospect due to their perceived self-confidence towards their skill sets with using CT.

Forty respondents (36\%) answered that they were somewhat positive about such a prospect and, while each felt that they were not overly adept at CT, they answered that they had confidence in their abilities to learn any required CT. Twelve respondents $(10.8 \%)$ answered that their feelings were irrelevant to the proposition. These respondents answered that should such a scenario, the 
requirement to learn new $\mathrm{CT}$ to perform one's work, were to occur that regardless of their personal feelings on the matter they would simply have to do what was required. Three respondents $(2.7 \%)$ responded that each felt somewhat negative about such a prospect. These respondents answered that while they have in the past operated a computer, they each had moments of frustration while doing so. Two respondents (1.8\%) chose the "Other" option. These responses will be detailed below. Finally, none of the respondents had very negative feelings about the prospect of having to learn new CT.

The details of the respondents that chose the "Other" option are as follows:

1. "Any change in the workforce affects every single member and their families."

2. "I can learn whatever I need to learn, but these opportunities in house have gone to the younger workers and not available at the local training level, again putting the mature seasoned workers out of work."

The response to point 2 demonstrates some negativity but, also that the respondent also will learn skills as deemed necessary. Therefore, this is added to the fourth preselect answer, somewhat negative, which causes its response count to rise from 3 to 4 and its response rate to be 3.6\%. The response in Point 1 does not clearly fit into any category of preselect answers and therefore it is not added to any of these.

The responses that were given in the survey on question 7 are also supportive of portions of the literature that I cited which centers on technology adoption. One of which is in the responses to question 7 . There the respondents were overwhelmingly positive, 94 of 111 or $84.7 \%$, (including "very positive" and "somewhat positive") regarding their feelings regarding learning new CTs. Here it is helpful to be reminded of the culture of SMART and its 
longstanding commitment to apprenticeship. The culture of SMART is one where learning the trade is expected and most rank-and-file members serve an apprenticeship before earning their journeypersons rank. This adds support to the conclusions that culture moderates technology adoption (Kappos \& Rivard, 2008). Namely, the respondent's positive feeling towards learning new technology demonstrates this. Additionally, the responses also portend well for SMART with this demonstrating positive feelings of these respondents" "individual's evaluation about the individual and organizational capacity for making a successful change, the need for change, and the benefits the organization and its members may gain from change" (Choi \& Ruona, 2011, p. $51)$.

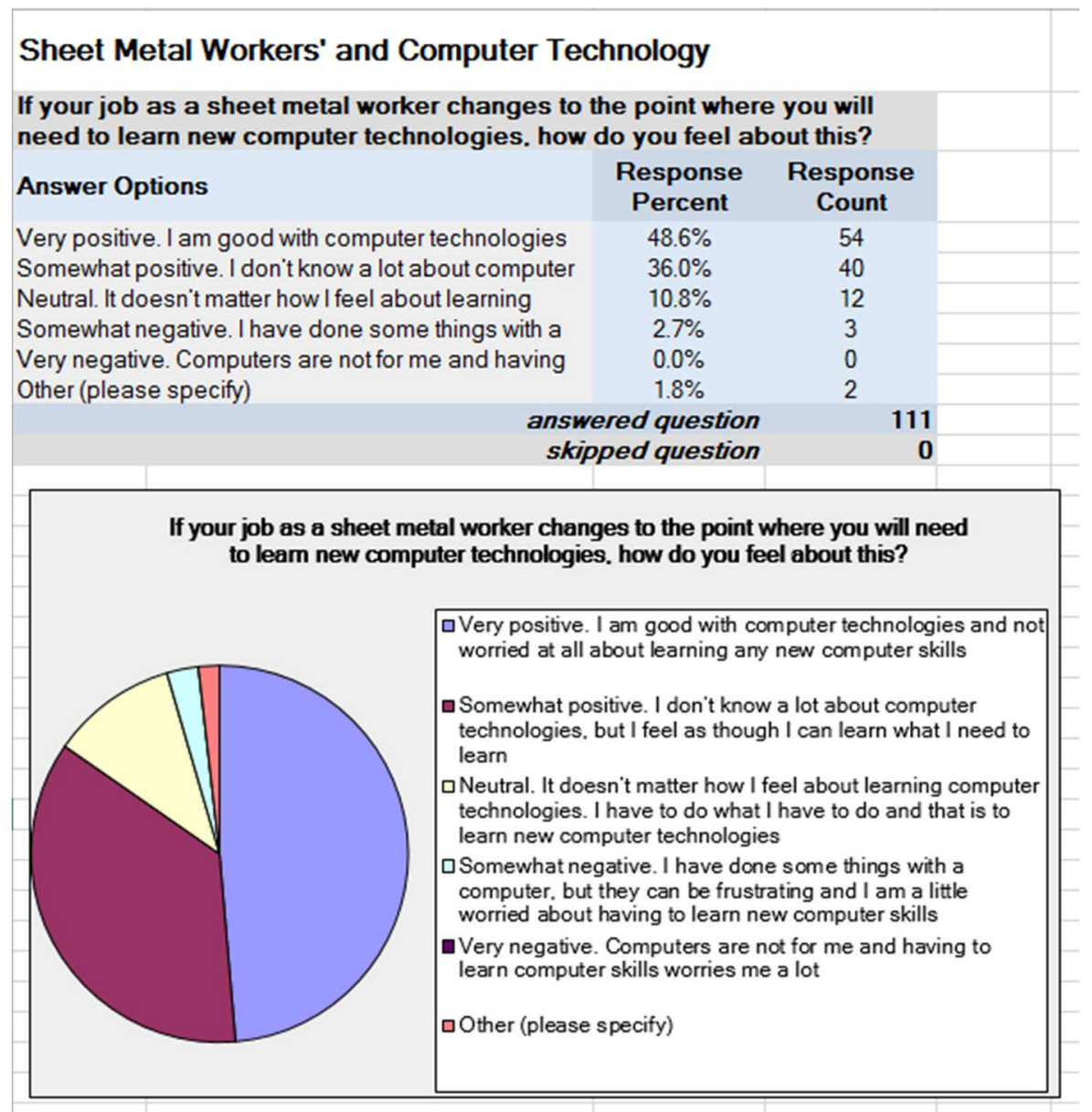

Figure 8: Question 7 SurveyMonkey Results Chart 
Question 8 asked how the respondents felt about the impact CT would have on the overall numbers of jobs available to each respondent's local union's members. Forty-six respondents (41.4\%) answered that CT had somewhat of an impact and this resulted in many jobs that were once available to each's respective local union's members are now no longer available. Thirty-seven respondents $(33.3 \%)$ answered that $\mathrm{CT}$ will have a minimal impact upon the overall numbers of jobs available to each respondent's local union's members. Twelve respondents (10.8\%) answered that CT has a large impact upon the overall number of jobs available to each respondent's local union's members. Ten respondents $(9 \%)$ answered that they felt that while CT will have an impact, which may indeed be a large impact, upon the overall numbers of jobs available to each respondent's local union's members, that the results will not be a net loss of jobs as the new jobs will be filled by members who are newly trained to perform this work. Four respondents (3.6\%) answered that they felt that there would be no impact upon the overall numbers of jobs that are available to each respondent's local union's members. Two respondents $(1.8 \%)$ chose the "Other" option. Finally, none of the respondents felt that there would be a catastrophic impact upon the number of jobs available to their local union's members.

The details of those respondents that chose the "Other" option are as follows:

1. "The choice just above this is truly my best choice to this answer. But my $50+$ years in the trade, $25+$ of which was as a JATC instructor, tells me that convincing my journeyman brothers on re-training is a "really" tough sell."

2. "Programs can't climb ladders and run machines yet." 
The response in point 1 does not suggest any correlation to any of the preselect answers. Therefore, it is not added to any preselect category. The response in point 2 suggests that at this point in history CT has no impact as the physical work required to be performed in the field is such that CT cannot perform it. Therefore, this response is categorized with the first preselect answer, no impact, which causes its response count to rise from 4 to 5 and its response rate to rise to $4.5 \%$. Here too the results do show that the respondents do feel as though CT will devalue or make obsolete the skills of a sheet metal worker. The positive take on this, though, is that coupled with the response from question 7 the results of the survey show that the respondents do see skills devaluation/obsolescence, but they feel ready to change and as a majority feel positive moving forward with change.

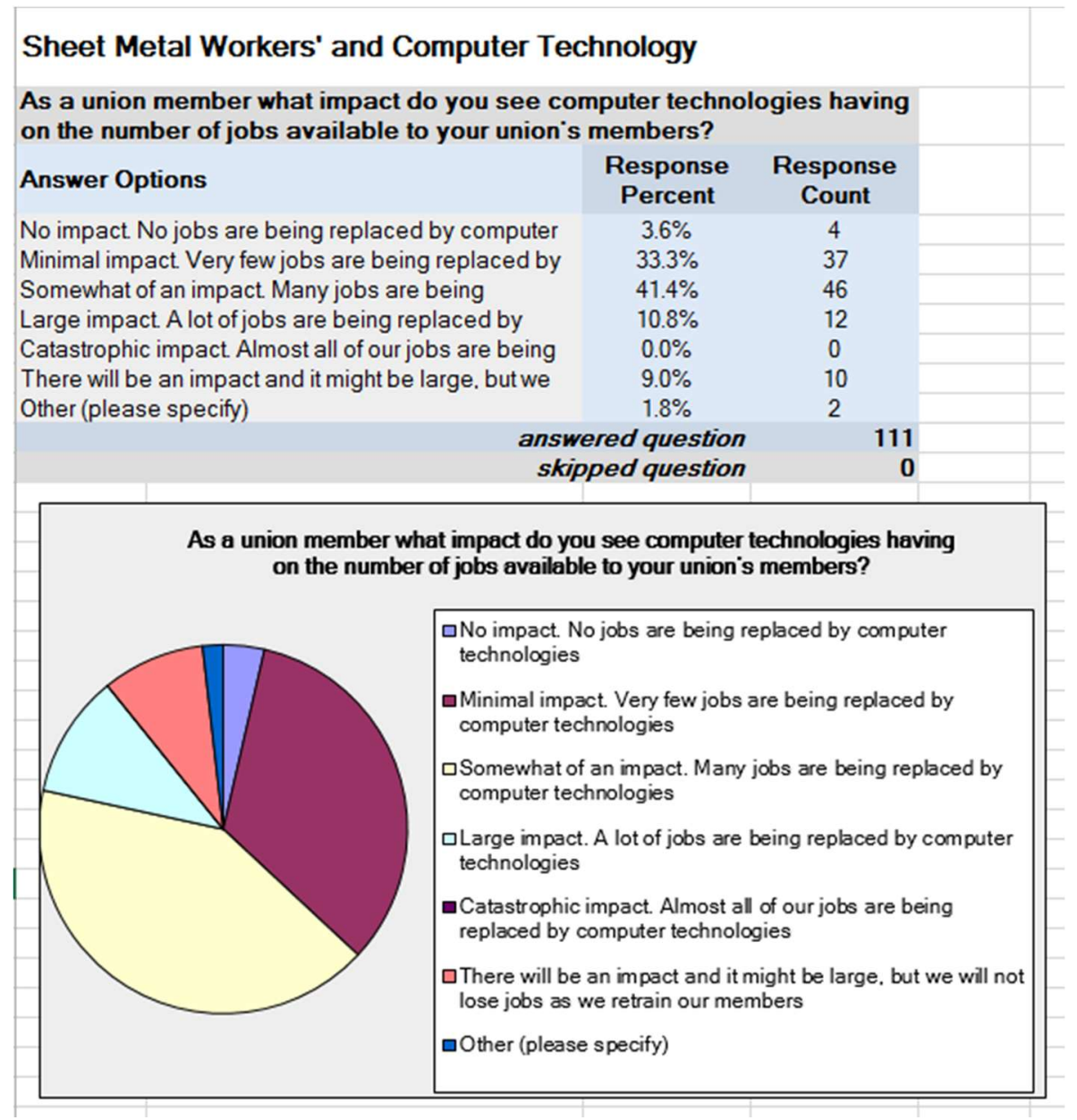


Figure 9: Question 8 SurveyMonkey Results Chart

Question 9 asked respondents how they felt CT's impact on jobs in the sheet metal industry had affected each respondent's personal life; the results were mixed. Forty-three respondents (38.7\%) answered that they felt very positive about their life and their respective futures. These respondents answered that they felt that they each possessed or will possess the skills that are, or will be, in high demand within the sheet metal industry. Thirty-one respondents (27.9\%) answered that they were somewhat positive about their respective lives and futures. Like the largest group of respondents, these respondents felt that they have, or will have, the skills that are, or will be, in high demand within the sheet metal industry, but these respondents tempered this optimism with concern that these skills may become soon outdated and no longer in high demand. Twenty-four respondents (21.6\%) answered that they were neither positive nor negative about their lives and future as it pertained to CT's impact upon the jobs prospects within the sheet metal industry. This group of respondents felt that they would make do regardless of any impact CT may cause upon available jobs within the sheet metal industry. Six respondents (5.4\%) chose the "Other" option. One respondent (0.9\%) felt very negative about their lives and futures and answered that he or she was very worried as to whether he or she would be employable in the future. The respondents was concerned that they would not be able to learn any new CT skills that would be required to perform work tasks within the sheet metal industry.

The details of the responses by those respondents who chose the "Other" option are as follows:

1. "As jobs are eliminated by technology so shrinks the workforce."

2. "Retire no comment." 
3. "Computer / cad / detailing skills kept me working for many years, now I am looked at as a one company office man, and my field and foreman skills are overlooked making my last years as a sheet metal worker. Very stressful and questionable"

4. "As a retired SMW, I believe that the computer skills I learned made me a much more employable journeyman than I would have been without those skills."

5. "Negative - It's not learning new skills that worries me, it is age for me personally, and outdated, uninformed and uneducated leadership by Union officials."

6. "I worked mostly in small shops and they're the last to get high-tech tools."

The responses found in Points 1,2 and 6 do not address the question and therefore they cannot be added to any preselect category. The responses found in Point 4 demonstrates a high level of positivity but, the response is from a retired sheet metal worker and therefore, the preselect answers do not fit well. However, the response does state "computer skills I learned made me a much more employable journeyman" and therefore this correlates well with the first preselected answer. This is therefore added to that category which causes that response count to rise from 43 to 44 and the response rate to rise to $39.6 \%$. The responses in Points 3 and 5 express negativity but not extreme negativity and therefore they are both added to the fourth preselect category of somewhat negative. This causes the response count for that category to rise from 6 to 8 and its response rate to rise to $7.2 \%$.

Relating the results of question 9 to the cited literature, the results again show a readiness for change from the respondents. Question 9 looked into how the respondent felt about their 
personal life as it may have been impacted by CTs. The majority of respondents, 75 of 111 or $67.6 \%$, felt as though their personal lives have a positive outlook and do not feel as though CT's impact will be too great upon their personal lives. This also lends credence to the literature cited on readiness for change.

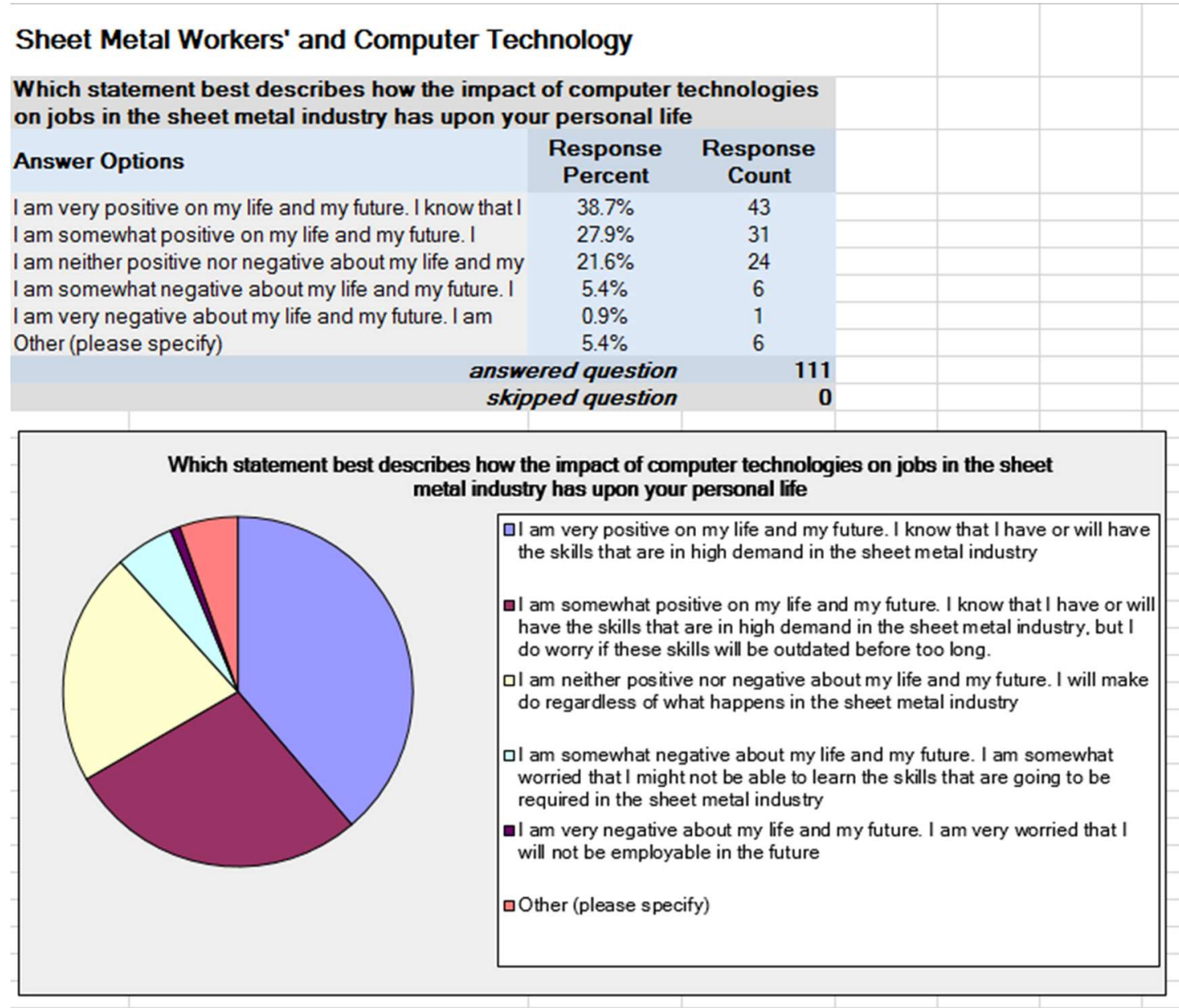

Figure 10: Question 9 SurveyMonkey Results Chart

Question 10 asked respondents how they personally adapted to changes brought upon the sheet metal industry by CT. Eighty-three respondents $(74.8 \%)$ answered that each would simply 
learn any new CT skills on an as-needed basis. Seventeen respondents (15.3\%) answered that each was respectively attempting to get ahead of the technology curve by attending new training in the present. Seven respondents (6.3\%) chose the "Other" option. Three respondents $(2.7 \%)$ answered that each will choose to do nothing to adapt to changes that CT may bring to the sheet metal industry. One respondent $(0.9 \%)$ answered that he or she would leave the sheet metal industry and find work within a different industry altogether.

The respondents who chose the "Other" option are as follows:

1. "Have not been expected to use any."

2. "As a retiree I have witnessed how promises of wage classifications and technology have promised sustainable markets, neither has worked."

3. "Retire."

4. "We need more specific program training at the local level such as solid works, BIM, and others, not just cad classes, to continue advancing our working skills."

5. “As a retired SMW this question really doesn't apply to me. However, I do believe that the closer a journeyman is to emerging technologies, the more employable he is."

6. "I am looking for new technologies to bring into the sheet metal industry."

7. "I've already left the industry and work in a high tech computer driven field in wireless communication."

The responses in Points 1, 2, 3, 4, 5 and 6 are all unrelated to the posed question and therefore they cannot be added to any preselected category. The response in Point 7 can clearly 
be associated with the second preselect answer, leaving the sheet metal industry, and is therefore added to it. This causes that category's response count to rise from 1 to 2 and its response rate to rise to $1.8 \%$. The responses to question 10 also add support to some of the points in the cited literature. Here too perceived usefulness (Agarwal \& Prasad, 1999) can be correlated with the responses of learning new skills when they are needed and learning new skills to stay ahead of the technology curve.

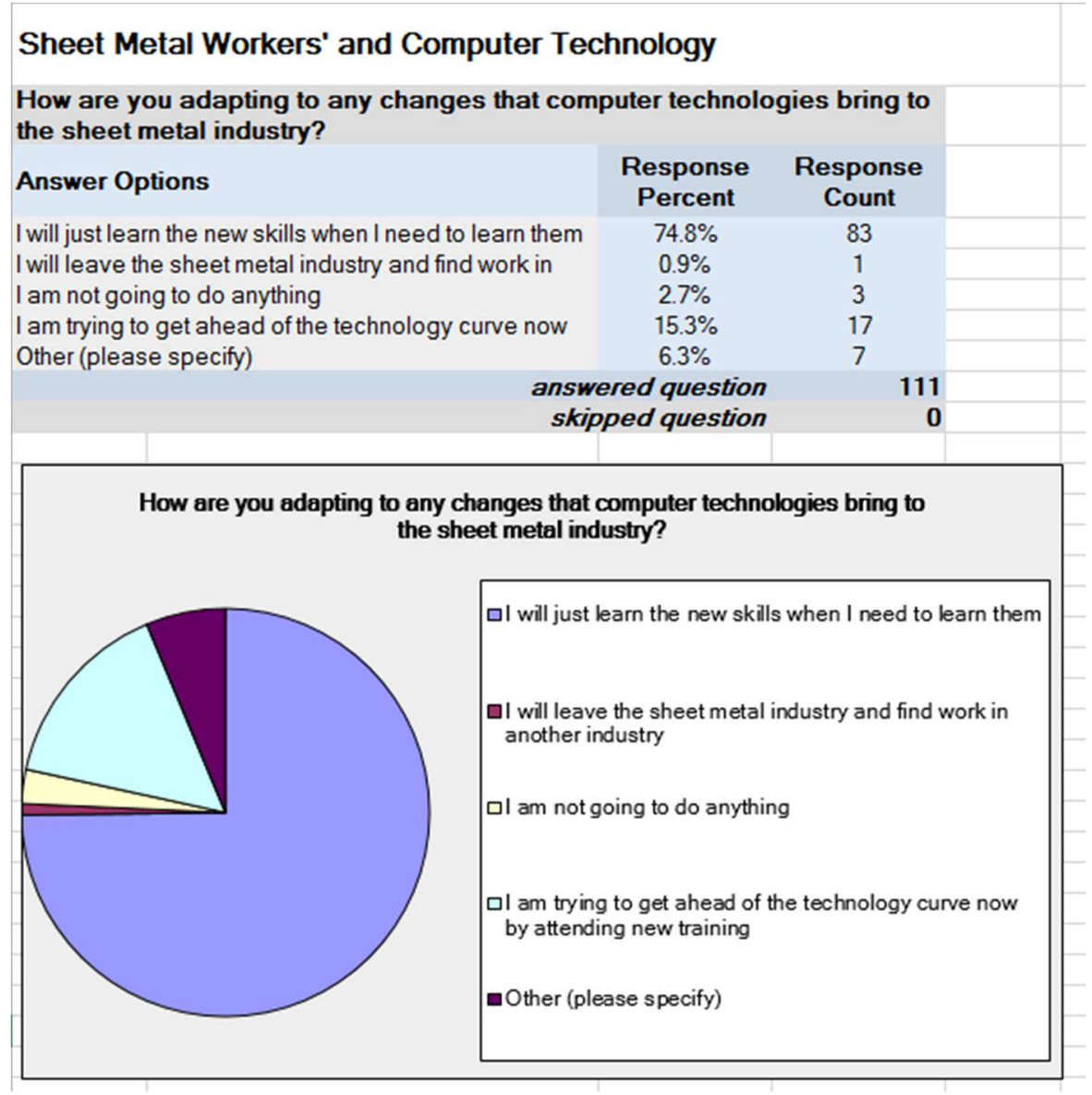

Figure 11: Question 10 SurveyMonkey Results Chart 
Question 11 asked respondents what their expectations were for how their respective union's leadership's response should be towards CT. Forty-four respondents (39.6\%) answered that they expected their respective union's leadership should embrace CT and work to ensure that any new work created by CT would be covered employment within that union's CBA. Fortythree respondents (38.7\%) answered that they felt that their respective local unions must embrace CT regardless of any consequences to the union itself. These saw change as constant and that their respective unions needed to adapt to any changes within the sheet metal industry so as to ensure that their union's members remained relevant in the sheet metal industry. Nineteen respondents (17.1\%) answered that their union's leadership should embrace CT, but that the leadership should attempt to manage CT's implementation into the industry. These respondents felt that implementing CT into the sheet metal industry too quickly would have a negative impact upon the union's members. Three respondents $(2.7 \%)$ answered that they felt that their union's leadership must fight against CT's implementation into the sheet metal industry. These respondents answered that they felt it was the job of their respective union's leadership to fight for the jobs of the membership of each respective local union. Two respondents $(1.8 \%)$ chose the "Other" option. The details of these responses are as follows:

1. "Answer 4 along with proper and available training for and with our contractors, however this can be difficult as diversified as our contractors work can be."

2. "Our leadership must embrace the new technology and make sure training is available to our members to stay ahead of the change."

Both responses in Points 1 and 2 express that the union's leadership take an embracing position as it relates to CT. Point 2 is less clear, but it does suggest that the work created by CT be such that it is work that is covered by the union agreement. Therefore, both of these answers 
are added to the fourth preselect answer, which is for the union to embrace the technology and that it is covered employment. This causes that answers response count to rise from 44 to 46 and its response rate to rise to $41.1 \%$. The responses to question 11 demonstrate a readiness for change with 108 or 111 or $97.3 \%$ of the respondents feeling that the SMART leadership should or must embrace CTs.

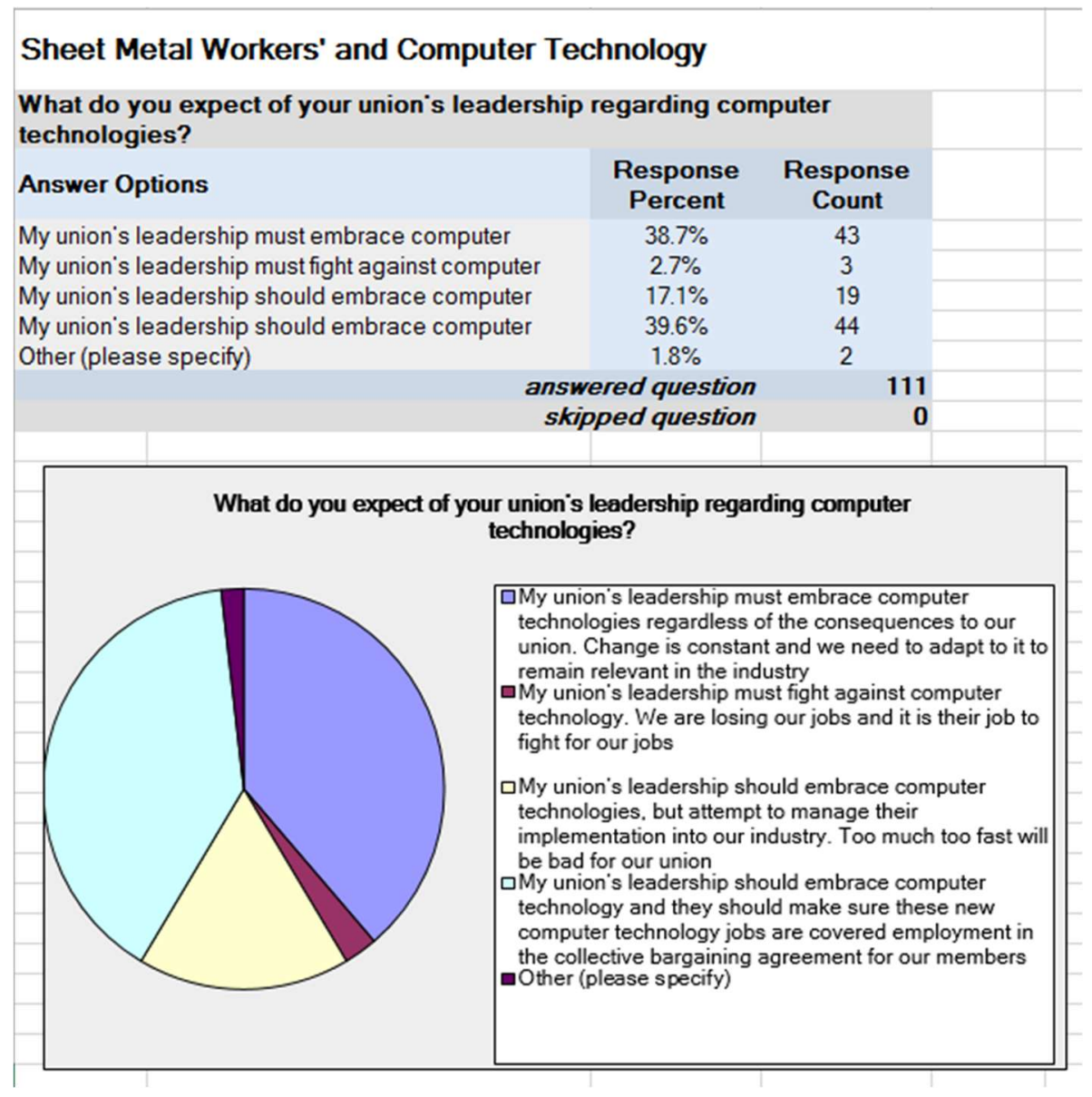

Figure 12: Question 11 SurveyMonkey Results Chart

Question 12 asked respondents their thoughts about CT's impact upon the construction industry as a whole. Fifty respondents (45\%) felt that while some changes will be brought to the 
construction industry as a whole by $\mathrm{CT}$, that they foresaw that there would always be a need of a lot of workers to perform tasks that cannot be done by CT. Thirty respondents $(27 \%)$ answered that CT will cause a few changes to the construction industry as a whole, but that CT was limited in what tasks that it could be used to perform. Sixteen respondents $(14.4 \%)$ answered that while CT may indeed cause large changes to the work that is to be performed within the construction industry in the future, that, overall, jobs would not be lost as workers will be trained to perform the work that CT creates within the construction industry. Six respondents $(5.4 \%)$ answered that they felt no changes would occur to the construction industry. These respondents felt that the means and methods of constructing buildings have remained constant for a long period of time and that this would not change in the future. Five respondents $(4.5 \%)$ chose the "Other" option. This will be detailed below. Four respondents (3.6\%) felt that CT would have a huge impact upon the construction industry. These respondents felt that almost all of the tasks that are done to construct an edifice could be done using CT.

The details of the responses of those respondents that chose the "Other" option are as follows:

1. "Our union has survived for over 100 years because we adapt to change and set new standards for our industry."

2. "Computer technology has been affecting construction more and more since the 90's? And will continue, from design, coordination, shop work, logistics, etc. and will continue to find its way into more areas of construction (tooling, materials) etc. but I think labor will continue to be the backbone of construction and a well trained workforce is the backbone of our unions." 
3. "The choice just above this is truly my best choice to this answer. But my $50+$ years in the trade, $25+$ of which was as a JATC instructor, tells me that convincing my journeyman brothers on re-training is a "really" tough sell."

4. "I remember when plasma technology took the place of 4 to 5 "cutters" or lay out men in the shop, this same technology also enhanced our ability to provide a new product line for our employers and helped us prepare for BIM by learning the computerized 2D type of layout. Things are bound to change in the future, we can learn to adapt as we will always need the "human" touch in our industry to direct this industries technology. Just as with the first plasma table we started using them to enhance our productivity by making them perform outside of their designed parameters (think Cybermation)."

5. "As technology increases, so does productivity which reduces man hours. We must adapt to the change or we will die, but inevitably, traditional man hours will decrease."

The responses in Points 1, 2, 4 and 5 all suggest that some changes will occur in the construction industry as a whole but, that there will always be a need for the individual worker to perform some work. Therefore, these four answers all fit into the third preselect answer which causes its response count to rise from 50 to 53 and its response rate to rise to $47.7 \%$. The response in Point 3 is undeterminable as how it relates to the question and therefore it cannot be added to any category of answer. Here the respondents were asked to express their thoughts and feelings regarding CT's impact upon the whole of the construction industry and the results also demonstrate the respondent's feelings that skills in the whole of the construction industry will be devalued or, at least somewhat, made obsolete. 
Sheet Metal Workers' and Computer Technology

What future do you see regarding the impact computer technologies will have upon the construction industry as a whole?

Answer Options

No changes will occur in the construction industry. We A few changes will occur in the construction industry.

Some changes will occur in the construction industry. Huge changes will occur in the construction industry.

Changes will occur. and they may be big. but jobs will Other (please specify)

$\begin{array}{cc}\begin{array}{c}\text { Response } \\ \text { Percent }\end{array} & \begin{array}{c}\text { Respons } \\ \text { Count }\end{array} \\ 5.4 \% & 6 \\ 27.0 \% & 30 \\ 45.0 \% & 50 \\ 3.6 \% & 4 \\ 14.4 \% & 16 \\ 4.5 \% & 5\end{array}$

answered question skipped question 
$(\mathrm{BIC} 4560.502, \mathrm{LMR}-\mathrm{LTR}=108.695, \mathrm{p}=.3372$, entropy $=.902)$. These results suggest that the two-class solution contains the best model fit for this study.

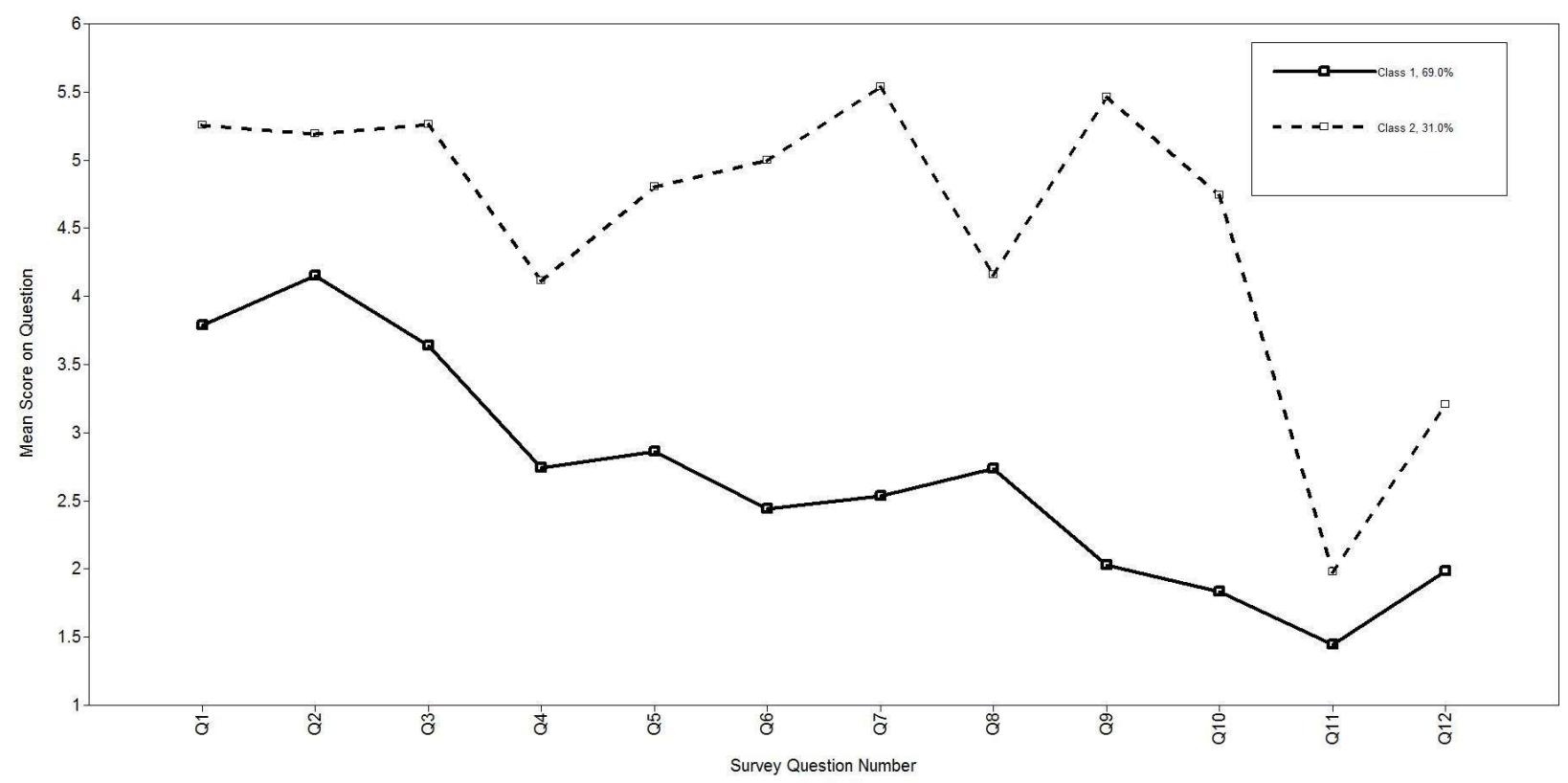

Figure 14. Mean Score of Negative Impact of Technology among Sheet Metal Workers (N =111)

As shown in Figure 14, the low negative impact latent class (class 1) accounted for 69\% $(n=77)$ of the sample and were composed of sheet metal workers who possessed lower mean scores on their ratings of the negative impact of technology compared to those in the high negative impact latent class (class 2$)$, which accounted for $31 \%(n=34)$ of the sample.

LCA of the sheet metal workers' responses had two latent classes, class 1 and class 2 , which consists of $69 \%$ and $31 \%$ of the sample, respectively. For all 12 items in the survey, a lower score on the scale indicates a lower impact of computer technology and a higher score indicates a higher impact of computer technology in different contexts. The survey items quantified the impact of technology, as well as quantified the feelings of the sheet metal worker toward the increasing presence of computer technology at work. 
For items 1 and 2, respondents were asked to rate the current impact of computer technology on their own job. For latent class 1, the estimated mean score of 4.2 is lower than for class 2, which had an estimated mean score of 5.2. For item 4, respondents rated the future impact of technology on their own job. Similar to item 1, class 1, has a lower estimated mean score of 2.7 than class 2 , which had a mean score of 4.1. For item 12, respondents rated the future impact of technology on the whole construction industry. Similar to items 2 and 4, class 1 has a lower mean score of 2.0 compared to class 2 , which had a mean score of 3.2 .

Taken together, these results suggest that compared to class 1, class 2 respondents thought technology will have a higher negative impact as it could potentially replace most or all of their jobs. This is applicable for both current and future times when including the whole construction industry. Class 2 respondents can be considered as potentially resistant to change, whereas class 1 respondents are more ready for change.

Item 8 measures how respondents think technology will affect the number of jobs available for union workers. A lower score indicates less impact and no loss of jobs while a higher score indicates a larger impact due to higher loss of jobs. Class 1 have a lower mean score of 2.7, while class 2 have a higher mean score of 4.2 indicating that class 2 think more jobs will be lost._This is in sync with their responses to impact of technology on their own job in current and future time as well as construction industry as a whole. Item 11 is directed towards understanding how respondents expect their union leadership to react to computer technologies in terms of embracing or rejecting it and how. Class 2 employees have a mean score of 2.0 indicating a higher tendency to expect unions to fight against computer technology. 
Item 3 and item 5 are targeted toward knowing how respondents feel about relevance of their current non-technical skills, and how they anticipate these same skills changing with increased adoption of computer technologies in their industry respectively.

For item 3, class 1 respondents have an estimated mean score of 3.6 and class 2 respondents have higher estimate score of 5.3. The lower score for class 1 indicates that computer technology has a lower impact and their own non-technical skills are relevant to their respective industry. On the other hand, a higher score for class 2 indicates that computer technology has a higher negative impact on their jobs making their own skills obsolete.

For item 5, class 1 respondents have an estimate score of 2.9, which is much lower than the estimate mean score of 4.8 for class 2 respondents. Class 1 respondents who believe that technology will have lower impact and their non-technical skills are relevant have also taken a neutral stance towards the future effect of technology on their own skills, as computer skills are irrelevant to their own job. On the other hand, class 2 respondents who believe technology will have a higher impact on their current non-technical skills also believe that their skills will completely change and they have to learn computer technology skills for their job.

Items 6 and 7 further explore on the topic of computer technology skills. In item 6 , respondents answer whether they have learned any new skills. It further delves into the mode of learning these new skills. Class 1 respondents have a lower score of 2.4 compared to Class 2 score of 5.0 indicating that unlike class 2, class 1 respondents have learned new skills.

Item 7 questions respondents on their feeling about learning new technology skills when they have to. Class 1 respondents have a lower estimate mean score of 2.5 compared to class 2 respondents mean score of 5.5. Thus, class 1 has a somewhat positive to neutral approach 
towards learning technology. They acknowledge current lack of technical knowledge but are fairly confident about learning them. On the other hand, class 2 respondents have a negative attitude towards learning new technology. They believe that learning these skills can be frustrating and they are little worried about learning them.

Item 10 in the survey further delves into topic of skills. Item 7 checks on the feelings of the respondents about having to learn new technologies and item 10 on ways they are responding to changes computer technology is bringing. Class 1 and 2 have an estimate mean score of 1.8 and 4.7 on item 10 respectively. This means class 1 are actively learning or will learn new computer technology skills. On the other hand, class 2 score indicates their intention to either not learn or leave the industry itself.

To summarize to the topic of skills, class 1 respondents are more confident about their own current non-technical skills and believe that their own skills would not change drastically with time. The same class of respondents did make an effort to learn new technology and have a somewhat positive approach to learning them in future.

Class 2 respondents are not as confident about their current skills and expect a major change in skill set required for their current job. However, as much as they are cognizant about having to upgrade their skills, they have not taken steps towards changing this and are worried about learning new skills in future. Class 2 is also the same set of respondents who expect technology will lead to greater loss of jobs in future as per item 1.

Item 9 asks respondents to rate the impact of technology on their own personal life. Class 1 has a lower mean score of 2.0 while class 2 has a mean score of 5.5. Class 1 respondents display positive outlooks towards life and future. They believe their current skills are in demand 
and show a hint of skepticism that these skills my get outdated. Class 2 have a negative outlook to life and future and are worried about their future employability.

To conclude, latent profile analysis of sheet metal worker's data reveals a clear pattern on how two classes have emerged with distinct characteristics based on their responses. Class 1, which, again, consists of $69 \%$ of the respondents, displays characteristics of being optimistic about impact and effect on technology on number of jobs as well as changing skills. They do not think technology will replace jobs. They also think their own non-technical skills are relevant and display a positive attitude towards life and future. At the same time, they display a practical approach to changing times by actively learning new skills and displaying a positive attitude towards learning them in future. Class 1 emerges as the ("Progressive) "Acceptors" of change. They do not look at technology as an evil entity waiting to snatch away their jobs. They believe that with changing times, they can upgrade their skills and keep themselves relevant in the industry in future.

On the other hand, Class 2 , which, again, consists of $31 \%$ of the respondents, consistently display a higher score on impact of technology indicating that they believe that technology will lead to losses of jobs. They are worried about their future and seem pessimistic about their personal life and future. One would expect these set of employees to be ready to learn new skills. However, a different pattern emerges. As much as these set of people are expecting change, they do not want to do anything about it or are worried about learning new skills. Their biggest fear seems to be fear of coming obsolete. They are "resisters" of change and would rather want their union leadership to maintain status quo by fighting increased use of computer technology at work. Lastly, there was no apparent crossover of respondents between classes. 


\section{Qualitative Research Findings}

\section{$\underline{\text { Introduction }}$}

Automation and CTs have altered the work experiences for the blue-collar worker including abstraction of work, skills devaluation, and skills obsolescence on a global scale. Having a grasp of the global impact of this phenomenon will enable the reader to better understand the results of the quantitative portion of my research. Specifically, it is best to see a larger picture as to what automation has meant for work and workers' experiences in the larger global context. Indeed, the effects of automation have had a global impact that has reached all industrialized economies and, consequently, those workers who are employed within them. Understanding this impact upon such workers from industrial economies will help to clarify the picture that the sheet metal worker finds his or herself vying for employment within. To demonstrate the reach of this phenomenon within industrialized economies, internet searches for examples of where such technology has affected the work and work experiences was conducted and the results of those searches are as follows. To repeat from earlier, for these searches I entered into a Google search using key words and phrases, such as "work and automation" and "workers experiencing work differently due to automation."

\section{$\underline{\text { Results of Qualitative Findings }}$}

A search of the internet will yield numerous examples to draw from which to demonstrate the phenomena of the abstraction of work, deskilling and skills obsolescence, and the need for higher skill sets, and many examples were detailed in the literature review of this particular research. In the Wall Street Journal (WSJ) article, "What Clever Robots Mean for Jobs" (Aeppel, 2017), economist Erik Brynjolfsson rethought his position that automation would not devour jobs. The article goes on to detail the growing debate about the impacts of automation upon work 
and offers several pertinent charts. One of which shows that, in part, due to automation, there is "more work" and "less labor."

\section{More Work, Less Labor}

In the post-war economy, U.S. productivity and jobs grew roughly in tandem until 2000. Economists account for the change because of globalization and new automation, which allows the economy to produce more goods with fewer workers.

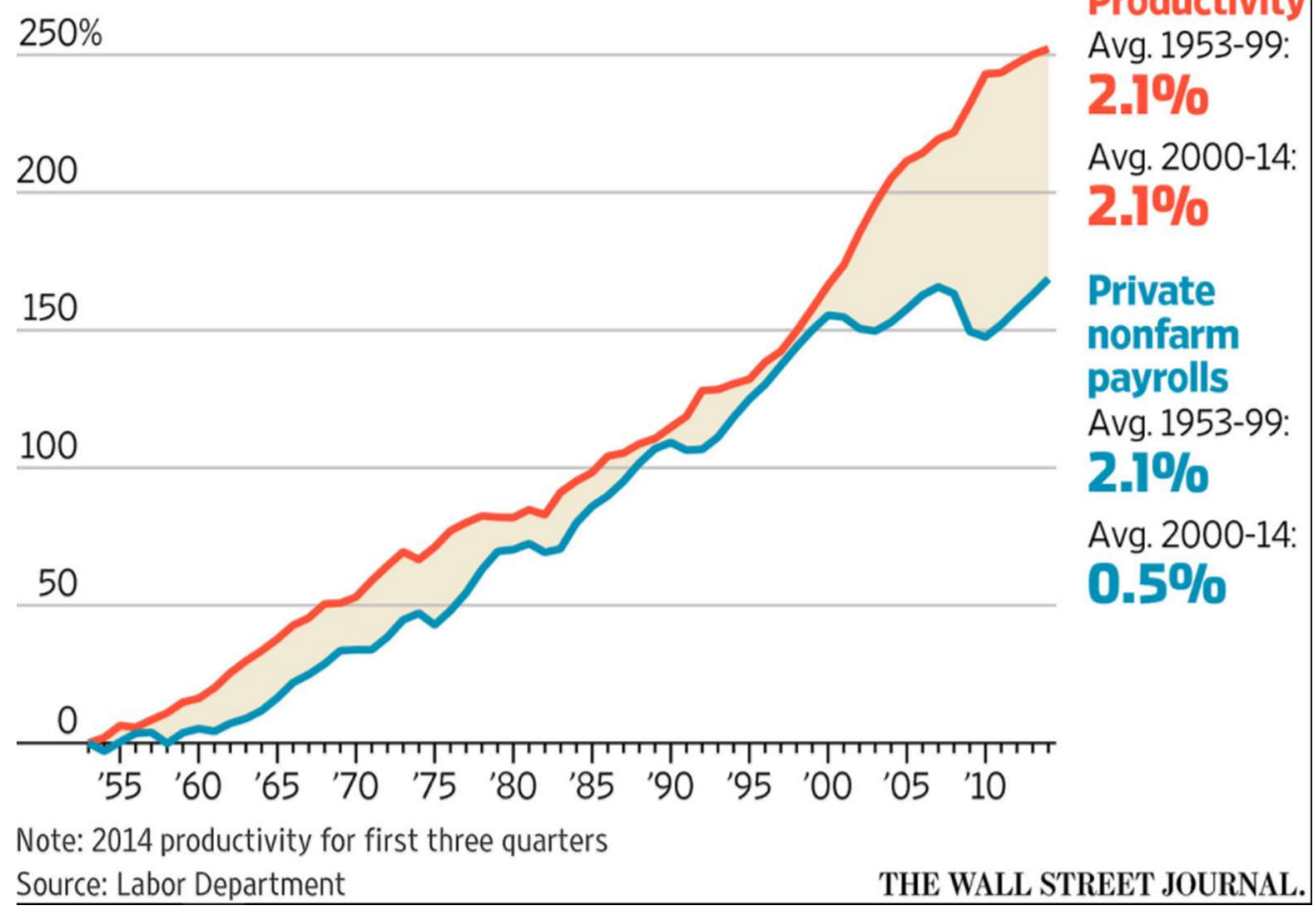

Figure 15: Wall Street Journal Article Chart

Furthermore, the WSJ article also shows a chart, which details the number of robot installations on a global scale. 


\section{Adding Machines}

World-wide industrial robot installations

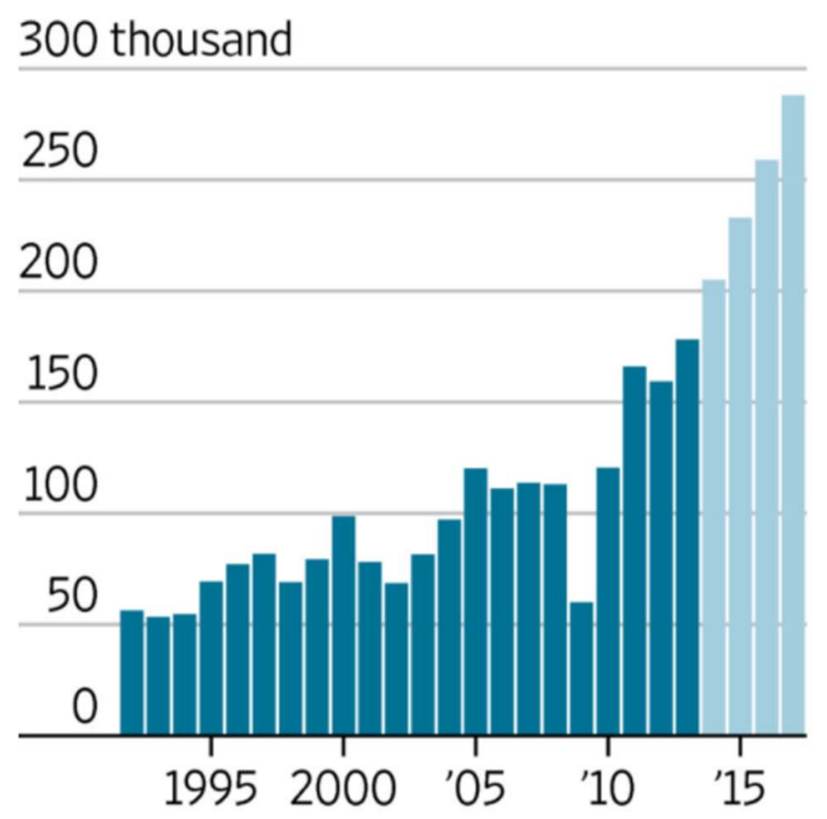

Note: 2014 and later are projections.

Source: International Federation of Robotics

THE WALL STREET JOURNAL.

Figure 16: Wall Street Journal Chart

The evidence detailed in the Wall Street Journal article does in fact demonstrate the rise of automation globally and the resultant implications this has for productivity and for jobs as a whole. While this does not intrinsically demonstrate abstraction of work, deskilling, or skills obsolescence of human labor, it does provide a foundation where these can be explored. Indeed, if the utilization of automation is a growing phenomenon and if this phenomenon necessarily results in fewer jobs then it is reasonable to explore what value these phenomena have upon work abstraction, skills devaluing, and skills obsolescence. 
While increased usage of automated and computerized technologies demonstrates the phenomenological occurrence of the abstraction of work, there is another derived implication, which has not yet been discussed. Specifically, not only does the worker now have to understand computer symbols as Zuboff asserts, but implicit to the abstraction of work is an implication of responsibility for the blue-collar worker, which may have been previously unknown by him or her. The authors of The Changing Nature of Work: Implications for Occupational Analysis (National Research Council, 1999) discuss how the role of blue collar workers, who were once presumed to be managed, has now changed so as to include these workers in the "decisionmaking tasks" (p. 109). Furthermore, a central argument from those authors is:

That blue-collar work structures are changing because the highly specialized division of labor that supported cost minimization in mass production is no longer compatible with current markets. Under the logic of mass production, which emphasized quantity over quality, work was divided into individualized, repetitive jobs that require low discretion and skill. Today's markets demand competitiveness on the basis of quality, innovation, and customization (Piore \& Sabel, 1984;

Where the authors assert that their "understanding of blue-collar work builds on research concerning the adoption of 'high-involvement' or 'high-performance' work systems" (p. 109), they further argue:

Under the logic of high-involvement systems, quality and innovation result from work designed to utilize high skills, discretion, and the participation of front line workers in operational decision making (p. 110)

Firstly, with the assertion that new blue-collar work requiring "discretion" the notion of abstraction of work is easily supported. If the blue-collar worker must now use individual personal discretion, the idea that the work experience, which once excluded such discretion and 
now requires discretion, it is reasonable to conclude that work has become abstracted. Secondly, an implication derived from discretion is the resultant responsibility implicit within it. This is to say that now work has changed to where cognitive value assessment and choice emerges. If work at one time precluded the notion of value assessment and choice and now is a requirement of work, the conclusion that the work experience has changed is easily supported. To elaborate, if the historical experience of a blue-collar worker is that decisions were made by a manager and precluded that worker from having to concern his or herself with such matters, then the change to work where decision making, and the implicit responsibility that is inherent to it, is now the purview of the blue-collar worker, this clearly creates a different experience for that worker. From this it can be concluded that for the worker of yore it seems logical to hold that when the pressures inherent to being responsible for the consequences of a work related decision are not part of the workers experience, that such a worker experienced, at least in one sense, a lesser degree of job related stress. The converse is also true. With automation altering work so as to cause that work to be abstracted and therefore require discretion and responsibility, the work of today's blue-collar worker has been changed thereby creating a new work experience and the resultant responsibility could create new area of job related stress for such workers.

Adding to the hypothesis that work has become abstracted is a New York Times article titled "Blue-Collar Jobs Gain, but the Work Changes in Tone" (Hershey Jr., 1997) where the author discusses the theme that work has changed to where work is "neither blue collar nor white collar but something in between" and that this work has been abstracted. The author writes:

Perhaps more telling, the very nature of blue-collar work is changing, moving away from the manufacturing assembly line to a whole range of other sectors that require workers to use their heads as well as their hands (Hershey Jr., 2016) 
Implicit within the statement that blue-collar worker's work has changed and now requires that worker to use his or her head as well as their hands is additional evidence that work has been abstracted. As was discussed previously, if blue-collar work now requires the worker to use his or her "head" to perform work tasks, that work has now become abstracted and for the worker who was not previously required to use his or her "head" to perform those work tasks, such a worker will now experiences their work differently. Furthermore, this abstraction of work skills necessarily implies that the worker's skills have been devalued since there are new requirements upon the skills that are now required. If a worker's previous skills are no longer adequate to perform a given work task and now that work task requires additional skills, the previous skills are, at least, deskilled because they are no longer adequate to perform a needed work task.

The last data point that is offered here related to the abstraction of work is a presentation by the Institute for the Future where the discussion centered on the changing nature of work. In that report, the authors wrote about ten skills required for the future. Among many other points, they concluded:

As smart machines take over rote, routine manufacturing and service jobs, there will be an increasing demand for the kinds of skills that machines are not good at. These are higher level thinking skills that cannot be codified. We call these sensemaking skills, skills that help us create unique insights into critical decision making (Davies, Fidler, \& Gorbis, 2011, p. 8).

Here too, the notion that work has been abstracted is supported. The ideas of "sense-making skills" and "critical decision making" necessarily mean that the worker must participate in a valuation process which is clearly an abstraction of such work. If the previous experience of a worker was one where the work skills did not required the worker to make sense of, or a 
valuation, his or her work, then the new requirements of sense making clearly demonstrates that the work requirements now require the intellectual capacities of the worker and are therefore abstracted. Furthermore and as will be argued later, implicit to the abstraction of work is that this necessarily means that past labor skills have been at least devalued.

Turning to the deskilling and/or skills obsolescence created by computerized and automated work technologies, here too apart from the literature review citations there are ample examples to draw from when an online search is performed. One such example is in the online article in the Harvard Business Review titled "What Happens to Society When Robots Replace Workers?" where the authors stated:

Technological progress has always displaced workers. But it also has created new opportunities for human employment, at an even a faster rate. This time, things may be very different - especially as the Internet of Things takes the human factor out of so many transactions and decisions

and that one of the "main byproducts is the replacement of workers with intelligent machines." They further stated:

If the Second Economy does achieve that rate of growth, it will be replacing the work of approximately 100 million workers. To put that number in perspective, the current total employed civilian labor force today is 146 million. A sizeable fraction of those replaced jobs will be made up by new ones in the Second Economy. But not all of them. Left behind may be as many as 40 million citizens of no economic value in the U.S alone. The dislocations will be profound (Davidow \& Malone, 2016).

Here it is clear and easily concluded that within this scenario that worker's skills are at least being deskilled and largely made obsolete. To elaborate, if a machine possessed equal skills as a human worker, it is reasonable to conclude that the skills of the human worker have been devalued as they no longer possess a competitive advantage over those of the machine. The 
scenario described within this article is such that the automated machines will possess a greater level of skills than of those possessed by the human worker. Thereby, clearly demonstrating the deskilling and skills obsolescence effect that automated technologies have upon human work. Therefore, this data is supportive of the hypothesis that computerized and automated technologies have devalued human labor and, consequently, the human worker finds a different experience with work.

Another article by The Atlantic offers further support of automated and computerized technologies deskilling and/or making human skills obsolete. In "A World Without Work," Thompson stated:

The U.S. Labor Force has been shaped by millennia of technological progress. Agricultural technology birthed the farming industry, the industrial revolution moved people into factories, and then globalization and automation moved them back out, giving rise to a nation of services. But throughout these reshufflings, the total number of jobs has always increased. What may be looming is something different: an era of technological unemployment, in which computer scientists and software engineers essentially invent us out of work, and the total number of jobs declines steadily and permanently (2016).

This is obviously supportive of the hypothesis that computerized and automated technologies are devaluing human labor and consequently, the human worker is experiencing work differently. If technologically induced unemployment is the effect, then it naturally follows that skills obsolescence is the cause. If a worker cannot find employment due to technology's inroads into the work once performed by human labor, then it logically follows that, assuming that productivity is the impetus, the human labor is not as valuable as the automated machinery. And if the machinery is more valuable than human labor, then the human labor skills have been either deskilled in that the machine can perform the same work skills or they have been rendered 
obsolete in that a machine possesses superior work skills. In either case, the human worker experiences work differently because of his or her need for different skills that are valued.

Implicit in the notion that the deskilling of human labor or skills obsolescence is the idea that a higher level of skills is demanded. If automated machines cause human skills to be obsolete or to be deskilled, then it logically follows that for the human being to be able to compete with automation, a higher level of work skill is required. Indeed, as is evidenced in all of the articles cited, no researcher foresees a future where absolutely no one will be working in the future and that those who are and will continue to find employment will possess a higher level of skills. This too is a cause for the blue-collar worker to experience work differently in that a higher level of skills requirements clearly implies that the human skill, or human labor, has been devalued.

In an online Business Insider article, Snyder (2012) wrote of a particularly gloomy outlook for blue-collar workers. He contended that "blue collar workers are becoming an 'endangered species' in the United States" (Snyder, 2012). Snyder further contended that "thanks to robotics, automation, and computers, there is simply not as much of a need for physical laborers anymore and nothing is going to reverse that trend." He stated that "if you are a blue collar worker in America, you are simply not valued" and "if you are an unskilled worker in America today, you simply are not needed. Yes, once upon a time nearly anyone could go out and get a factory job, but those days are over" (Snyder, 2012). Here, it is obvious that Snyder's article relates to the findings that I cited in the literature review related to skills devaluation and skills obsolescence. The statements that blue collar workers are not "valued" and "not needed" clearly demonstrate skills devaluation and skills obsolescence. If these workers possessed skills that were in demand, then it naturally follows that they would be valued by someone interested in employing those 
skills. While this example specifically addresses American blue-collar workers, coupled with the findings in the WSJ article, this applies to other industrialized economies as well.

Evidence of the global reach is an online article in City A.M. In that article, Bank of England's chief economist, Andrew Haldane, is quoted as saying that he "believes that millions of jobs will come under threat from automation over the coming decades, fueling unemployment and inequality," which was specifically addressed to a United Kingdom trades union conference. Haldane was further quoted saying that as machines improve "the greater the likelihood that the space remaining for uniquely-human skills could shrink further (Papadopoullos, 2016)" Furthermore, Haldane offered to the trades union conference that:

If these visions were to be realised, however futuristic this sounds, the labour market patterns of the past three centuries would shift to warp speed. If the option of skilling-up is no longer available, this increases the risk of large scale un- or under-employment. The wage premium for those occupying skilled positions could explode, further widening wage differentials. And labour's share of the pie could fall even more dramatically than in the past. On this view, the tree would be so thoroughly hollowed-out that it may no longer be able to support itself" (Papadopoullos, 2016).

Here too, this clearly is supportive of the cited literature as it relates to skills obsolescence and skills devaluation. However, in this article, Mr. Haldane is specifically addressing a possible future that he foresees that labor unions in the U.K. may be facing in the future. Mr. Haldane's statement about "labour's share of the pie" falling dramatically bodes ominously for U.K. unions and unions everywhere. In fact, with the reach of automation being global and with it deskilling and causing work skills to be obsolete, it seems that it would be wise for the SMART to at least plan now for such a changed economic reality.

In a Harvard Business Review online article, Davidow and Malone (2014) also wrote about automation's effects upon work and society. They opened with the following: 
The technologies of the past, by replacing human muscle, increased the value of human effort - and in the process drove rapid economic progress. Those of the future, by substituting for man's senses and brain, will accelerate that process-but at the risk of creating millions of citizens who are simply unable to contribute economically, and with greater damage to an already declining middle class. (Davidow \& Malone, Economics \& Society, 2014)

They conclude with "this is why we will soon be looking at hordes of citizens of zero economic value" (Davidow \& Malone, 2014). Their article continues with an argument, which attempts to demonstrate how robotics will continue to replace workers. This article also demonstrates the deskilling effects and skills obsolescence that automation has upon work and here too the authors strike an ominous tone towards blue-collar work in the future. Furthermore, the notion that automation will create "hordes of citizens with zero economic value" portends frighteningly.

In another online article by CBS News, the story is the same. Picchi (2016) citing a report from the World Economic Forum (WEF) states that by the year 2020 robots will replace over 5 million jobs. While the construction industry, pertinent to SMART, will lose jobs, according to that report, the majority of jobs lost will be in office and administrative jobs. The report continues by adding a quote from the WEF report stating "Instead it is critical that businesses take an active role in supporting their current workforces through re-training, that individuals take a proactive approach to their own lifelong learning" (Picchi, 2016) Here again this article offers testimonials that support the literature related to skills obsolescence and skills devaluation. The idea that re-training is a pathway that businesses take for their employees lends support to the idea that skills in the least will be devalued. For if a work skill was not devalued, then retraining would not be required.

Particularly pertinent to my specific research is the online article in The Our Great Minds (OGM) where Stephen Lamb discusses "the digital technological revolution and its impact on 
the construction industry" (Lamb, 2015). Mr. Lamb is a former executive vice-president of the Mechanical Contractors Association of Chicago, an association in the Chicago, Illinois market that represents contractors especially within the pipe fitting trades. Mr. Lamb writes:

For many years, construction was sort of exempted from this trend. But those days are gone. By using BIM and GPS we can now design and build materials far away from the job site and still install them within $1 / 10^{\text {th }}$ of an inch. As a result, contractors can experience the cost and safety advantages related to building much of a job in the shop. And, by building everything at the same fab shop the process can be mechanized to a much greater extent (think assembly line).

In short, we are going to become manufacturers of buildings rather than constructors. Yes, materials will still have to be assembled on the job site, but even that process will become more and more mechanized, to the point where most installation will be a commodity done by less expensive "assemblers".

So what does all that mean? I think it means that traditional construction companies are going to have to be in a position to buy serious amounts of technology, hire rooms full of BIM guys who have to be paid whether they are doing BIM or not, construct fab shops to pre-fab the majority of the work and be able to afford the overhead people to coordinate everything.

Mr. Lamb's insights are supportive of the deskilling and skills obsolescence effects that automation has which has been cited. For those people who are hired to "assemble" work on a construction site rather than be "constructors," the implication is clear; less skill is needed. And, specific to my research, with SMART also being a building trades union, knowing that the rankand-file member is ready to address and learn new skills that the construction industry is moving towards seems to demand a call to action by the SMART leadership.

In an opinion piece regarding automation, Loosemoor wrote:

Smart machines could replace as many as 40 million to 75 million jobs worldwide. Many areas of manual and professional work are already being displaced by rapid advances in affordable technology. Robots are being developed which can be taught and programmed by any regular worker to perform virtually any hand-eye coordination task and are already being trialled with tasks such as painting, laying bricks and laying pipes (Loosemore, 2016). 
He continued:

In the US, a robot called Baxter has been developed to handle a wide variety of manual tasks such as loading, unloading, sorting, and handling of materials. Designed to be low cost (around US\$20,000) and sold to the types of small companies which dominate the construction industry. (Loosemore, 2016)

While this is another example where automation is expected to deskill or make work skills obsolete, related to SMART, the inroads expected into the construction industry loom ominously. While Loosemoor's opinions are supportive of the studies cited in my literature review related to skills devaluation and skills obsolescence, Loosemoor opted to end his opinion piece on a positive thought:

Let's finish on a positive note and learn from history. Looking back to the industrial revolution, the evidence clearly shows that on balance, while some manual jobs and professions will be replaced by new technology, it will create more jobs than it will destroy by creating new alternative industries in knowledge intensive sectors that supply, manage and rely on this technology (Loosemore, 2016).

However, even here, the positive ending speaks loudly to skills devaluation and skills obsolescence. If the "new alternative industries" created will require skills that "supply, manage and rely on this technology," then it necessarily follows that what skills this technology replaced will necessarily be devalued or made obsolete.

In another online article in D Construction Dive, Peiffer details ten trends that were "defining the construction industry" in 2015 (Peiffer, 2015). Two of these trends, which are related to my research, are the usage of "building information modeling (BIM) and technology/apps on the jobsite" and, secondly, that "3-D printing and off-site construction" are emerging in their use by the construction worker. Here too, these trends are supportive of idea of skills devaluation and skills obsolescence. If machines, whether BIM or 3-D printing, are used to perform work tasks 
that were once performed by a worker, then those skills that the worker once had have necessarily been devalued at best or made obsolete at worst.

All of these examples demonstrate the hypothesis that human workers are experiencing work differently due to the devaluing of human labor by automated and computerized technologies. There are ample articles regarding what economic effects these cause on a society and even the idea that there will be fewer jobs available to lower skilled workers, but there is a gap on the how these changes affect the unionized building trades sheet metal worker. Therefore, while there is ample evidence that work has changed and that human labor in particular has been devalued and how this affects a society in general has been discussed in an abstract manner, but the specific, individual meaning that his has upon the worker's experiences has not been discussed nor studied. Indeed, if even half of the worst case scenarios are realized then the implications for society seem ominous at best, yet catastrophic for the individual lower skilled worker. For the sheet metal worker, whose skills have already been deskilled in part, this research portends a clarion call to action.

\section{$\underline{\text { Summary of Qualitative Findings }}$}

The industrial revolution brought a change to work. This change mechanized work processes and the need for human labor was still a valuable requirement to the production process, but this has changed with computerized and automated technologies. This so-called Industry 4.0, or the fourth industrial revolution, has changed work and work experiences. While 2017 European study offers a more hopeful outlook on automation's impact upon jobs, it nevertheless does concede that "many jobs might not be automated completely but consist of a large share of activities that are automatable. The automation of these tasks will significantly change the way these jobs are conducted" (emphasis theirs; de Groen, Lenaerts, Bosc, \& 
Paquier, 2017, p. 12). Furthermore, the report stated that "jobs created by new technologies predominantly require high skills" (de Groen, Lenaerts, Bosc, \& Paquier, 2017, p. 14) and that "automation is likely to make labour a less important production factor" (de Groen et al., 2017, p. 15). In another European report specifically on low skilled work, the conclusion was the same. That report stated, "It is obvious to assume that the introduction of Industry 4.0 systems will bring about deep and lasting change in work in general" (Hirsch-Kreinsen, 2016, p. 4). Yet while this report offers a more balanced presentation of competing theories regarding the impacts that automation will have upon low-skilled work in nevertheless still concludes that "despite their sometimes contradictory theses, most of the authors discussed above agree that a technology push is currently under way, with technology-driven and more or less predictable tendencies to change work" (emphasis mine; 2016, p.9)

With automated and computerized technologies having abstracted work, deskilled work tasks, and made other skills obsolete, having required a higher skill level from the workers who perform the work, and having decoupled employment opportunities relative to productivity levels unlike any other time in human history, this topic is immediate for the labor organization. These technologies have combined to devalue human labor leaving the human being in a previously unknown situation with no reference points to provide guidance. This sensation of drifting and uncertainty related to the devaluation of human labor is a cause of workers experiencing work differently than in past times. Additionally, as may be typical of many young adults who listen to the work experience stories expressed by their parents and grandparents, such young adults may expect to have work experiences similar to those of his or her parents or grandparents and this can be a guiding light to such a person. However, this paradigm has clearly shifted causing the experience of work to change with it. It is as if the individual worker were 
standing on solid ground as the heavens revolved around andas the heavens may have indeed been revolving, the earth beneath was shifting too; where the earth is representative of the individual's work experience. Simply put, the paradigm of work has shifted causing the worker to experience work differently from what the individual worker has come to know or expect. Therefore, for the individual who once need not concern his or herself with abstracted work, or that their work skills were sufficient and in-demand, or where there was not a need for that worker to obtain higher skills to remain employed, the conclusion that a new paradigm brought about by computerized and automated technologies is supported by the data. For my research on sheet metal worker's readiness for or resistance to change, these findings provide context for the work environment with which is present at this time in history. As was previously discussed, a structural element institutionalized within SMART's business model is a division of labor, which commoditizes the labor of SMART's members. With work skills changing on a global scale which necessarily creates skills obsolescence or skills devaluation caused by abstraction of work, then the wisdom of rethinking what SMART's mission should be and how it plans to achieve a new (or revised) mission seems to be needed.

These qualitative findings provide a foundation whereby the sense that is made by my quantitative findings can be supported. Better understanding the value that CTs and automation have had upon blue-collar work in general provides a foundation to understand the reasons why I came to question what the implications of my work at the ITI meant for my union and its members. Personally knowing many of the members and knowing how I believed they saw themselves led to my ambivalence about what I was really accomplishing while employed by the ITI. Foreseeing what changes I was to bring to the work of these brother and sister sheet metal workers led me to want to know how they felt about it. Therefore, for this research, the 
qualitative findings provide a foundation whereby the interested reader of my research can better understand the results of my quantitative research. 
Chapter Five: Conclusions, Discussion, Implications, and Suggestions for Future Research 


\section{$\underline{\text { Introduction }}$}

The sheet metal industry has experienced skills obsolescence due to computerized technologies. This occurred when the plasma table reached widespread use in the industry. While very few layout work positions remain to this day, the vast majority of layout positions vanished when the plasma table came to the industry. The skills of the bench layout person, which included trigonometry, applied calculus and other mathematical knowledge, were widely indemand and a source of power when it came to contract negotiations. The plasma table ended this by performing the mathematical functions that were once exclusive to humans. The sheet metal industry has experienced skills devaluation due to CTs. Work positions in the sheet metal industry where workers hand drew shop drawings (akin to a blue print) required work skills such as spatial knowledge. This is the ability to "see" a three-dimensional object relative to other three dimensional objects as one draws those three-dimensional objects in two dimensions on a sheet of paper. This was an in-demand skill in the sheet metal industry. 3-D modeling and subsequently BIM has deskilled these work tasks. Whereas the individual worker was the sole source of "seeing" how a three dimensional object physically fit into space within a soon to be constructed building, BIM enabled this to be seen in the three dimensional virtual reality of a computer. BIM performs many of the higher skills required by the draftsperson. To be sure, BIM did create new work for some sheet metal workers, but it is not a one-to-one ratio. While there currently is, at the time of this writing, a demand for sheet metal workers who can perform BIM skills, BIM has replaced more draftspersons than it has created work for. BIM has provided efficiencies to the skills of drafting. Furthermore, it has enabled automated the listing of parts to be installed into the construction project. This means that once the draftsperson is done with his or her work, a few simple computerized commands can retrieve accurate and reliable lists of 
parts to be installed. This feature of BIM has eliminated sheet metal work positions that required a manual listing of parts to be installed by a sheet metal worker. Included in the power of BIM listing is the fact that BIM can directly create the computer file whereby the plasma table fabricates the individual pieces that make up a part that is to be installed in a newly constructed building. Where the plasma table did create new work for sheet metal workers was in needing workers to enter data into a computer that provided the plasma table with the information needed to fabricate the pieces of a given part. Now, with BIM, this too has been largely eliminated. There are other skills too that have been devalued due to CT's impact on the sheet metal industry. Computerized spreadsheets, scheduling software, journaling software, etc. have all affect the trade, with the result of deskilling the sheet metal worker.

While history clearly demonstrates that technology deskills work tasks and make other work skills obsolete, one important question for the sheet metal worker and for SMART is what course of action the union should take as it relates to embracing or resisting technology's impact on the work skills of the sheet metal worker. Should the union embrace technology? If so, how can this be realized? What does embracing it look like? What form does it take? These and related questions are pertinent for SMART and its members. Simply put, though, embracing technology, especially CTs, is essential for SMART. This, however, is not going to be painless for the union or its members. While it is possible to seek legislative relief from technology's impact upon the sheet metal trade, the simple fact that the economy is at least nominally capitalistic and there is inherent competition within the organization, SMART and its members will find competition from somewhere else. Even if, for example, legislative relief were to create an environment whereby sheet metal work was required to be unionized labor, a corporation that would choose to locate in any given city could choose to locate its building within a legislative 
jurisdiction that did not have such laws, thereby creating competition. Fighting technology's reach into the skills of the sheet metal worker seems to be an exercise in futility and, therefore, embracing technology is the only sensible route to take.

This course of action, embracing technology, is not without existential consequences though. The adversarial structure of the CBA, or contract, while not obsolete, must be reimagined to be more collaborative than adversarial. The CBA as it is known today creates a structural element, which may have made sense in an industrial economic model, but makes far less sense within an information economy. The battle is not exclusively between labor and management any longer, but between both of these as they are now and with each individually against technology's reach and with each together against technology's reach. Simply put, CT has changed the groundwork on which labor and management stand. With the ground work having changed the implications for the structural power of the union needs to be considered. The power of the union resides in an adversarial framework and this framework makes sense when the economic dynamics are bilateral: labor and management. However, when a third dynamic is added, one which alters the very ground which the existing structure stands, then an adversarial structure should be reconsidered. When the union recognizes that their power, created from skilled labor, has been made obsolete or has been deskilled to a point where a greater pool of workers outside of the union can perform these same work tasks, then fighting to maintain such a structure as the adversarial CBA seems to be short sighted and remiss in the union's duties. Ceding power in this situation must feel like a dereliction of one's duties, but that feeling is predicated upon a paradigm that is obsolete. With power comes privilege and this, as I have seen firsthand, is true of SMART and ceding power is to cede privilege, which is something that seems contrary to human nature. Nonetheless, SMART leadership must embark upon a new way 
of a CBA, one that understands and recognizes the new realities of the information economy. The data from my study, as I will detail below, offers a hopeful optimistic look forward for SMART. The data from my study clearly shows that while there are those within the union rankand-file membership that are resisters of change, that the vast majority of members recognize that $\mathrm{CT}$ is impacting the work of a sheet metal worker and that they are ready to change so the union can capture the new work skill that CT brings to the trade.

Human labor has been devalued and it is continuing to be devalued due to computerized and automated technologies and, consequently, the worker is experiencing their work differently. With a foundational change to work and the worker experiencing work differently due to computerized and automated technologies, it is little wonder that we find self-preserving behaviors from such workers. For indeed, if a worker has anxious feelings or feelings of insecurity due to no fault of the worker, such behaviors can be easily anticipated. Within the United Kingdom (UK), for example, there were many different reasons why the voters voted to leave the European Union (EU), but a story by The Atlantic showed data "that average levels of education of the people in a region correlate quite strongly with their Brexit leanings" (emphasis mine; McGill, 2016). For those regions with a higher population of residents who have a college degree, there was a "far more" likelihood that area voted to remain in the EU and, therefore, those areas where residents had fewer college degrees, they were more likely to vote to leave the EU. Furthermore, there is evidence that a lower level of education generally implies lesser employment skill sets, which, in turn, are becoming increasingly marginalized (Spitz, 2006). It is therefore logical to conclude that since many Britons who voted to leave the EU did not have a high level of education, with low levels of education correlated to outdated employment skills, many of those who voted to leave the EU may have done so due to their perceived sense of 
employability. To expand upon this concept, it is nonetheless logical to state that with low levels of education meaning skills that no longer meet minimum employment needs, those who do not have higher levels of education would have a sense that their employment skills are no longer in the demand as they once were. With such an individual worker sensing that their employment skills being in less demand or obsolete, it would follow that such a worker, who desired employment, would necessarily possess worried or anxious feelings related to employment and employability. A 53-year-old British construction worker Mr. Steve Mcllhagga, from the bluecollar neighborhood of Poplar in East London, who expressed his desire to leave the EU in an interview with The Wall Street Journal, said, "where I live, there's a lot of unemployment. I can't afford things. Everything's gotten worse.” (Muñoz \& Turner, 2016). Here, while Mr. Mcllhagga expresses his concerns over the ability to afford "things," his statements regarding unemployment within his local community and "everything" getting worse are particularly noteworthy. Undoubtedly, Mr. Mcllhagga likely does not hold that all of his existence is getting worse, but his expression is one where he is iterating his feelings that, within the context of British bankers losing their jobs, espouse a feeling of doom and hopelessness. Indeed, Mr. Mcllhagga expresses a sense of despair as it relates to unemployment where he lives and with his sense that his world is getting worse it can be concluded that, at least for Mr. Mcllhagga, leaving the EU would be beneficial.

In the United States, as was detailed earlier, both Hillary Clinton and Donald Trump both use jobs, especially manufacturing jobs, as a key platform issue. Indeed, Ms. Clinton's story is noteworthy in very many ways, especially being the first female candidate from a major U.S. party, but Ms. Clinton has served as United States Senator and United States Secretary of State and, thus, while her rise is noteworthy, is not as surprising as is Mr. Trump's. Few believed he 
would survive the Republican primary races (Savransky, 2016; Collinson, 2016; Stanford Politics, 2016), let alone become President of the United States. However, conventional political wisdom may have seen it, Mr. Trump's rise to the nomination, and subsequently the presidency, is in part due to the sense by the Republican primary electorate that he would be best to solve economic issues (Pew Research Center, 2016). In summary, for the working classes of the United States and, indeed, the industrialized world, computerized and automated technologies have devalued human labor and thereby altered the individual worker's experience with work.

Relative to the sheet metal worker, it was widely believed that usage of CTs by the construction worker has lagged behind the workforce in general (Bennett \& Taras, 2002). However this may have been, CT's inroads into and subsequent impact upon the construction industry has continued to grow and the results of this impact are such that today fewer workers are required to perform the same amount of work than prior to the advent of CTs (Mattingly, 2002). Furthermore, the usage of BIM in the construction has further increased worker productivity (SmartMarket Report, 2015) and BIM is evolving too to the point that there is a trend toward Industry Foundation Classes (IFC) based BIM which is enabling foreign construction companies to compete in the American construction market (Smith, 2012).

For the sheet metal worker as was discussed previously, CT has already deskilled and eliminated the bench layout position to the point that for some preserving the "lost art" of sheet metal layout is a life mission (McConnell, 2003). Additionally, simply looking at the growth of the sheet metal workers union, both SMWIA and SMART, shows that the union is shrinking relative to the overall population of the United States. In 1970 the SMWIA had over 150,000 members (Palladino, 2012) whereas today SMART claims 136,000 members, 14,000 fewer members, in the sheet metal trades (Sheet Metal, 2016) approximately a 10\% loss in claimed 
membership. Conversely, the population of the United States has grown from over 203 million in 1970 (United States Census Bureau, 2016) to over 321 million in 2015 (United States Census Bureau, 2016) an increase in population of over $50 \%$. Furthermore, construction spending in 1970 within the United States was $\$ 88.8$ billion (Chicago Tribune, 1970) whereas in 2016 construction spending was \$1.1 trillion (United States Census Bureau, 2016). Adjusted for inflation $\$ 88.8$ billion equals $\$ 545$ billion in construction spending in today’s dollars (Bureau of Labor Statistics, 2016), which, in turn, means that today construction spending has more than doubled over the same period of time. Simply put, while there has been more than twice the amount of construction in the United States, the number of sheet metal workers needed to do their portion of that construction work has substantially decreased relative to the amount of construction spending. If twice the number of sheet metal workers were needed to perform the doubled amount of work, the actual number of sheet metal workers needed today would be over 300,000 . However, with the current number of members being 136,000 , it can be reasoned that SMART has shrunk in the size of its membership by more than half over the period of 1970 until today. Furthermore, these numbers mean that the actual reduction of members of SMART is approximately 55\% relative to construction spending in the United States between 1970 and today. This is ominous for the union and it is little wonder that the SMWIA merged with the United Transportation Union (UTU) in 2011.

Yet this picture is a snapshot of this time in history. The trend of CT usage in the construction industry is far from over. At one time, it was argued that the non-routine tasks, such as those found on the construction site, were a buffer from computerization of such work (Autor, Levy, \& Murnane, 2003). More recently, however, it is argued that, due in part to greater computing capacity, even non-routine tasks can be performed by CTs (Brynjolfsson \& McAfee, 
2011), including the non-routine tasks found at the construction site (Frey \& Osborne, 2013) and, there is evidence that this is occurring. The Wall Street Journal reported that Komatsu Ltd. plans on using unmanned drones, bulldozers and excavators to automate foundation work on construction sites (Nicas, 2015).

Therefore, CT has already had a dramatic impact upon construction work in general and the work of a sheet metal worker specifically and that impact may never be fully completed until only a few workers that can operate such technologies remain. This is not new as technology in general has made industries obsolete. The automobile has essentially eliminated the horse drawn carriage, the electric light bulb eliminated gas-lit lamps, etc. Indeed, the work of a sheet metal worker has already changed and has already been deskilled, and this trend will likely continue. Learning whether the rank-and-file sheet metal worker member of SMART is aware that computerization of their skills is at hand and whether they are ready for or resistant to these changes is the purpose of this study.

Technology in general and CT specifically has altered the nature of work. Organizations such as the building trades unions whose commodity is traditional skilled labor are finding themselves in a period of human history where the very nature of their organizations are being threatened by the deskilling effects and wholesale elimination of work that CT brings. While these organizations certainly have contributed to the betterment of the lives of their individual members and, arguably, to the betterment of society as a whole, for SMART, they are facing declining membership relative to construction spending which, in part, is due to technology's impact upon the sheet metal industry. The role of a labor union in general is to offset the power over the worker of management of any given company or corporation. In the current labormanagement structure, it is possible that a corporation's management could have unilateral 
power to decide what a worker's wages are and what the worker's working conditions are within the bounds of the law. The worker without a union has far more limited bargaining power in what his or her wages will be or what the working conditions will be. While this, of course, is not true for all workers, as computer coders are in such high demand today that a coder has a lot of weight towards determining wages and working conditions, however, while there certainly are exceptions, this is not the case for many workers and an organization such as workers who are members of a labor union. A labor union creates a more bilateral power structure within company or with corporate management.

With CT affecting the work of the building trades more and more, embracing change would seem to some people to be an obvious course to take for each individual building trade union whose work is being deskilled or made obsolete by such technologies. For SMART in particular, implementing a plan to embrace the changes that $\mathrm{CT}$ brings and to evolve the nature of the organization would seem to serve their own self-interest and towards their survival. The promising results of this research evidence that the majority of the rank-and-file members of SMART are open to and ready to embrace such changes which are currently at hand, that CT brings.

In my quantitative research, the data shows two latent classes of respondents to an online survey. These classes, titled class 1 and class 2, consist of $69 \%$ and $31 \%$ of the sample respectively. The survey items quantify the perceived impact that technology, as well as quantify the feelings of the sheet metal worker towards CT at work, as it relates to both their work and personal lives. For the class 2 respondents of this research, consisting of $31 \%$ of the sample, which are viewed as resistant to change, they demonstrate resistance behaviors conducive to established research on resistance to change. Regarding the individual sources of resistance to 
change, habit, security, economic factors, fear of the unknown, and selective information processing (Robbins \& Judge, 2013), the class 2 respondents to the survey, as will be discussed below, demonstrate most of these behaviors.

In Essential Psychiatry, a habit is described as, "an automatic response to specific situations, acquired normally as a result of repetition and learning” (Sheahan, 1979). A habit, it can be said, is how an individual behaves, oftentimes unknowingly, given any individual circumstance and within the work setting, individual habits are both how the individual behaves while performing the specific work task or how the individual behaves in an organizational setting given any set of circumstances; that is, the group dynamics setting. Habits are the learned behaviors that, for the healthy individual, serve the sense of self-preservation instinct and established data shows that habit is a source of resistance to new technology adoption by individuals (Sheth, 1981)(Aladwani, 2001). Therefore, it is reasonable to conclude that when an individual is behaving in a habitual manner that such an individual is acting with self-preserving behaviors as he or she understands this to be. It can be further stated, that when an individual is demonstrating habitual behaviors, that this individual is, oftentimes unknowingly, behaving with the instinctive sense of preserving themselves. Therefore, when analyzing the data from the survey results, it is reasonable to conclude that when an individual responds to the survey where it is concluded that such respondents are resistant to the changes brought by CT to their work as a sheet metal worker, that this person is behaving in a self-preserving manner, as they understand it. Consequently, such individuals tend to feel more secure employing their habitual work behaviors, thereby demonstrating the established resistance behavior out of habit.

Further in my study, items 6 and 7 explore the respondents' thoughts and feelings related to learning new computerized skills as it relates to the work of a sheet metal worker. In item 6, 
where respondents answered whether they have learned any new computerized skills at the time of the survey as they related to their individual work, the class 2 respondents, classified as resistant to change, were less likely to have embarked upon learning new computerized skills relative to the sheet metal trade. Also, a minority of respondents answered that while they have had the opportunity to learn new computerized skills that they have made the personal choice to not participate in such training. Given this result, coupled with the data results from items 2 and 4, which centered around the respondents' thoughts and feelings regarding the impact that CT has already has and will continue to have upon the work that a sheet metal worker performs, it is reasonable to conclude that for those who are categorized as resistant to change responded with self-preserving behaviors, as they understand self-preserving to be. While they may see both the present and future work environment as it is changed by CT's impact upon the sheet metal trade as somewhat bleak, they have opted to resist these changes by maintaining a status quo approach to their personal skills. This opting for a preservation of their personal skills sets can be said to be acting on habit or behaving on one's known paradigm. Perhaps fear of the unknown is a primary factor as to why these individuals have chosen not to upgrade their skills even in the face of acknowledged changes. Regardless, it is concluded that whatever the determinants are, these respondents are behaving in a habitual manner and consequently, they are behaving in a self-preserving manner.

In item 7, respondents are asked about being required to learn new CT skills for the work as a sheet metal worker. The class 2 respondents, again classified as resistant to change, as the LCA demonstrates possess a negative attitude towards learning new technologies and they believe that learning such skills can be frustrating. Additionally, the results of the survey analysis show that they have some worries about learning the new skills. Here too, given the reasoning 
mentioned above, it is reasonable to conclude that for such people who feel frustrated and at least somewhat worried about learning new computerized skills which their work tasks may require, are behaving in a habitual and a self-preservationist manner. If an individual has a personal sense of frustration at any given work task, it is reasonable to conclude that, for the healthy individual, avoidance of frustration would be considered an expected behavior and, therefore, it would then, in turn, have become a habitual behavior for that individual. For the respondents of this research, those who expressed frustration and especially for those who expressed some level of worry about learning new skills, it is reasonable to conclude that these individuals opted for habitual behavior as this would seem to the individual to be self-preserving.

Moreover, the concept of individual security is rooted in the individual's personal sense of safety. Security has long been viewed as a primary motivator for humans (Maslow, 1943). While the idea that security as it relates to one's job seems to necessarily imply an embracing of change to one's industry or specific work, there are many individuals whom resist change due to their individual feelings of security (Oreg, 2004)(Lorenzi \& Riley, 2000)(Robbins \& Judge, 2013). Therefore, while there is a potential gap between one's sense of security and one's actual security, the phenomenon of those that resist change due to their perceived personal sense of security has been well established. The idea that individuals resist change due to their perceived sense of security or lack of security, it follows, is rooted in that individual's sense of selfassuredness. If the individual had feelings that their work was assured, they would have feelings of security. Conversely, if the individual had feelings that their work was not certain, or assured, that individual would have feelings of insecurity and such an individual would behave in ways, which created a sense of security. If one was unsure that his or her skills would be relevant to the changes brought by $\mathrm{CT}$, then it seems likely that this individual would not have feelings of job 
security and, consequently, would resort to behaviors that would make the individual feel secure. In this case, this would mean the individual would resist the technological changes to one's work because such changes create feelings of insecurity and the individual desires feelings of security. Additionally, for the individual that felt a lack of sense of security of one's job, it would be reasonable that this person would have feelings of anxiety and these feelings of anxiety would be undesirable. For the individual who has feelings of anxiety that are caused by a personal sense of the lack of job security, behaviors that tended to alleviate the anxiety would be expected. Among the behaviors that alleviated the individual's sense of anxiety, would be behaviors that were comforting and comforting behaviors would be known or second nature to the individual. Simply put, the behaviors would be habitual.

In my study, items 1 and 2 explore the respondent's feelings on the current impact that CT has had upon the sheet metal trade and item 4 explores the respondent's feelings about the future impact of CT upon their personal job. Whereas, item 12 explores how the respondents feel CT will affect the whole of the construction industry. Additionally, item 8 explores how respondents feel technology will affect the number of jobs available to union workers and items 3 and 5 are targeted towards knowing how respondents feel about the relevance of their current non-technical skills and how they foresee these same skills changing with increased adoption within the sheet metal industry respectively. The conclusions drawn from these respondents show a clear correlation to the existing research literature. For the class 2 respondents, resistant to change, in this study, demonstrated feelings that CT has and will continue to have a high negative impact upon the sheet metal trade, including the possible elimination of most or all jobs available to sheet metal workers. Additionally, the class 2 respondents felt that CT will make 
their personal skills obsolete or that their skills will change so completely that they will be compelled to learn new CT skills just to perform their work.

With the class 2 respondents feeling that their personal skills would be rendered obsolete or that for them to remain relevant to the skills needs of the industry, they would need to learn new computerized technological skills, coupled with their being adverse to learning new computerized technological skills, it is a logical say that they would experience a personal sense of anxiety due to the sense of a lack of job security. Additionally, with the class 2 respondents possessing feelings that $\mathrm{CT}$ has and will continue to have a negative impact upon the quality and quantity of jobs available to sheet metal workers, it is logical to conclude that these respondents would possess feelings of job insecurity and, consequently, they would be resistant to changes brought to the work and industry of the sheet metal worker.

Regarding an individual worker's economic factors as a source of resistance to change hereto the class 2 respondents of this research demonstrate this resistance behavior. Specifically, item 9 of the survey asked respondents their feelings related to the impact of CT on their personal life. The LCA showed that the class 2 respondents have a negative outlook to life and their futures and are worried about their future employability. Furthermore, the results of item 10 of this survey shows that the class 2 respondents indicated that they may leave the industry itself, but that they have no intentions of learning new skills brought about by CT. Included in the class 2 respondents, the results from item 11 show that these class 2 respondents have expectations from the union's leadership to resist as an organization these changes brought about by CT. Additionally, the results show that class 2 respondents to this survey demonstrate a negative outlook regarding life and their respective futures and that their future employability is uncertain. Fear of the unknown is a reason that some individuals resist change (Mealiea, 1978) and fear of 
the unknown can lead to feelings of uncertainty by the individual. As was detailed above, feelings of uncertainty can lead to feelings of anxiety, which would naturally be eschewed by the individual and, therefore, the individual who had feelings of uncertainty would seek to reduce or eliminate these feelings of anxiety and this would lead to status quo behaviors. Therefore, the results of this research related to resistance to change behaviors are supportive of the existing literature. More specifically, the respondent sheet metal workers to this survey, titled class 2, demonstrate resistant to change behaviors, which present research shows to be expected behaviors.

The evidence of my study also shows that a class of members, comprising approximately one-third (33\%) of the membership, is resistant to the changes that CT brings to the sheet metal trade. This sizeable minority focused on the negative impacts that CT brings to the sheet metal trade and they will likely be resistant to change. It seems likely that if any organization were to alienate one-third of its members that the results could prove to be detrimental in the least. Thus, it would seem wise for the SMART leadership to develop a comprehensive strategy to embrace the inevitability of more changes to the nature of the work of a sheet metal worker that CT has and as part of that strategy SMART would be best served to engage those members who are resistant to such change.

As this study relates to readiness for change, the results of my study support much of the existing research as well. The majority of respondents in this research were ready to address the changes that CT has for the sheet metal industry. More specifically, those within this study who are ready for change see that the organization of SMART is capable of making a successful change, that there is a need for that change and that it is beneficial to make these changes (Choi \& Ruona) (Armenakis, Harris, \& Mossholder) (Eby, Adams, Russell, \& Gaby) (Holt, 
Armenakis,, Feild, \& Harris) (Jansen). These respondents show a positive outlook towards the effects that $\mathrm{CT}$ has upon the sheet metal industry. They demonstrated an understanding that change was occurring and that embracing these changes as individuals and as an organization as a whole is a natural evolutional step. More specifically, this was seen in items 2 and 4 where respondents were asked to rate the current and future impact of CT upon their job. Item 12, which asks respondents to rate the impact $\mathrm{CT}$ will have upon the future of the whole of the construction industry, the respondents who are classified as ready for change view CT's impact in a much more positive light. Item 8 asked the respondents to rate CT's impact upon union workers' jobs. These respondents see the impact and effect upon their work and skills changing as having an impact, that jobs will be lost, but with CT creating new jobs in their stead. Therefore, these respondents clearly see the appropriateness of changing and the personal benefit to changing. Items 3 and 5 sought to know how respondents feel about the relevancy of their current non-technical skills and how they anticipated these non-technical skills would require change due to CT's impact and effects. Here, the ready for change respondents demonstrated that they say CT as not being prohibitive related to their skills. It is a short step to conclude that these respondents see change efficacy as something that can be easily achieved. Items 6 and 7 further explore CT skills related to learning new skills and the respondent has already at the time of the survey learned new $\mathrm{CT}$ skills and learning new $\mathrm{CT}$ skills when required or is necessary. Here too, the ready for change respondents demonstrated that they have already participated in learning and that they are ready to further learn new CT skills as is necessary to perform their work. These respondents clearly show a belief in the change-specific efficacy, the appropriateness of the change, and the personal benefit of the change. Item 10 delves further into the topic of CT skills in the future and, here too, the ready for change respondents demonstrated 
the same efficacy, appropriateness, and personal benefit responses that Holt et al. defined. Item 9 asked respondents to rate CT's impact upon their personal lives and in those responses classified as ready for change, the respondents were positive as they saw their personal lives and their futures. This gives weight to the assessment that those respondents from this study who were classified as ready for change as believing in the efficacy, the appropriateness and the personal benefit towards changing to meet the demands brought about by CT. Finally, item 11 asked respondents to define how they expected the union's leadership to react to CT. Here too, the respondents who were classified as ready for change had expectations of the union's leadership to embrace these changes, thereby giving credence to the concept of management support for the change. This final item is different from Holt et al.'s research in that management of the union relative to the union rank-and-file members due to the rank-and-file members' election of their leaders rather than the corporate model of managers and employees. Therefore, those respondents who have been classified in this research as being ready for change have demonstrated that they have a belief in the change-specific efficacy, the appropriateness of these changes, their personal benefit from these changes and the need for the union's management to support these changes, thereby the results from this research as it relates to readiness for change are supportive of existing research.

In summary, the results of my quantitative research show two distinct classes of respondents. The first class, which comprised approximately $67 \%$ of the participants in the survey, was ready for and accepting of the change that CT has upon the sheet metal trade. This bodes hopeful for SMART as technology's reach into the work that a sheet metal worker performs grows. This evidences that the majority of the membership of SMART are open to a redefining of what it means to be a sheet metal worker and to what work a sheet metal worker 
must perform. This shows promise that the organization of SMART will have the support of the majority of the membership to evolve into a technological economy and, to some extent, away from an industrial economic model.

\section{$\underline{\text { Conclusions and Discussion }}$}

Computerized and automated technologies have altered work and devalued human labor and the traditional building trades unions are not immune to this phenomenon. The phenomenon of abstracted work, skills obsolescence and the deskilling of work tasks, requiring higher skills from workers and the phenomenon of fewer employment opportunities for workers relative to the productivity of these technologies have combined to cause human labor to be devalued. For SMART and its members and, indeed, all labor organizations face the change dynamics that computerized and automated technologies bring. In this light and with SMART having a business model, which appears to place the organization on the losing side of technology's wake. Since, as previous examples through history demonstrate, industries emerge and other industries become extinct. The skilled building trade of the sheet metal worker has been deskilled in large extent by the effects of CT, as one only need to look at the advent of the plasma table and correlated decline and near extinction of the bench layout person. The net jobs lost from the plasma table's advent were large and now we are experiencing the next emergence of CT, BIM. Among other benefits, BIM has created construction efficiencies within the construction industry previously unforeseen (Doumbouya, Gao, \& Guan, 2016) and while this may appear to be beneficial, for the labor union whose sole purpose is to provide labor, efficiencies mean less work for the members of such a union. Less work, of course, means a reduction of work opportunities for the members of the union, but, also, it means that the labor union itself receives a smaller amount of funds to sustain itself. Simply put, BIM, as well as other CTs that create a 
more efficient construction site, necessarily means a lesser amount of work for the labor union rank-and-file member and a lesser amount of funds to the labor union itself. Adding to this is a trend within the construction industry where BIM is being outsourced (Fountain, 2016). If BIM work begins to be outsourced for the sheet metal worker then, obviously, this means there is a possibility that work opportunities for sheet metal workers will become even scarcer. This, in turn, means it becomes even more difficult for the institution of the labor union to sustain its existence.

Additionally, BIM has already altered the work that a sheet metal worker performs and, furthermore, BIM has blurred the line that once clearly defined the division of labor that separated work that a sheet metal worker performed from work that others performed. For today, a mechanical engineer, who is not a member of SMART, through BIM technologies create a mechanical design BIM model that has all of the information that a sheet metal worker requires to perform the necessary fabrication portion of sheet metal ductwork parts. This means that the non-SMART member who is a mechanical engineer can perform the work that a SMART member can perform, but this is not reciprocal. To explain, a mechanical engineer has the education to design the physical code required heating, ventilation and air conditioning requirements of any edifice and at the very same moment this mechanical engineer is creating a design model, he or she is simultaneously creating the construction model. This is the power and productivity promised within BIM. It is important to stress that point again, as in this, the education that a mechanical engineer possesses is primary and that of the sheet metal worker is secondary. Thus, with the design requirements of an edifice being primary and since BIM enables simultaneous modeling, the work that a sheet metal worker performs is to some extent being performed by mechanical engineers. Mechanical engineering is primary as each edifice 
requires fresh, breathable air, heating and or cooling (conditioning of the air within a building) for the safety and comfort of the occupants of that edifice. The mechanical engineer is educated in this whereas the sheet metal worker is not and with BIM, when the mechanical engineer creates the design BIM model, the information created during the design also could contain the construction information and herein lies one threat to the work that a sheet metal worker performs from $\mathrm{CT}$.

With the pressures that $\mathrm{CT}$ is bringing to the work that a sheet metal worker performs and consequently to SMART as a whole, it appears to be in order for the union to take stock of this moment in history and to develop a plan to evolve the organization of the union. The positive framework for such change is knowing, as the results of this study demonstrate, that the majority of the membership of SMART is fully ready to embrace the organizational changes that would come. The leadership does have to develop a plan for the sizeable minority who are resistant to change, but the majority is ready for change. Indeed, I hope that the leadership will commence immediately. The findings of this study show that the rank-and-file members of the sheet metal arm of SMART are cohesive with existing research. Specifically, those studies cited in the literature review showed that CT necessarily correlated to a need for workers with skills upgrading (Krueger, Autor, \& Katz)(Sheridan, Vamos, \& Aida) this study shows that a majority of rank-and-file sheet metal members of SMART have taken it upon themselves to seek training to have their skills remain relevant to the needs of the industry. Furthermore, this study has supported the research of Sheridan et al. when that research showed that workers demand to be trained for the new work via new training programs created by the union.

Regarding resistance to change, there are differences from the cited research and the results of this research. Perhaps it is due to the structural model of the building trades where the 
CBA defines what work is performed by the unionized trade worker and changes to these definitions inherently are subjected to the management versus labor negotiations. Regardless, the responses of those in this study who showed resistance to change did not show any potentially positive engagement with the change process (Ford, Ford, \& D'Amelio, 2008; Knowles \& Linn, 2004). Rather, those resistant to change showed negative feelings towards such change. This research speaks loudly to the nature of the management/labor divide institutionalized in the CBA. Those respondents who were resistant to change clearly did not see themselves as change agents in the process.

While considering this last point, it is helpful to understand the individual set of circumstances that likely affected the respondents when they participated in this research. The most dramatic of such circumstances is that of "The Great Recession." Therefore, when looking at the responses, both those that are ready for change and resistant to change, it is helpful to consider and understand why the results are as they are shown to be. As research has shown, there are many reasons that people are resistant to change or are ready for change, but the unique set of circumstances that any given group would find themselves undoubtedly is a cause towards the individual's readiness or resistance to such change. For the sheet metal workers the experience of the great recession as it has come to be known as, has most certainly shaped the responses given in this research. Indeed, within the construction industry as a whole, 1.6 million construction industry jobs disappeared during the Great Recession and unemployment reached over 19\% (Rosenberg, 2012). Thus, while the individual respondent may not have been directly affected by the overall lack of work and jobs during the great recession, each individual respondent certainly knew of fellow members of his or her local union who were affected. Pessimism towards the future would be understandable. For the respondents of this research, the 
fresh sting of a long and protracted recession in construction spending likely was an impetus for the responses learned in this research. For those who were resistant to change, they likely correlated CT's deskilling effects and skills obsolescence as an additional reason as to why they, or people they knew, were not working. And while they maybe could not do anything about construction spending, and its corresponding jobs creation, they could do something about CT's affects to job losses, and that is to resist its inroads and affect to the work of a sheet metal worker. For those who were ready for change, the same set of circumstances led to a different conclusion. For these, the idea of inevitability of skills obsolescence and the deskilling effects of CT was such that they felt that the only means of having marketable skills in the future was to embrace the inevitable changes brought by CT. These respondents saw technology as inevitable and thus it must be embraced so as to ensure that the sheet metal worker of tomorrow was capable and ready to perform any new work that was necessary. Therefore, both the respondents who were resistant to change and those ready for change had shared experiences, especially in regards to the great recession, and while they concluded differently, they both acknowledge the inroads that CT has upon the work that a sheet metal worker performs. Those that resist the impact seek to slow or all together cease the impact that CT has upon their work. For those who are ready for change, they acknowledged the inevitability of CT's impact on their work and sought to meld and adapt their current skills so as to ensure that any newly created work or skill required of a sheet metal worker is work that they and their fellow union workers would be capable of performing, thereby ensuring the future of the union and work for the individual member.

For an organization such as SMART, who chooses to be called "organized labor," where under the information economy mass obsolescence of industrial skill (Schurman, 2012) is 
occurring, change is essential. But, how to change an organization from its known paradigm of an industrial economic model to the unknown paradigm of an information economic model where their business leaders are elected by rank-and-file members who in most cases are without post-high school educational experience and not business school graduates who have been educated in business or economic theories and the inherent real life results of such theories, the need for wholesale change may not be understood, let alone embraced. Thus, change may be seen as merely a fashionable idea and not an existential necessity leaving such an organization not even realizing the immediacy of the need to embrace change. However, it may be that the leadership of any building trades union, or SMART specifically, chooses to embrace these changes, or not, henceforth are some ideas on how to proceed.

Schurman argued that within the newly emerged information economic model that organized labor's monopolized bargaining power was dead and that unions needed to understand that transformational changes to the work of their members and to the organization of the union itself was required to reinvent our unions (2012). I share this belief and understand that this is far easier said than done. Transitioning from an organization whose identity is based upon an understanding of an economic model which is not fully applicable any longer, to an organization that operates within both economic models, industrial and information, until such a time if and when the transition to a fully information economic model is required, seems to be a difficult undertaking. Especially, since there are not any existing examples to learn from. Thus, embarking somewhat blindly upon such a transition will require bold vision and fearlessness by the union's leadership, vision, and fearlessness previously unknown. However, it may be that there are not any examples to light a pathway towards transitioning to the information economic model for a building trades union. 
The CBA has historically been the basis of organized labor's power and it has been used by union leadership to secure relatively high rates of pay and working conditions that are favorable to its membership. Built around the western legal tradition of contractual "consideration," the CBA as presently used by the building trades organized labor unions primarily views consideration as obtaining a larger and larger wage and benefit package from those contractors who agree to the CBA. This is realized via a periodical cycle of negotiation and agreement, oftentimes interrupted by threats of striking workers or an actual strike by the workers. Conversely, lockouts of union workers by the contractors, while feasible, never occur as these contractors are contractually required to meet any given construction deadline which requires labor to complete such projects. However, a balance of power that these may create, this is a view of the industrial economic model and speaks nothing to the wholesale changes that technology is bringing to the building trades. As was detailed above, for the sheet metal workers, their membership is down over 50\% relative to construction spending in the United States from 1970 to 2016 . Should this trend continue, sustaining a union may be difficult and transitioning the union essential. Therefore, incorporating alternate forms of consideration, or alternate consideration, into the $\mathrm{CBA}$ is a means of transitioning. Alternate consideration is the idea that what the contractor is obligated to pay to each member does not completely take a monetary form. While this may seem to be difficult to understand, there are examples in other, non-related industries to draw an analogy from.

An interesting example to draw from is that of RiverHOURS alternate currency. RiverHOURS alternate currency is a local currency from the Gorge Local Currency Cooperative local to the Columbia River gorge area in the States of Oregon and Washington (Gorge Local Currency Cooperative, 2016). (There are many examples of alternate currency systems to choose 
from as an example, but I chose RiverHOURS as the example to for this discussion. Any of the other alternate currencies would serve as a good example.) The idea of the RiverHOURS local currency is to be a complimentary currency to the Federal Reserve Note, or the U.S. dollar, and the RiverHOURS currency is designed to supplement the U.S. dollar. With RiverHOURS, the currency stays local as it is not a recognized form of money outside of the cooperative of people and businesses who accept it and while this last point does not directly correlate to what the unions should do, it does open up the idea of alternate forms of consideration or payments. In the case of the CBA, it lends to the idea of alternate forms of "wages and benefits." Alternate forms of consideration could be that in lieu of a wage increase, the contractors agree to host training programs at their place of business. Such training programs could include management courses, computer coding, information technologies (IT) courses, etc. This would supplement the wages and benefits already paid by the contractor and is not to be seen as replacing these. Additionally, other alternate consideration could be ownership of the business. Perhaps the contractors could set aside $40 \%$ of their business, thereby maintaining majority ownership of the business, and allowing the employees (individual members of the sheet metal union) to collectively purchase a percentage of the business. Finally, the most practical use of alternate consideration could be that the CBA should permit journeyperson members to accept less than full journeyperson wage scale while employed at a contractor during a training period where the journeyperson embarks upon learning skills that are both beneficial to the member and the contractor; at the same time, this will not cause the union to lose the vital funds that are collected on behalf of the individual journeyperson's hourly wage and benefit package.

To elaborate on this last point, currently there is a lot of resistance from contractors to hire journeyperson's to perform high-tech work, such as BIM due to the cost of training such a 
worker. Traditionally, training has been performed at an apprenticeship training school, or trade school, where when the individual was newer to the trade, skills were taught to that person and at the same time, the financial wage and benefit obligation are less than that of a journeyperson. As the individual progresses yearly in the apprentice school, his or her wages would increase. (The benefits package in most cases is the same as that of the journeypersons. It is only the wages that increase periodically.) And, it is indeed true that the building trades unions are seeking to address such training at the apprentice level, but the difficult obstacle to overcome is that of experience. The largest issue for training a BIM technician is that of experience within the specific trade. For the sheet metal worker, understanding what is required to fabricate and install the necessary ductwork is rarely known by an apprentice level worker. Such an apprentice may understand the technical formulae, in the case of ductwork fabrication, but without experience at the trade, not understand the times to alternate what is fabricated. For example, if an existing building were to be retrofit (remodeled) and thus require, say, a 120 inch by 30 inch 90 degree elbow (ductwork that turned 90 degrees) a younger, less experienced (apprentice level) worker may not understand that such a large sized ductwork may not be physically fit through a doorway to be brought into the building. Whereas a journeyperson, with years of experience, would know to convert the 90degree duct elbow into three 30-degree elbows to ensure that such ductwork could be physically brought into the building. This is minor example of where an apprentice would lack experience that a journeyperson would possess.

For the contractor, employing someone who could create a BIM model where such issues were addressed, thereby causing fewer issues at the jobsite itself, is highly desirable. However, the cost to train a journeyperson is prohibitive. The journeyperson would know the potential issues and approach a construction project with an eye towards such issues; however, such a 
journeyperson would not know how to operate the software, and in some cases, the hardware to create a BIM model and to coordinate the BIM model with the other building trades (plumbers, electricians, etc.) Therefore, the crux of the issue facing the union, its members, and the contractors is that as a norm, the apprentice has the wage scale that a contractor can afford to pay during a training period, but the apprentice lacks the skills and experience needed to use. Conversely, the journeyperson possesses the skills and experience needed to create a BIM model, but the wage level is prohibitive during the period that a journeyperson would require to learn the CTs. This is where alternate consideration would prove to be a method where the individual journeyperson could become employed at the CTs required for BIM.

Wage reductions during a training period could include the alternate consideration of bonus incentives, tied to the expected profit margins of any given project that the worker is assigned to. Of course, the training itself has value and when the worker becomes proficient in CTs, BIM especially, then that worker will be highly employable and will likely never see unemployment. Additionally, alternate forms of consideration could be achieved on a case-bycase basis, allowing the individual worker to individually negotiate the alternate forms of consideration that the individual values. Thus, empowering the individual worker to learn new, in demand, skills and at the same time be of a cost to the contractor, which is permissive. The worker could negotiate bonuses, perhaps company stock, perhaps paid vacations or holidays. Regardless, of what the individual worker agrees to with the contractor, this circumstance is a win for all parties: the union, the contractor, and the individual worker. In time, when the computerized skills are learned and the productivity level that the contractor can accept is achieved, then the individual worker would resort to back to the CBA's regular journeyperson rate. 
The institution of the union, or the organization of the union, must undertake to set a committee to look into the future of the organization and to ask itself what the arc of technological advances in machinery, materials, means and methods, and CTs means to the work that a sheet metal worker does. However, when they look forward as to where they see this arc of technology going, they must look back to where it all came from. With the advent of the industrial revolution, machinery replaced much work that once required human power to complete. Machinery continued to improve in its capacity and fewer and fewer people were needed to complete any given work. The advent of the information economy and computerized modelling enabled productivity towards a given work task to be greatly sped up to the point where very few people were needed to complete a work task. With CT continually improving work tasks, the union should look and see what this necessarily means to the work that a sheet metal worker does. Indeed, the effects have already been felt with the replacement of the bench layout person's work being replaced by the plasma table and with the examples cited above, it is not difficult to foresee that fewer and fewer sheet metal workers will be required to do any given sheet metal work task.

In summary, the union should recognize that many of the skills of the sheet metal worker have been made obsolete, as it is with pattern layout for example, and that technology, especially $\mathrm{CT}$, will continue to deskill the work that the sheet metal worker performs. The idea that relative high wage and benefit rates are based upon the scarcity of task skills is undermined when those skills are diminished in complexity and technology, especially CT, has in fact diminished the complexity of the skills that a sheet metal worker possesses. The union has traditionally capitalized upon the monopolization of a skill set that at one time in history was scarce, but with the advances in CT these skills are either obsolete or have been deskilled to the point where they 
are not scarce. Indeed, as my sheet metal apprentice instructor often said, "the world does not need another ductwork installer." Therefore, the union must recognize that the power that it once possessed via monopolization of scarce skills, has been and will continue to be diminished by technology, especially CT, and opt to negotiate with the contractors alternate forms of consideration that enable the individual member to learn new skills that are relevant and in demand.

Considering the strengths and weaknesses of the results of my research there are several worth noting. Firstly, strengths of the results of my qualitative research lie within the many global examples of automation's effects upon work as experienced by the worker to draw from. Indeed, this is not simply an American phenomenon. There are numerous examples from stories and reports from around the globe, easily obtained via the internet, that detail the travails, brought about by automation, of many workers from all walks of that globe. These provide quality examples that demonstrate the ubiquity of these phenomena. The weaknesses of my qualitative research primarily lies within the fact that no personal interviews were performed, including follow up questions related to workers' experiences with how automation has affected their work and lives. This would enhance that data and likely provided a richer understanding of those effects.

The strengths of my quantitative research lie within the ability to include workers from a broad swath of the United States. While the numbers of individuals who participated in my online survey were concentrated largely within the middle parts of America, I did nonetheless receive responses from a much wider area of United States. The weakness of my quantitative research is in the relative dearth of interviews of sheet metal workers that I was able to obtain. While the fact that so few sheet metal workers opted to be interviewed may signify an 
organizational deficiency within the union, it nonetheless can definitely be seen as a weakness. Greater numbers of interviews would most likely have enriched the research. Additionally, regarding the online survey, the research would have been enhanced if a greater number of members had opted to participate in that survey.

\section{Theoretical and Practical Implications}

The findings of my study have important theoretical and practical implications. Firstly, regarding the cited literature related to technology and skilled work my study offers additional support for it. The respondents of my study indicated that $\mathrm{CT}$ did create a demand for higher skill sets among sheet metal workers and that the need for skills upgrading was important for their own futures and for the future of SMART. With technology being "biased" towards skilled workers and with the devaluing of skills nature of technologies in general and CTs specifically, the results of my study, which shows that the respondents have an understanding of the need to upgrade their skills offers support for this theory. The respondents of my study acknowledged, at least in part, the impact that $\mathrm{CT}$ was having on the sheet metal trade as a whole. The practical implication is stark for SMART. With skills being devalued or made obsolete the implications for the organization whose sole purpose is found within a commoditized labor model, the threats posed by CT is real, immediate, and existential.

However, when it comes to wages the results of my study seems to offer contrary results than the cited literature. While I will soon argue that the results of my research do in fact offer support to the cited literature, it is important to note that wages and benefits negotiated by SMART have, in fact, risen. This, as was previously discussed, is likely due to the structure of the relationship between SMART and the companies who sign onto the CBA. In the cited literature, the results show a correlation between higher wage earnings and CT work skills. 
While the topic of wages was not directly researched in my study, it is known that the wages (and benefits) of SMART member has increased considerably since the advent of CT inroads into the sheet metal trade. While this can be attributed to the political power discussed above, the results of my research, nonetheless, do suggest that for the individual SMART member who competes for work that he or she does have the sense of potential wage loss due to CT inroads into the sheet metal trade. This is so because it is important to remember that work is not guaranteed. The contractor is the person who chooses to employ any worker and if CTs have eliminated work, then it necessarily follows that the workers from SMART are competing for a lesser number of work positions. If a member of SMART cannot find work due to technology's impact then his or her wages are zero. Therefore, while the power of SMART embodied in the CBA enables the leadership of the union to have negotiated higher rates of wages and benefits, for those members whose skills are not in demand because of technology's impact, wages have indeed decreased. One practical implication lies within the stress between increasing wages and benefits package that is negotiated in the CBA and with the skills of the sheet metal worker being devalued. Apart from raw power, what impetus is there for increased wages and benefits? Within a capitalistic economic paradigm, as a general rule, wages, in theory, should decrease. However, since wages and benefits for the SMART member has increased due primarily to the political power of the union, it then seems likely that technology usage by the contractor will increase so as to decrease the overall number of work positions (jobs) available to SMART members. Indeed, using an automated machine to do the work of a person makes economic sense to the employer. The practical implication of this is that it seems that the strategies chosen by the SMART leadership do not appear to be self-preserving of the union in the long term. 
Secondly, regarding the studies related to technology and the worker the results of my research are largely supportive of the cited literature. My study revealed that for the members of SMART who responded to the research survey that there was a clear recognition that technology demanded higher skill sets, which tacitly implies that such technologies have a deskilling effect upon work skills, and that the respondents intended to acquire such skills on an as-needed basis. The results of my study showed a clear class of respondents who recognized that change was occurring to the sheet metal trade caused by technology and that they were optimistic and ready to learn new skill sets to remain relevant and employable. These results offer support to the cited literature, and they enhance the literature in light of the commoditized labor structure of SMART. This suggests that while the member may indeed hold a level of deference or loyalty to the union that, for the members who participated in my research, they are not looking to the union as a sole means for work opportunities. That they look to themselves as being the primary source of employment opportunities. One practical implication of this is that with the evolution of the construction industry as it relates to the sheet metal trade being such, that strategies should be employed so that SMART positions itself to be able to have its members employed to do this work. This will likely require a different structure than the labor/management divide. The commoditized labor model was (and still to an extent is) important and needed, especially within an industrial economy, but with the advent of the information economy, with the so-called Industry 4.0, the labor/management divide needs to be rethought; needs to be recreated. SMART can lead in this, but it will require bold leadership that is not afraid of what this means to the accumulated power of the union. Ceding power is potentially political suicide, but with the dynamic of a changing/changed economy holding onto models from a previous era may lead to union extinction. 
Thirdly, regarding the studies related to adoption of technology here too my study is supportive of the cited literature. The respondents to my survey demonstrated behaviors supporting the concepts that one's individual beliefs affect technology acceptance, that intrinsic motivation was a determinant of technology acceptance, and with the culture of apprenticeship within SMART that culture informed the respondents willingness to accept technological change. While the first two points, individual beliefs, and intrinsic motivation, were directly ascertainable from the responses to the survey, the last point, that of culture informing the willingness to accept or resist technological change, is less obvious. However, the results of my study can also be comparted to the cited literature. Here it is important to recall that SMART is a building trades union, which has an apprenticeship model. Apprenticeship and apprentice training has been the model of the union since its inception in 1888 . With the understanding that to be a sheet metal worker means attending training to learn the sheet metal trade, it is easy to conclude that training is a cultural aspect of SMART. With a culture of learning and training, it can also be concluded that for the members of SMART there is a tacit understanding that training is expected by the individual member. With training equaling the obtaining of work skills that are relatively scarce and with this model being acculturated in SMART, then to add training to learn new technology based skill sets that are relevant and in demand, it can then be concluded that the SMART cultural norm of membership training informed the respondents when they demonstrated a willingness to accept technological change. Therefore, it can be concluded that there is a parallel between the culture of SMART and the willingness to accept technological change expressed in the respondents' answers. The practical implication is positive for SMART. With technology changing the work of the sheet metal worker and with the individual member of the union willing and ready to accept these changes and to learn new skill sets, the union is in a 
good position to begin the change process. The opportunity for SMART to consider its structures, its model, and its future and to implement a change strategy, especially in light of the changing economy, is overall in a positive place. The rank-and-file member is not only aware of the changing economy and the changes to the skills requirements needed from the sheet metal worker, but he or she is ready to make needed changes. This bodes well for SMART.

Next, regarding the studies related specifically to the unionized workforce the results of my study are less clear. Regarding the theoretical implication related to innovative behavior due to a proactive approach to technology the results of my survey are inconclusive. While the respondents of my survey did express a willingness to learn new CT skills and for some they had already completed such training, including for some training at the local union, none of the responses can be construed so as to mean that a local union was either proactive or reactive in its approach to technology. Therefore, my study did not shed any additional light to this particular topic. And regarding technology usage by a unionized workforce being intrinsic to the union labor force itself, the results of my study are also inconclusive. This is concluded in light of the fact that, again, none of the responses to my survey suggested either a proactive or a reactive approach being used by any of the respondent's local union chapter. While most of the individual respondents expressed a willingness to accept technology it was not expressed that their respective local union chapters were either proactive or reactive in its approach. Indeed, some respondents did express that they received training from their local union; however, this does not necessarily equal either proactivity or reactivity. Therefore, the results of my research are inconclusive related to this literature.

Next, regarding the theoretical implications of my study related to resistance to change, my results are partially supportive, but in most cases inconclusive. The only area from the results 
of my research that can be positively connected to the cited literature is in the area of values. Specifically, one conclusion from the cited studies is that values alignment plays a role in change adoption. While this conclusion can apply to either resistance or readiness for change, it can be inferred that the results from those respondents who were determined to be resisters of change did so because of their values were such that self-preservation is instinctual. For the respondent who expressed that SMART's leadership should resist change due to technology's impact upon jobs loss, it can be easily seen that such respondents valued their jobs and that resistance to technology was seen by them as a form of preservation of their work. Therefore, regarding this particular issue, the results of my study are supportive. However, my study does not speak one way or another regarding the other conclusions from the cited literature. When it comes to the practical implications regarding values alignment and resistance to change, SMART must be aware that, if the percentage of respondents to my research can be extrapolated to the union as a whole, a sizable minority of its members hold values that express the need to resist changes brought to the sheet metal trade from CTs. If SMART opts to embark upon a change initiative relative to technological change, then preparing for the likely backlash from such members seems to be in order.

Finally, regarding the theoretical implications of my study related to readiness for change the results of my study are supportive of most of the cited literature. Regarding the individual's evaluation about the individual's and SMART's capacity for change, the need for change, and the benefits of these changes, the majority of respondents of my study responded to the survey in a manner that supports the cited literature. Specifically, the respondents who were deemed ready for change expressed that they expect the union to embrace technological changes and that training should be created and delivered to the membership so as to enable the individual 
member to be able to perform this work. In this type of response, the respondent is clearly expressing that both the individual and SMART possesses the capacity to make these changes. Otherwise, the response would necessarily be resistant. Only if a person were not serious about a change initiative would that person embrace the change initiative if they believed that it was doomed to fail from its onset. Assuming the sincerity of the respondents to my survey, it makes sense that only if a person believes that change can be achieved would that person embrace a change initiative. Therefore, without knowing any level of sincerity of the respondents to my survey and imparting sincere answers, I conclude that my study is supportive of the cited literature regarding readiness for change. Regarding, a learning environment positively effecting change adoption, as was mentioned above, the results of my study are supportive. The structural component of apprenticeship and apprentice training have been part of SMART since its inception and, therefore, the environment and the culture of SMART is such whereby the membership has come to expect training to be part of what it is to be a sheet metal worker. Therefore, the respondents who expressed that training for technology work skills should be created and implemented by SMART demonstrate that the learning environment, which is part of the SMART culture, can positively affect a change initiative. The practical implications of this are very positive for SMART. The learning culture that is found at SMART is a solid foundation where the union can embark upon change initiatives as they relate to technological changes to work skills. Therefore, if my study can be extrapolated to the SMART union membership as a whole, the majority of the membership is ready for change.

\section{$\underline{\text { Suggestions for Future Research }}$}

There are several areas that deserve further exploration. Related to the worker in general, research on how the personal life of the worker whose labor has been devalued has been changed 
should be explored. In America, the rust belt is a symbol of lost industry and while much has been chronicled regarding lost work, the idea of devalued skills or skills obsolescence and how this finds expression in the lives of workers in such circumstances would add quite a bit to the topic. Studies on how these workers see their employment prospects and what they see as possible solutions for the devaluing of human labor will help society greatly. Lessons that can be learned from these workers should cast light upon how educational systems may need to be changed. With devalued skills, skills obsolescence, and a new work reality where higher skills are needed, what sociological and psychological implications does that have for the younger worker in particular and for society? Does the devaluing of skills and skills obsolescence find expression in seemingly xenophobic ways? Is there a relation between devaluing of skills and skills obsolescence and the rise of nationalistic political expressions? Answering these questions would add to society's understanding of how such devaluation of skills and skills obsolescence may be realized by a segment of that society's population.

As a proponent of change to SMART, I propose that new research should be conducted to examine what knowledge is essential to SMART, what it cannot afford to lose. More specifically, it was expressed by some participants in my study that some new technologies could not replace traditional knowledge and acquired skills. Knowing what specific skills are becoming obsolete or are being devalued will enable SMART to adapt its focus for training and its goals for future contract bargaining. This specific skill research can shed light for SMART on the particular skills that need to be preserved somehow and the work that must be evolved or created so as to enable SMART to remain viable in the future. Building a new business model based upon evolved skills seems to me wise. Learning what the rank-and-file sheet metal workers, the ones who are actually doing sheet metal work on a daily basis, feel are the skills that are likely to 
remain in demand and what skill seem to be in waning in demand will enable the union to see a clearer path forward. Learning what skills the younger rank-and-file sheet metal worker feel comfortable attempting to learn would also help guide the SMART leadership. These are areas that need exploration. Additionally, learning what skills the contractors find useful and in demand for their businesses would helpful to SMART in any prospective skills training programs. Using both qualitative and quantitative research methods helped me gain insight into the phenomena examined in my study and enabled me to discover that automation has a global reach; at the same time, I learned how automation and CT has affected the lives of my fellow union members and about their readiness or resistance to these changes. For future studies, especially on building trades unions, using both research methods could help provide a deeper insight into how these workers feel regarding the particular issue being studied. Enabling the respondent to quantify his or her feelings and at the same time providing the value of those responses will certainly enhance the results. 


\section{Bibliography}

Addleson, M. (2011). Beyond Management Taking Charge at Work. New York: Palgrave MacMillan.

Adler, P. S. (1988). Automation, Skill and the Future of Capitalism. Berkeley Journal of Sociology, 33, 1-36.

Aeppel, T. (2017, December 10). Tech. Retrieved from The Wall Street Journal: https://www.wsj.com/articles/what-clever-robots-mean-for-jobs-1424835002

Agarwal, R., \& Prasad, J. (1999). Are Individual Differences Germane to the Acceptance of New Informaion Technologies? Decision Sciences, 30(2), 361-391.

Aladwani, A. M. (2001). Change management strategies for successful ERP implementation. Business Process Mangement, 7(3), 266-275.

Amason, A. C. (1996). Distinguishing the Effects of Functional and Dysfunctional Conflict on Strategic Decision Making: Resolving a Paradox for Top Management Teams. Academy of Management Journal, 39(1), 123-148.

Armenakis, A. A., Harris, S. G., \& Mossholder, K. W. (1993). Creating Readiness for Organizational Change. Human Relations, 46(6), 681-703.

Arnesen, E. (2007). Encyclopedia of U.S. Labor and Working-Class History. New York: Routledge.

Aronowitz, S., \& DiFazio, W. (1996). High Technoloty and Work Tomorrow. Annals of the American Academy of Political and Social Science, 544(1), 52-67. 
Atkinson, P. A., \& Coffey, A. (2004). Analyzing documentary realities. In D. Silverman, Qualitative Research: Theory, Method and Practice (pp. 56-75). London: Sage.

Autor, D. H., Levy, F., \& Murnane, R. J. (2003). The Skill Content of Recent Technological Change: An Empirical Exploration. The Quarterly Journal of Economics, 118(4), 12791333.

Barrett, F. J., Thomas, G. F., \& Hocevar, S. P. (1995). The Central Role of Discourse in LargeScale Change: A Social Construction Perspective. Journal of Applied Behavioral Science, $31(3), 352-372$.

Bartelsman, E. J., Gautier, P. A., \& Wind, J. d. (2011). Employment protection, technology choice, and worker allocation. Amsterdam: De Nederlandsche Bank NV.

Battilana, J., \& Casciaro, T. (2013). Overcoming Resistance to Organizational Change: Strong Ties and Affective Cooptation. Management Science, 59(4), 819-836.

Bennett, J. T., \& Taras, D. G. (2002). Technological change and employment conditions in traditionally heavily unionized industries. Journal of Labor Research, 23(4), 507-511.

Berman, E., Bound, J., \& Machin, S. (1998). Implications of Skill-Biased Technological Change: International Evidence. The Quarterly Journal of Economics, 113(4), 1245-1279.

Bickman, L., \& Rog, D. J. (1998). Handbook of Applied Social Research Methods. Thousand Oaks: Sage Publications.

Blauner, R. (1964). Alienation and Freedom: The factory worker and his industry. London: The University of Chicago Press. 
Bowen, G. A. (2009). Document Analysis as a Qualitative Research Method. Qualitative Research Journal, 9(2), 27-40.

Braverman, H. (1974). Labor and Monopoly Capital. New York: Monthly Review Press.

Bright, J. R. (1958). Automation and Management. Boston: Harvard University Press.

Brynjolfsson, E., \& McAfee, A. (2011). How the Digital Revolution is Accelerating Innovation, Driving Productivity, and Irreversibly Transforming Employment and the Economy. Lexington: Digital Frontier Press.

Brynjolfsson, E., \& McAfee, A. (2014). The Second Machine Age: Work, Progress, and Prosperity in a Time of Brilliant Technologies. New York: W. W. Norton \& Company, Inc.

Bureau of Labor Statistics. (2016, April 17). Databases, Tables \& Calculators by Subject: CPI Inflation Calculator. Retrieved from United States Department of Labor: Bureau of Labor Statistics: http://www.bls.gov/data/inflation_calculator.htm

Burnes, B., \& Jackson, P. (2011). Success and Failure in Organizaiton Change: An Exploration of the Role of Values. Journal of Change Management, 11(2), 133-162.

Celeux, G., \& Soromenho, G. (1996). An Entropy Criterion for Assessing the Number of Clusters in a Mixture Model. Journal of Classification, 13(2), 195-212.

Chennells, L., \& Van Reenen, J. (1999). Has Technology Hurt Less Skilled Workers? A survey of the Micro-Econometric Evidence. London: The Institute for Fiscal Studies.

Chicago Tribune. (1970, August 4). Construction Spending Is Steady In June. Chicago Tribune, p. Section 3 Page 7. 
Chin, R., \& Benne, K. D. (1985). General Strategies for Effecting Changes in Human Systems. In W. G. Bennis, K. D. Benne, \& R. Chin, The Planning of Change (pp. 22-43). New York: Holt, Rinehart \& Winston.

Choi, M., \& Ruona, W. E. (2011). Individual Readiness for Organizational Change and Its Implications for Human Resource and Organization Development. Human Resource Development Review, 10(1), 46-73.

Christiansen, C. H. (1999). Defining Lives: Occupation as Identity: An Essay on Competence, Coherence, and the Creation of Meaning. American Journal of Occupational Therapy, $53(6), 547-558$.

Collinson, S. (2016, August 13). How Donald Trump defied all odds. Retrieved from CNN Politics: http://www.cnn.com/2016/05/04/politics/donald-trump-republican-nomination/

Davidow, W. H., \& Malone, M. S. (2016, August 20). Economics \& Society. Retrieved from Harvard Business Review: https://hbr.org/2014/12/what-happens-to-society-when-robotsreplace-workers

Davies, A., Fidler, D., \& Gorbis, M. (2011). Future Work Skills. Palo Alto: Apollo Research Institute.

Davis, F. D. (1989). Perceived Usefulness, Perceived Ease of Use, and User Acceptance of Information Technology. Management Information Systems Quarterly, 13(3), 319-340.

de Groen, W. P., Lenaerts, K., Bosc, R., \& Paquier, F. (2017). Impact of digitalisation and the on-demand economy on labour markets and the consequences for employment and industrial relations. Brussels: European Economic and Social Committee. 
Delaney, J. T., Jarley, P., \& Fiorito, J. (1996). Planning For Chang: Determinants Of Innovation In U.S. National Unions. Industrial and Labor Relations Review, 49(4), 597-614.

Deutskens, E. R., \& Wetzels, M. (2006). An Assessment of Equivalence Between Online and Mail Surveys in Service Research. Journal of Service Research, 8(4), 346-355.

Doms, M., Dunne, T., \& Troske, K. (1997). Workers, Wages, and Technology. The Quarterly Journal of Economics, 112(1), 253-290.

Donald J. Trump for President, Inc. (2016, July 7). Reforming The U.S.-China Trade Relationship To Make America Great Again. Retrieved from Donald J. Trump for President, Inc.: https://www.donaldjtrump.com/positions/us-china-trade-reform

Doumbouya, L., Gao, G., \& Guan, C. (2016). Adoption of the building information modeling (BIM) for construction project effectiveness: The review of BIM benefits. American Journal of Civil Engineering and Architecture, 4(3), 74-79.

Eby, L. T., Adams, D. M., Russell, J. E., \& Gaby, S. H. (2000). Perceptions of Organizational Readiness for Change: Factors Related to Employees' Reactions to the Implementation of Team-Based Selling. Human Relations, 53(3), 419-442.

Ford, J. D., Ford, L. W., \& D'Amelio, A. (2008). Risistance To Change: The Rest Of The Story. Academy of Management Review, 33(2), 362-377.

Fountain, J. W. (2016, December). Outsourcing of building information modeling (BIM) among general contractors in the United States. The Aquila Digital Community. Mississippi, United States of America: The University of Southern Mississippi. 
Frey, C. B., \& Osborne, M. A. (2013). The Future of Employment: How Susceptible are Jobs to Computerisation? September: Oxford University.

Friedberg, L. (2003). The Impact of Technological Change on Older Workers: Evidence from Data on Computer Use. Industrial and Labor Relations Review, 56(3), 511-529.

Fuegen, K., \& Brehm, J. W. (2004). The Intensity of Affect and Resistance to Social Influence. In E. S. Knowles, \& J. A. Linn, Resistance and Persuation (pp. 39-64). Mahway, N.J.: Lawrence Erlbaum Associates.

Giebel, G. (1980). Alienation From Freedom: The Effect of the Loss of Union Power Upon the Relationship Between Technology and Work.

Gorge Local Currency Cooperative. (2016, April 23). Welcome to RiverHOURS. Retrieved from Gorge Local Currency Cooperative: http://riverhoursalternate.weebly.com/riverhourshome.html

Hagenaars, J. A., \& McCutcheon, A. L. (2002). Applied Latent Class Analysis. Cambridge: Cambridge University Press.

Hershey Jr., R. D. (2016, August 20). Business Day: The Rise Of The Working Class. Retrieved from The New York Times: http://www.nytimes.com/1997/09/03/business/blue-collarjobs-gain-but-the-work-changes-in-tone.html?pagewanted=all\&_r=0

Hillary For America. (2016, July 7). Manufacturing. Retrieved from Hillary For America: https://www.hillaryclinton.com/issues/manufacturing/

Hirsch-Kreinsen, H. (2016). Digitalisation and low-skilled work. Bonn: Friedrich-Ebert-Stiftung. 
Holt, D. T., Armenakis,, A. A., Feild, H. S., \& Harris, S. G. (2007). Readiness for Organizational Change: The Systematic Development of a Scale. Journal of Applied Behavioral Science, 43(2), 232-255.

Hon, A. H., Bloom, M., \& Crant, J. M. (2014). Overcoming Resistance to Change and Enhancing Creative Performance. Journal of Management, 40(3), 919-941.

Ikenson, D. J. (2016, July 7). The Myth of a Manufacturing Renaissance. Retrieved from Cato Institute: http://www.cato.org/blog/myth-manufacturing-renaissance

International Association of Sheet Metal, A. R. (2015, August 29). Master Constitution Document. Retrieved from SMART: https://smart-union.org/files/2015/04/MasterConstitution-Document-4-15-15.pdf

Jacobs, G., Witteloostuijn, A. v., \& Christe-Zeyse, J. (2013). A Theoretical Framework of Organizational Change. Journal of Organizational Change Managment, 26(5), 772-792.

Jansen, K. J. (2000). The Emerging Dynamics of Change: Resistance, Readiness, and Momentum. Human Resource Planning, 23(2), 53-55.

Kappos, A., \& Rivard, S. (2008). A Three-Perspective Model of Culture, Information Systems, and Their Development and Use. Management Information Systems Quarterly, 32(3), 601-634.

Kaye, B. K., \& Johnson, T. J. (1999). Research Methodology: Taming the Cyber Frontier. Social Science Computer Review, 17(3), 323-337.

Keefe, J. H. (1991). Do Unions Influence the Diffusion of Technology? Industrial and Labor Relations Review, 44(2), 261-274. 
Klein, D. (1985). Some Notes on the Dynamics of Resistance to Change: The Defender Role. In W. G. Bennis, K. D. Benne, \& R. Chin, The Planning of Change (pp. 98-105). New York: Holt, Rinehart \& Winston.

Knowles, E. S., \& Linn, J. A. (2004). Resistance and Persuation. Mahwah, N.J.: Lawrence Erlbaum Associates.

Krueger, A. B., Autor, D. H., \& Katz, L. F. (1998). Computing Inequality: Have Computers Changed the Labor Market? Quarterly Journal of Economics, 113(4), 1169-1214.

Lamb, S. (2015, February 17). The Digital Technological Revolution and its Impact on the Construction Industry. Retrieved from The OGM: http://theogm.com/2015/02/17/thedigital-technological-revolution-and-its-impact-on-the-construction-industry/

Larkin, M., Watts, S., \& Clifton, E. (2006). Giving voice and making sense in interpretive phenomenological analysis. Qualitative Research in Psychology, 3(2), 102-120.

Levine, R. W. (1985). United States of America Patent No. 4,554,635.

Lewin, K. (1997). Action Research and Minority Problems. In K. Lewin, Resolving Social Conflicts \& Field Theory in Social Science (pp. 143-152). Washington, DC: American Psychology Association.

Li, W., \& Nyholt, D. R. (2001). Marker Selection by Akaike Information Criterion and Bayesian Information Criterion. Genetic Epidemiology, 21(S1), S272-S277.

Lo, Y., Mendell, N. R., \& Rubin, D. B. (2001). Testing the Number of Components in a Normal Mixture. Biometrika, 88(3), 767-778. 
Loosemore, M. (2016, February 10). Newsroom. Retrieved from University of New South Wales Sydney: https://newsroom.unsw.edu.au/news/art-architecture-design/impact-technologyemployment-construction

Lorenzi, N. M., \& Riley, R. T. (2000). Managing change: an overview. Journal of the American Medical Informatics Association, 7(2), 116-124.

MacDonald, G., \& Weisbach, M. S. (2004). The Economics of Has-beens. Journal of Political Economy, 12(S1), S289-S310.

Machin, S., \& Van Reenen, J. (1998). Technology and Changes in Skill Structure. The Quarterly Journal of Economics, 113(4), 1215-1244.

Madill, A., Gough, B., Lawton, R., \& Stratton, P. (2005). How should we supervise qualitative projects? The Psycologist, 18(10), 616-618.

Maslow, A. H. (1943). A theory of human motivation. Psychological Review, 50(4), 370-396.

Mattingly, S. (2002, December 23). Construction methods change as technology improves for the industry. Retrieved from Louisville Business First: http://www.bizjournals.com/louisville/stories/2002/12/23/story2.html

McConnell, M. (2003, September 1). Turning back the pages. Retrieved from Snips: http://www.snipsmag.com/articles/85229-turning-back-the-pages

McGill, A. (2016, August 7). Who Voted for Brexit? Retrieved from The Atlantic: http://www.theatlantic.com/international/archive/2016/06/brexit-vote-statistics-unitedkingdom-european-union/488780/

McLachlan, G., \& Peel, D. (2000). Finite Mixture Models. New York: John Wiley. 
McNamee, S., \& Hosking, D. M. (2012). Research and Social Change: A Relational Constructionist Approach. New York: Routledge.

Mealiea, L. W. (1978). Learned behavior: the key to understanding and preventing employee resistance to change. Group Organizational Management, 3(2), 211-223.

Muñoz, S. S., \& Turner, G. (2016, August 7). Working-Class Britons Unsympathetic to Banker Brexit Woes. Retrieved from The Wall Street Journal: http://www.wsj.com/articles/u-kbankers-could-suffer-fallout-from-vote-to-leave-eu-1466333181

Muthen, L. K., \& Muthen, B. O. (1998-2015). Mplus Users Guide. Los Angeles: Muthen \& Muthen.

National Association of Manufacturers. (2016, July 7). Top 20 Facts About Manufacturing. Retrieved from National Association of Manufacturers: http://www.nam.org/Newsroom/Top-20-Facts-About-Manufacturing/

National Research Council. (1999). The Changing Nature of Work: Implications for Occupational Analysis. Washington, DC: The National Academies Press.

Nicas, J. (2015, January 20). Drones' Next Job: Construction Work. The Wall Street Journal.

Oreg, S. (2006). Personality, context, and resistance to organizational change. European Journal of Work and Organizational Psychology, 15(1), 73-101.

Oreg, S., \& Sverdlik, N. (2011). Ambivalence Toward Imposed Change: The Conflict Between Dispositional Resistance to Change and the Orientation Toward the Change Agent. Journal of Applied Psychology, 96(2), 337-349. 
Palladino, G. (2012). A History of the Sheet Metal, Air, Rail, and Transporation Workers International Association: From SMWIA to SMART. Retrieved from 125 Years Sheet Metal Air Rail Transportation SMART Expertise: http://www.smwia.org/LinkClick.aspx?fileticket=Y2avo1G\%2b1XA\%3d\&tabid=494\&m $\mathrm{id}=855$

Papadopoullos, C. (2016, February). Millions of jobs at risk of automation over the coming decades, Bank of England's Andy Haldane tells trade union. Retrieved from City A.M.: http://www.cityam.com/228674/millions-of-jobs-at-risk-of-automation-over-the-comingdecades-bank-of-englands-andy-haldane-tells-trade-union

Peiffer, E. (2015, August 26). 10 trends defining the construction industry. Retrieved from Construction Dive: http://www.constructiondive.com/news/10-trends-defining-theconstruction-industry/404564/

Pew Research Center. (2016, August 13). 4. Top voting issues in 2016 election. Retrieved from Pew Research Center: http://www.people-press.org/2016/07/07/4-top-voting-issues-in2016-election/

Picchi, A. (2016, January 18). Money Watch. Retrieved from CBS News: https://www.cbsnews.com/news/the-robot-revolution-will-take-5-million-jobs-fromhumans/

Piderit, S. K. (2000). Rethinking Resistance and Recognizing Ambivalence: A Multidimensional View of Attitudes Toward an Organizational Change. Academy of Management Review, 25(4), 783-794.

Piore, M. J., \& Sabel, C. F. (1984). The Second Industrial Divide. New York: Basic Books. 
Raftery, A. (1995). Bayesian Model Selection in Social Research. Sociological Methodology, 25, $111-163$.

Robbins, S. P., \& Judge, T. A. (2013). Organizational Behavior. Upper Saddle River: Pearson.

Rosenberg, J. M. (2012). The Concise Encylopedia of The Great Recession 2007-2012. Lanham: Scarecrow Press, Inc.

Rotman, D. (2016, August 7). How Technology is Destroying Jobs. Retrieved from MIT Technology Review: https://www.technologyreview.com/s/515926/how-technology-isdestroying-jobs/

Savransky, R. (2016, August 13). Ex-House GOP Leader: Trump won't survive primaries. Retrieved from The Hill: http://thehill.com/blogs/blog-briefing-room/news/266577-exhouse-gop-leader-trump-wont-survive-primaries

Schein, E. H. (1988). Organizational Psychology. Englewood Cliffs, N.J.: Prentice-Hall.

Schurman, S. J. (2012, November 11). The Path to Effective Workers' Organizations in the 21st Century. George Mason University Graduate School Presentation. Arlington, Virginia, United States of America.

Sheahan, J. (1979). Essential Psychiatry. London: Hastings Hilton Publishers Limited.

Sheet Metal. (2016, April 10). Sheet Metal. Retrieved from Sheet Metal Air Rail Transportation SMART: https://smart-union.org/sheet-metal/

Shepard, J. M. (1977). Technology, Alienation, and Job Satisfaction. Annual Review of Sociology, 3, 1-21. 
Sheridan, T. B., Vamos, T., \& Aida, S. (1983). Adapting Automation to Man Culture and Society. Automatica, 19(6), 605-612.

Sheth, J. N. (1981). Psychology of innovation resistance: The less developed concept (LDC) in diffusion research. Research in Marketing, 273-282.

Shoulders, J. R., \& Keane, M. A. (2012). United States of America Patent No. US8285413 B1.

SmartMarket Report. (2015). Measuring the Impact of BIM on Complex Buildings. Bedford: Dodge Data \& Analytics.

Smith, D. K. (2012). Message from the buildingSMART alliance. Journal of Building Information Modeling, p 9.

Snyder, M. (2012, January 17). Why Blue Collar Jobs Are Disappearing. Retrieved from Business Insider: http://www.businessinsider.com/why-blue-collar-jobs-are-dissapearing2012-1

Spitz, A. (2006). Technical Change, Job Tasks and Rising Educational Demands: Looking Outside the Wage Structure. Journal of Labor Economics, 24(2), 235-270.

Stanford Politics. (2016, August 13). Donald Trump Will Not Win The Nomination. Retrieved from Stanford Political Journal: https://stanfordpolitics.com/donald-trump-will-not-winthe-nomination-93eb0dbace14\#.wih6azfaf

Statistics, U. S. (2015, May 3). Table 11: Employed Persons by Detailed Occupation and Sex, 2010 Annual Averages. Retrieved from The United States Department of Labor Bureau of Labor Statistics: http://www.bls.gov/cps/wlf-table11-2011.pdf 
SurveyMonkey. (2015, May 10). SurveyMonkey Help Center. Retrieved from

SurveyMonkey.com: http://help.surveymonkey.com/articles/en_US/kb/Are-my-surveyresponses-anonymous-andsecure?uid=n9r_2Fnz6858g3Sk9aaWjDMJA0qISfqzSvRRkfnYBD0JaGSYt4EF5QpKW MiyIoDt95X6uouMfsz_2B2tSIdThr1cIQ_3D_3D

The International Training Institute for the Sheet Metal and Air Conditioning Industry. (2015, March 21). Your Career in Sheet Metal. Retrieved from The International Training Institute for the Sheet Metal and Air Conditioning Industry: https://www.sheetmetaliti.org/careers/index.asp

Thompson, D. (2016, August 20). The Atlantic July/August 2015 Issue. Retrieved from The Atlantic: http://www.theatlantic.com/magazine/archive/2015/07/world-withoutwork/395294/

U.S. News \& World Report. (2015, March 15). Sheet Metal Worker. Retrieved from U.S. News \& World Report: http://money.usnews.com/careers/best-jobs/sheet-metal-worker

United States Census Bureau. (2016, April 10). 1970 Census of Population. Retrieved from United States Census Bureau: http://www2.census.gov/prod2/decennial/documents/1970a_us2-01.pdf

United States Census Bureau. (2016, April 10). United States. Retrieved from United States Census Bureau: http://www.census.gov/quickfacts/table/PST045215/00

United States Census Bureau. (2016, April 10). Value of Construction Put In Place. Retrieved from United States Census Bureau: https://www.census.gov/construction/c30/pdf/totsa.pdf 
Van Selm, M., \& Jankowski, N. W. (2006). Conducting Online Surveys. Quantity \& Quality, 40(3), 435-456.

Vivarelli, M. (2013). Technology, Employment and Skills: An Interpretive Framework. Eurasian Business Review, 3(1), 66-89.

Waddell, D., \& Sohal, A. S. (1998). Resistance: a constructive tool for change management. Management Decision, 36(8), 543-548.

Wall, T. D., Clegg, C. W., Davies, R. T., Kemp, N. J., \& Mueller, W. S. (1987). Advanced manufacturing technology and work simplification: an empirical study. Journal of Occupational Behaviour, 8(3), 233-250.

Whitely, P., \& Clarke, H. D. (2016, July 7). Independent. Retrieved from Brexit: Why did older voters choose to Leave the EU?: http://www.independent.co.uk/news/uk/politics/brexitwhy-did-old-people-vote-leave-young-voters-remain-eu-referendum-a 7103996.html

Woolgar, S. (1996). Psychology, Qualitative Methods and the Ideas of Science. Leicester': BPS Publications.

World Economic Forum. (2016). The Future of Jobs: Employment, Skills and Workforce Strategy for the Fourth Industrial Revolution. Geneva: World Economic Forum.

Zuboff, S. (1988). In the Age of the Smart Machine. New York: Basic Books, Inc. 
Appendices 


\section{Appendix One}

\section{$\underline{\text { Definition of Terms }}$}

Abstracted work: Work that once was achieved through physical means that is now achieved through intellectual understanding and manipulation of computer-generated symbols

Apprenticeship: The period of time when a sheet metal worker, or other building trades worker, is hired for both classroom and on-the-job training. Training is largely achieved by observation and practice.

Bench layout person: The sheet metal worker who uses trigonometry, applied calculus, and other mathematical means to create sheet metal patterns that will be turned into sheet metal fittings for use in a mechanical system, e.g., an air distribution system (ductwork).

Blue-collar worker: A worker in a non-managerial position who is usually covered by the National Labor Relations Act and the Fair Labor Standards Act

Building Information Modeling (BIM): The act of using a computer and software to create a virtual model of any building and assign information to virtual entities. These smart entities are used throughout the life cycle of a building.

Building trades: The trades that are used to erect a building or edifice. These can include carpenters, masons, sheet metal workers, pipefitting trades, electricians, glazers, roofers, laborers, etc.

Business manager: The Chief Executive Officer of the specific local union 
Collective bargaining agreement: The union contract that is negotiated with management by the union leadership on behalf of the membership of a union

Deskilling: The act of making a skill obsolete or the act of a computer or machine performing some tasks that are required in a skill.

Fully automated sheet metal shop: A sheet metal shop that uses plasma tables, robotic arms, and other automated computerized machines to the fullest extent so that the need for human participation in the production of sheet metal parts is minimized.

Human capital: The stock of knowledge, habits, social, and personality attributes, including creativity, embodied in the ability to perform labor so as to produce economic value Industrial economy: An economy in which the production of tangible goods and services is the source of value

Information economy: An economy in which knowledge is the primary raw material and source of value

Informative work: Work that is the creation of ideas or the manipulation of computer symbols to enhance an idea

Local union: A specific union chartered under SMART. The specific union has a geographic area of jurisdiction and individually negotiates the collective bargaining agreement for its members.

Mechanical contractor: A business that employs tradespersons from the mechanical building trades. The can include sheet metal workers, pipefitters, and plumbers.

Plasma Table: A machine that uses Computer Numerical Control (CNC) and creates a channel of ionized gas to cut through a sheet of metal that is laid on a table. 
Samuel Gompers: The first president of the American Federation of Labor (AFL; AFL-CIO)

Sheet metal contractor: A business that employs only sheet metal workers of the building trades.

Sheet Metal Workers' International Association (SMWIA): Former name of The International Association of Sheet Metal, Air, Rail, and Transportation Workers (SMART)

The International Association of Sheet Metal, Air, Rail, and Transportation Workers (SMART): The international union of sheet metal workers, which merged with the United Transportation Union (UTU).

The International Training Institute for the Sheet Metal and Air-Conditioning Industry (ITI): A Taft-Hartley training trust organization jointly sponsored by SMART and the Sheet Metal and Air Conditioning Contractors' National Association (SMACNA)

Traditional work of a sheet metal worker: Physical work to physically create or manually install parts in a ductwork air distribution system. This work usually includes the use of hand tools such as hammers, screwdrivers, etc. 
Appendix Two

Questionnaire 


\section{Sheet Metal Workers and Computer Technology}

\section{Sheet Metal Workers Survey}

Thank you for participating in this survey. The survey is designed to learn how sheet metal workers view issues related to computerized technology's impact upon the sheet metal industry.

*1. Which statement best describes your thoughts and feelings about the impact of computer technologies on sheet metal workers' jobs?

Computer technologies are going to replace more and more of our jobs like they've done in other industries. pple

Computer technologies are going to replace a lot of our jobs, but not all of our jobs can be replaced by computer technology.

Computer technologies are going to replace some of our jobs, but not that many as some of our skills are too advanced to be replaced

Computer technologies cannot replace our jobs. What we do is too advanced for computer technologies.

New jobs will be created by computer technologies, but it's not one to one, for every new job created more than one will be lost.

Computer technologies are going to create new jobs, but no one will lose his or her job as we will just retrain the members to for the new jobs.

Other (please specify)

*2. As computer technologies become more widely used in the sheet metal industry what impact do they have upon your job as a sheet metal worker?

Very positive impact. Computer technology will never be able to do exactly what I do, but it will help me do my job better.

Somewhat positive impact. Computer technology will replace some of the job tasks that I perform, but it cannot perform all of the job tasks that I do.

Neutral, neither positive nor negative impact. Computer technology is irrelevant to my job.

Somewhat negative impact. Computer technology will replace many of my job tasks, but not all of them.

Very negative impact. Computer technology could replace most or all of my job tasks.

Other (please specify) 
* 3. How do you feel about whether or not your sheet metal skills are relevant and needed in the industry today?

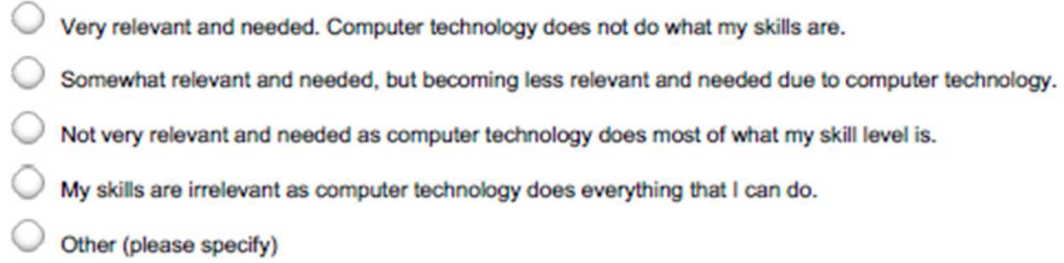

* 4. How do you see computer technology impacting your job as a sheet metal worker in the future?

Very Positive Impact. Computer technology will never be able to do exactly what I do, but it will help me do my job better.

Somewhat Positive Impact. Computer technology will replace some of the job tasks that I perform, but it cannot perform all of the job tasks that I do

Neutral, neither positive nor negative impact. Computer technology is irrelevant to my job

Somewhat negative impact. Computer technology will replace many of my job tasks, but not all of them

Very negative impact. Computer technology could replace most or all of my job tasks

Other (please specify)

* 5. As computer technologies become more widely used in the sheet metal industry how do you see your skills being changed?

Not changed at all. Computer technology cannot do what my skill sets are

Somewhat changed. I will need to learn some new computer technology skills to do my job

Neutral, computer technology is irrelevant to my job

Largely changed. I will need to learn many computer technology skills to do my job

Completely changed. I will need to learn a lot of computer technology skills to do my job

Other (please specify) 
* 6 . Since the beginning of your career as a sheet metal worker have you learned new computer technologies that help you do your job better?

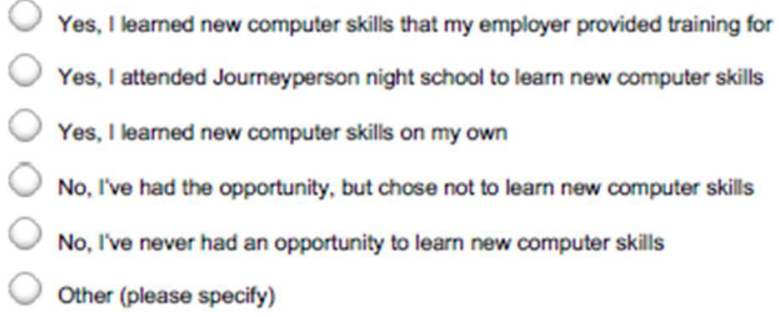

* 7. If your job as a sheet metal worker changes to the point where you will need to learn new computer technologies, how do you feel about this?

Very positive. I am good with computer technologies and not worried at all about learning any new computer skills

Somewhat positive. I don't know a lot about computer technologies, but I feel as though I can learn what I need to learn

Neutral. It doesn't matter how I feel about learning computer technologies. I have to do what I have to do and that is to learn new computer technologies

Somewhat negative. I have done some things with a computer, but they can be frustrating and I am a little worried about having to learn new computer skills

Very negative. Computers are not for me and having to learn computer skills worries me a lot

Other (please specify)

* 8. As a union member what impact do you see computer technologies having on the number of jobs available to your union's members?

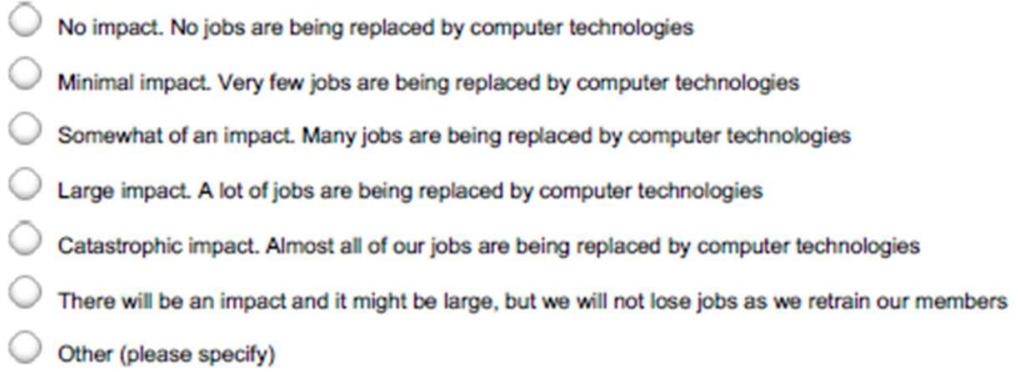


* 9 . Which statement best describes how the impact of computer technologies on jobs in the sheet metal industry has upon your personal life

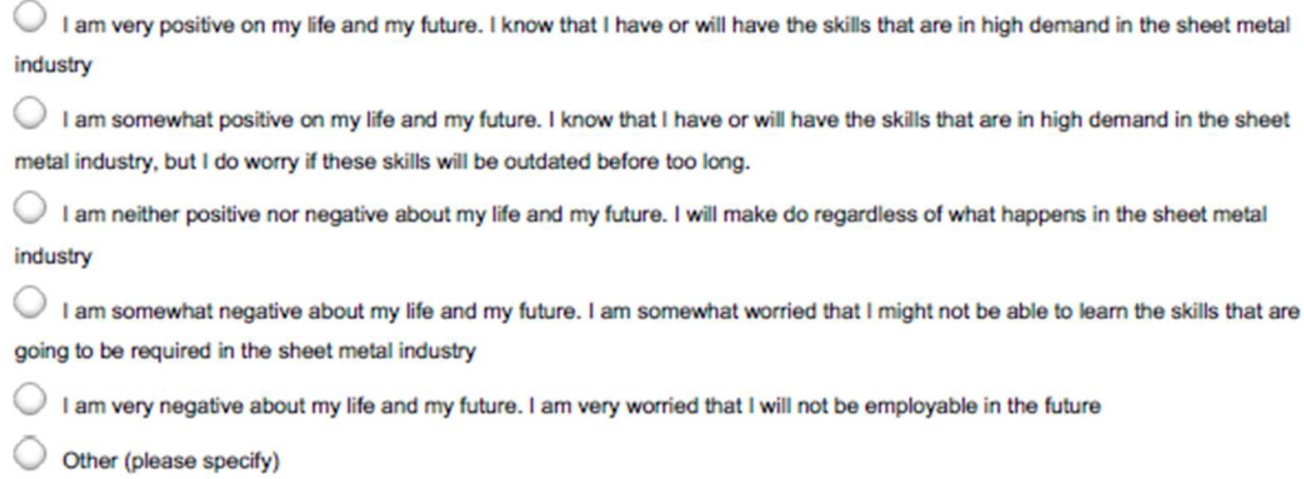

* 10. How are you adapting to any changes that computer technologies bring to the sheet metal industry?

I will just learn the new skills when I need to learn them

I will leave the sheet metal industry and find work in another industry

I am not going to do anything

I am trying to get ahead of the technology curve now by attending new training

Other (please specify)

*11. What do you expect of your union's leadership regarding computer technologies?

My union's leadership must embrace computer technologies regardless of the consequences to our union. Change is constant and we need to adapt to it to remain relevant in the industry

My union's leadership must fight against computer technology. We are losing our jobs and it is their job to fight for our jobs

My union's leadership should embrace computer technologies, but attempt to manage their implementation into our industry. Too much too fast will be bad for our union

My union's leadership should embrace computer technology and they should make sure these new computer technology jobs are covered employment in the collective bargaining agreement for our members

Other (please specify) 
*12. What future do you see regarding the impact computer technologies will have upon the construction industry as a whole?

No changes will occur in the construction industry. We have been constructing buildings the same way for a long time and that is not going to change

A few changes will occur in the construction industry. Constructing a building mostly requires people to do the work, but there are some things that computer technology can do

Some changes will occur in the construction industry. More and more tasks can be done with computer technologies, but there will still be a need for a lot of people to do the work

Huge changes will occur in the construction industry. Almost all of the tasks that are done constructing a building can be done with computer technologies

Changes will occur, and they may be big, but jobs will not be lost as we retrain workers to operate the new technologies

Other (please specify)

Figure 17. Online SurveyMonkey Survey 
Appendix Three

$\underline{\text { Photos of Sheet Metal Worker and Sheet Metal Work }}$

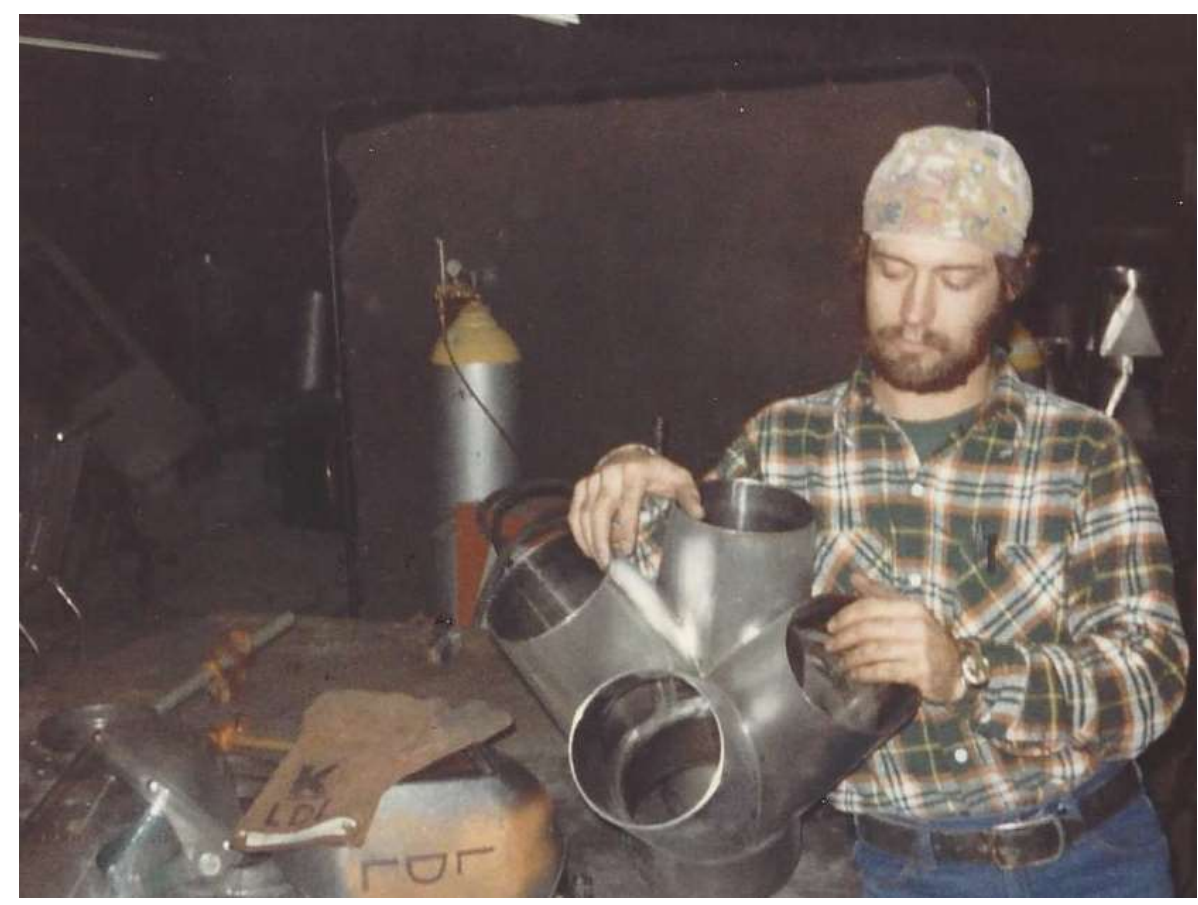

Traditional Sheet Metal Work 1

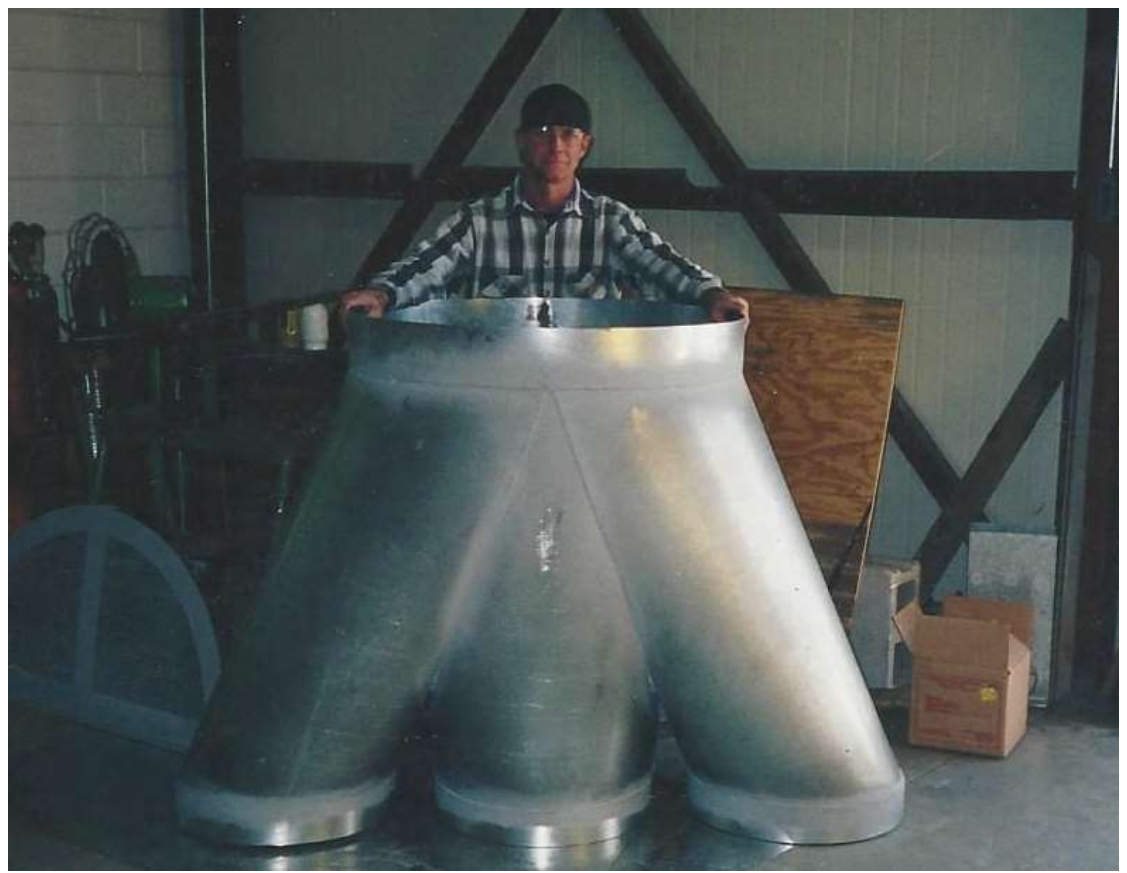

Traditional Sheet Metal Work 2 


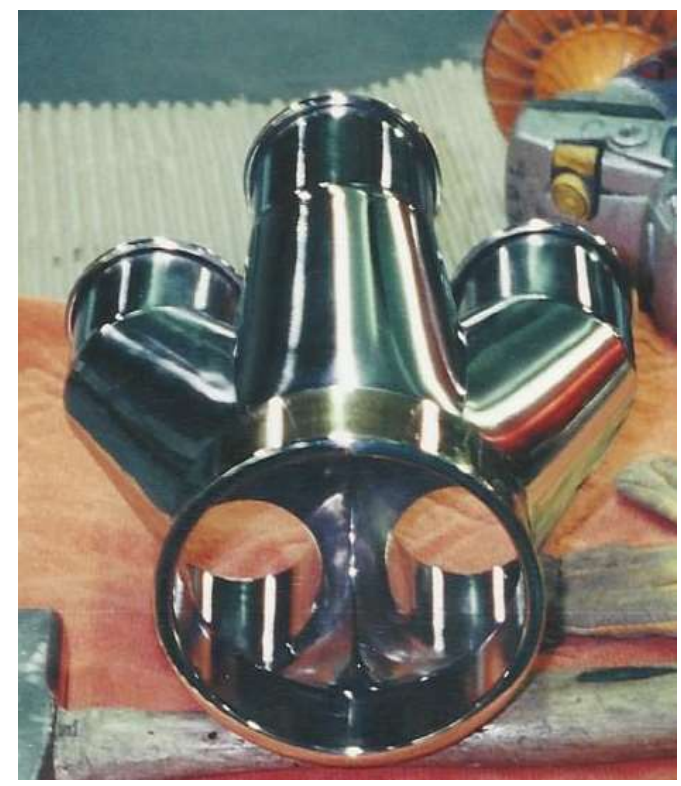

Traditional Sheet Metal Work 3

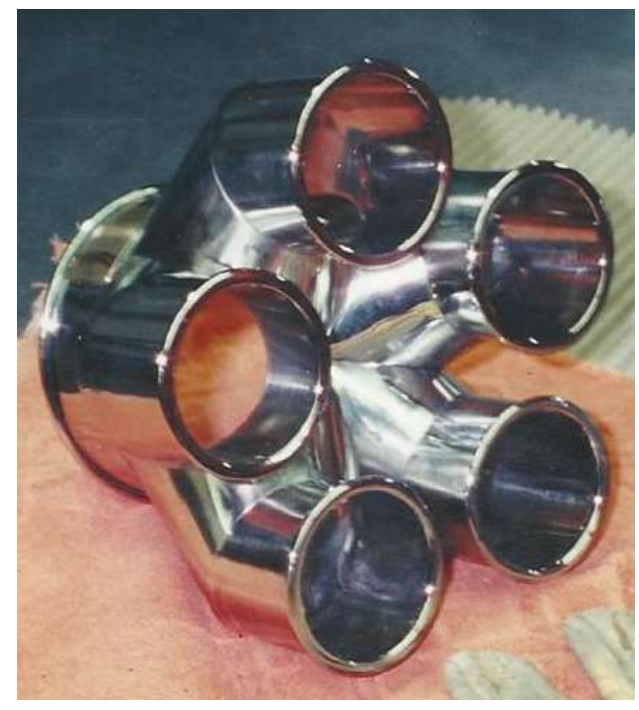

Traditional Sheet Metal Work 4 
